\author{
Universidade de São Paulo \\ Instituto de Física
}

\title{
Taxas de Aniquilação em Moléculas Positrônicas
}

\author{
Leonardo Bin Martins
}

Orientador: Prof. Dr. Márcio Teixeira do Nascimento Varella

Dissertação de mestrado apresentada ao Instituto de Física como requisito parcial para a obtenção do título de Mestre em Ciências.

Banca Examinadora:

Prof. Dr. Márcio Teixeira do Nascimento Varella (IFUSP)

Prof. Dr. Sergio d'Almeida Sanchez (UFPR)

Prof. Dr. Andrés Reyes Velasco (UNC)

São Paulo

2020 
FICHA CATALOGRÁFICA

Preparada pelo Serviço de Biblioteca e Informação do Instituto de Física da Universidade de São Paulo

Martins, Leonardo Bin

Taxas de aniquilação em moléculas positrônicas. São Paulo, 2020.

Dissertação (Mestrado) - Universidade de São Paulo. Instituto de Física. Depto. de Física Geral.

Orientador: Prof. Dr. Márcio Teixeira do Nascimento Varella Área de Concentração: Física Molecular

Unitermos: 1. Aniquilação de pósitrons; 2. Energias de ligação; 3. Física molecular; 4. Mecânica quântica; 5. Química teórica. 


\title{
University of São Paulo
}

Physics Institute

\section{Annihilation Rates in Positronic Molecules}

\author{
Leonardo Bin Martins
}

Supervisor: Prof. Dr. Márcio Teixeira do Nascimento Varella

Dissertation submitted to the Physics Institute of the University of São Paulo in partial fulfillment of the requirements for the degree of Master of Science.

Examining Committee:

Prof. Dr. Márcio Teixeira do Nascimento Varella (IFUSP)

Prof. Dr. Sergio d'Almeida Sanchez (UFPR)

Prof. Dr. Andrés Reyes Velasco (UNC) 


\section{Agradecimentos}

À Deus, minha família e todos os meus amigos, por todo o apoio recebido.

Ao CNPQ pelo apoio financeiro e ao IFUSP, onde realizei esta pesquisa.

Aos professores que tive na escola e na faculdade, que contribuíram significativamente para a minha formação e sem os quais este trabalho não seria possível

E à todos os integrante do meu grupo de pesquisa, mas principalmente ao prof. Márcio Varella, que sempre foi muito atencioso e disposto a esclarecer minhas dúvidas. 


\section{Resumo}

O objetivo deste trabalho é estudar a interação de um pósitron com moléculas, focando nos compostos que podem formar estados ligados. O programa utilizado pelo nosso grupo de pesquisa do IFUSP para calcular energias de ligação do pósitron nesses sistemas é o LOWDIN, desenvolvido pelo grupo do professor Andres Reyes da Universidade Nacional da Colômbia, que utiliza uma generalização do método da função de Green/propagadores para computar essas energias, dentre outras quantidades. Para realizar esse cálculo, é necessário conhecer as energias dos orbitais Hartree-Fock do pósitron e a sua auto-energia, a qual não pode ser calculada de forma exata. Para obtê-la, o LOWDIN emprega uma aproximação denominada de método OVGF (Outer Valence Green Function). Na primeira parte deste trabalho, o resultado do método OVGF é comparado com as aproximações propostas por outros autores que utilizam propagadores para estudar a interação de pósitrons com átomos. Esses autores empregam diagramas de Feynman para calcular a auto-energia e realizar somas infinitas de certos termos, o que permite levar em consideração a contribuição da formação do positrônio virtual, que deve ser de grande importância. Pretende-se analisar se os termos correspondentes a essa contribuição são levados em conta pelo método OVGF.

Há também um segundo objetivo, que é obter expressões que permitam o calculo de taxas de aniquilação de pósitrons em moléculas. Tendo inspiração em trabalhos desenvolvidos pelos mesmos autores mencionados acima, a taxa de aniquilação é expandida perturbativamente através do uso de diagramas, parecidos com os diagramas de Feynman para a função de Green e a auto-energia. As expressões obtidas são similares às da auto-energia e podem ser implementadas no LOWDIN futuramente. A mesma técnica também é utilizada para computar a energia de correlação do sistema molécula-pósitron. Esse cálculo já está presente no LOWDIN, porém apenas até o termo de segunda ordem em teoria de perturbação. Aqui mostra-se como é possível obter contribuições de termos de ordens mais altas e assim melhorar a aproximação já existente.

Palavras-chave: Pósitron, energia de ligação, taxa de aniquilação, energia de correlação. 


\section{Abstract}

The objective of this work is to study the interaction of a positron with molecules, focusing on compounds that can form bound states. The program used by our IFUSP research group to calculate positron binding energies in these systems is the LOWDIN, which was developed by the group of Professor Andres Reyes of the National University of Colombia. This program uses a generalization of the Green function method (also called propagator) to compute these energies, among other quantities. To perform this calculation, it is necessary to know the energies of the positron's Hartree-Fock orbitals and its self-energy, which cannot be calculated exactly. To obtain it, LOWDIN uses an approach called the OVGF (Outer Valence Green Function) method. In the first part of this work, the result of the OVGF method is compared with the approaches proposed by other authors who use propagators to study the interaction of positrons with atoms. These authors employ Feynman diagrams to compute the self-energy and to perform infinite sums of certain terms. This method allows one to take into account the contribution of the formation of the virtual positronium, which must be of great importance. Here, it is intended to analyze whether the terms corresponding to this contribution are taken into account by the OVGF method.

There is also a second objective, which is to obtain expressions that allow the calculation of positron annihilation rates in molecules. Taking inspiration from works developed by the same authors mentioned above, the annihilation rate is expanded perturbativelly through the use of diagrams similar to Feynman diagrams for Green function and self-energy. The expressions obtained are similar to those of the self-energy and can be implemented in LOWDIN in the future. The same technique is also used to obtain expressions for the correlation energy of the positron-molecule system. This calculation is already present in LOWDIN, but only until the second order in perturbation theory. Here it is shown how to obtain contributions from higher order terms and thus improve the existing approach.

Keywords: Positron, binding energy, annihilation rate, correlation energy. 


\section{Conteúdo}

1 Introdução $\quad 12$

1.1 Motivação e objetivos . . . . . . . . . . . . . . . . . . . . . . 14

1.2 Organização da dissertação . . . . . . . . . . . . . . . . . 16

2 Fundamentos Teóricos $\quad 18$

2.1 Sistema de férmions idênticos . . . . . . . . . . . . . . . . . . 18

2.2 Segunda Quantização . . . . . . . . . . . . . . . . . . . . . . . . 19

2.3 Função de Green . . . . . . . . . . . . . . . . . . . . . . . . . 20

2.3.1 Representação Espectral . . . . . . . . . . . . . . . . . 21

2.3.2 Expansão da Função de Green . . . . . . . . . . . . . . . . . . . . 22

2.4 O Teorema de Wick . . . . . . . . . . . . . . . . . . . . . . . 24

2.5 Diagramas de Feynman . . . . . . . . . . . . . . . . . . 26

2.6 A equação de Dyson . . . . . . . . . . . . . . . . . . . . . . 32

2.7 Função de Green na física atômica e molecular . . . . . . . . . . . . . . . . . . . . . . . . . . . . 35

2.7.1 Aproximação Born-Oppenheimer . . . . . . . . . . . . . . . 35

2.7.2 O Método Hartree-Fock . . . . . . . . . . . . . . . . . 36

2.7.3 Partição de Moller-Plesset . . . . . . . . . . . . . . . . . 37

2.7.4 Função de Green para átomos e moleculas . . . . . . . . . . . . . . . . . . . . . . . 38

2.7.5 Cálculo da auto-energia . . . . . . . . . . . . . . 39

3 Energias de Ligação

3.1 Átomos e moléculas que podem ligar pósitrons . . . . . . . . . . . . . . . . 43

3.2 Sistemas contendo elétrons e um pósitron . . . . . . . . . . . . . . . . . . . . . . . . 44

3.3 Função de Green para o pósitron . . . . . . . . . . . . . . . . . . . . . 46

3.4 A teoria APMO . . . . . . . . . . . . . . . . . . 51

4 O método OVGF $\quad 54$

4.1 Versão A . . . . . . . . . . . . . . . . . . . . 55

4.2 A formação do Ps virtual . . . . . . . . . . . . . . . . . . 58

4.3 O Ps virtual e o método OVGF . . . . . . . . . . . . . . . . . 60

4.4 As versões B e REN/PP3 . . . . . . . . . . . . . . . . . . . . . . . . . 61

5 Taxas de Aniquilação $\quad 64$

5.1 Aniquilação em estados ligados . . . . . . . . . . . . . . . . . . . . 64

5.2 Taxas de aniquilação em gases moleculares . . . . . . . . . . . . . . . . 65

5.3 Cálculo das taxas de aniquilação . . . . . . . . . . . . . . . . . 66

5.3.1 Construção dos Diagramas e Regras . . . . . . . . . . . . . . . . . . 67

5.3.2 Dedução das regras para diagramas . . . . . . . . . . . . . . . . . 71

5.4 Soma de diagramas . . . . . . . . . . . . . . . . . . . . 83 
5.5 Energia de correlação . . . . . . . . . . . . . . . . . . . . . . . 84

A Diagramas de segunda ordem $\quad 90$ 


\section{Lista de Tabelas}

1.1 Valores medidos e calculados de energias de ligação de pósitrons em moléculas. Todos os valores apresentados estão em meV.

${ }^{a}$ Ref. [1], ${ }^{b}$ Ref. [2], ${ }^{c}$ Ref. [3], ${ }^{d}$ Ref. [4], ${ }^{e}$ Ref. [5], ${ }^{f}$ Ref. [6] . . . . . . . . . 13

1.2 Energias de ligação de pósitrons a moléculas orgânicas (em meV), com diversas aproximações. Os valores calculados e medidos para as molécuas que possuem resultados experimentais foram retirados das mesmas referências que os dados apresentados na tabela 1.1.

${ }^{a}$ Ref. [7], ${ }^{b}$ Ref. [8] . . . . . . . . . . . . . . . . . . . . . 


\section{Lista de Figuras}

2.1 Representação da interação em um diagrama. . . . . . . . . . . . . . . .

2.2 Representação de um diagrama do denominador da função de Green de ordem $n$. As linhas onduladas representam os $n$ operadores $\hat{H}_{I}$ que aparecem no produto $T$ nesse termo. Por simplicidade, as setas que entram e saem das linhas onduladas não são mostradas. . . . . . . . . . . . . . . . . . .

2.3 Um exemplo de como construir diagramas. Primeiro desenha-se as linhas onduladas umas sobre as outras, e depois suas setas são conectadas. O segundo e o terceiro diagramas desta imagem representam diferentes maneiras de fazer essas ligações. . . . . . . . . . . . . . . . . . . . . 28

2.4 Diagramas de primeira ordem para o denominador da função de Green. . . . . 28

2.5 Representação de um diagrama do numerador da função de Green de ordem $n$. Novamente, as setas que entram e saem das linhas onduladas não são mostradas.

2.6 Alguns dos diagramas de primeira ordem possíveis para o numerador da função de Green. . . . . . . . . . . . . . . . . . . . . . .

2.7 Dois diagramas diferentes que têm a mesma contribuição. Apenas um deles precisa ser considerado. . . . . . . . . . . . . . . .

2.8 Dois diagramas com o mesmo valor numérico. Trocando a ordem das linhas ondulas no segundo, o primeiro é obtido. Novamente, apenas um deles precisa ser considerado. . . . . . . . . . . . . . . . . .

2.9 Alguns diagramas da função de Green. O primeiro pode ser separado no segundo e terceiro "cortando-o" ao meio, já o quarto não. . . . . . . . . . . . . . . . . 32

2.10 Mais alguns diagramas da auto-energia. . . . . . . . . . . . . . . 39

2.11 Exemplo de como associar instantes de tempo a cada uma das interações de um diagrama. . . . . . . . . . . . . . . . .

2.12 Alguns diagramas temporalmente ordenados obtidos a partir do diagrama de Feynman na figura 2.11, e as respectivas ordens dos instantes de tempo de cada um. . . . . . . . . . . . . . . . . . .

2.13 A figura (a) mostra como nomear as linhas do diagrama 2.12 (c), enquanto a (b) mostra como obter os fatores que aparecem no denominador da expressão do diagrama. . . . . . . . . . . . . . . . . .

2.14 Um diagrama da função de Green (a) e o diagrama da auto-energia obtido ao remover as suas linhas externas (b). Este diagrama da auto-energia não dependerá da energia $E \ldots \ldots \ldots \ldots \ldots \ldots$

3.1 Círculos pretos são medidas do parâmetro de aniquilação; as linhas tracejadas representam uma predição teórica para $Z_{\text {eff }}$ [9]; a linha contínua vermelha é um ajuste aos dados; a linha mais acima é o espectro de absorção da molécula. . 
3.2 Representação das interações de Coulomb entre elétrons e elétrons e entre elétrons e o pósitron, respectivamente. A primeira (segunda) figura representa o primeiro (segundo) termo da equação (3.7) . . . . . . . . . . . . . . . . . 47

3.3 Diagrama de segunda ordem para a auto-energia do pósitron. . . . . . . . . . . 48

3.4 Diagramas de terceira para a auto-energia do pósitron que dependem da energia. 49

4.1 Representação do termo (4.21) da auto-energia APMO utilizando um diagrama. 59

5.1 Símbolos utilizados nos diagramas da taxa de aniquilação para representar as interações de Coulomb de dois elétrons e um elétron e um pósitron, e o operador $\hat{\delta}$. 68

5.2 Diagramas possíveis para o termo de segunda ordem. A ordem em que os símbolos aparecem é importante e todas as possibilidades devem ser consideradas. As linhas que entram e saem de cada símbolo não estão sendo mostradas por simplicidade.

5.3 Alguns diagramas possíveis em ordens mais baixas. O primeiro é o único diagrama de ordem zero, o segundo é um diagrama de ordem 1 e os dois seguintes são diagramas de segunda ordem. . . . . . . . . . . . . . . . . . . 69

5.4 Exemplo de dois diagramas topologicamente equivalentes. . . . . . . . . . . . 69

5.5 Exemplos de algumas ligações que podem ocorrer em alguns diagramas. Os diagramas que contém uma ou mais dessas ligações devem ser excluídos quando utilizada a partição de MP.

5.6 Dois diagramas conectados que devem ser excluídos quanto utilizada a partição de MP. . . . . . . . . . . . . . . . . . . . . . . . . . 70

5.7 Dois diagramas de segunda ordem que correspondem a diferentes escolhas da ordem temporal. O da esquerda se refere a $t_{1} \leq t_{2} \leq 0$, e o da direita a $t_{1} \leq 0 \leq t_{2} \ldots \ldots \ldots \ldots \ldots \ldots \ldots \ldots \ldots \ldots \ldots \ldots \ldots \ldots \ldots \ldots \ldots \ldots$

5.8 Um diagrama de ordem $n$ que tem $m$ interações à esquerda do círculo e $n-m$ à direita. À cada interação associa-se um instante de tempo $t_{i}$. . . . . . . . . . . . 74

5.9 A primeira interação do diagrama, considerando o sentido da esquerda para a direita. . . . . . . . . . . . . . . . . 75

5.10 As $i$ primeiras linhas do diagrama, onde a linha $t_{j}$ está conectada à linha $t_{k}$. . 76

5.11 Exemplo de diagramas que irão se cancelar quando somados. . . . . . . . . . . 81

5.12 Alguns diagramas possíveis para a energia de correlação. . . . . . . . . . . . 85

5.13 Alguns diagramas desconectados da energia de correlação. . . . . . . . . . . . 85 


\section{Capítulo 1}

\section{Introdução}

A interação de pósitrons com átomos e moléculas é estudada há anos, desde as primeiras décadas da mecânica quântica. O pósitron, a primeira antipartícula introduzida na física, possui a mesma massa e spin do elétron, e uma carga elétrica com mesmo módulo mas sinal oposto. Sua existência foi proposta na primeira metade do século passado pelo físico Paul Dirac [10], sendo detectado experimentalmente alguns anos depois por Carl Anderson [11]. O fato de que um pósitron e um elétron podem se aniquilar, produzindo um determinado número de fótons, faz com que essa antipartícula tenha várias aplicações em diferentes campos, como na astrofísica [12], na ciência dos materiais [13], e na física de superfícies [14, 15].

Também há aplicações na medicina, com o uso da tomografia por emissão de pósitrons (PET, na sigla em inglês) [16], a qual pode ser usada, por exemplo, no diagnóstico de câncer. Esse exame consiste na administração de substância composta por radionuclídios, elementos que decaem emitindo pósitron, como ${ }^{15} \mathrm{O}$ e ${ }^{11} \mathrm{C}$. Os pósitrons emitidos irão se aniquilar, em geral produzindo dois fótons, os quais podem ser detecdos. Isso tem motivado o estudo do comportamento de pósitrons em meios biológicos [17], e sua interação com biomoléculas [18]. Além disso, também há evidências de que pósitrons podem ser utilizados no tratamento de câncer [19].

No início da década de 50, foi detectado pela primeira vez o átomo de positrônio (Ps) [20], um estado ligado formado por um pósitron e um elétron, sendo basicamente um átomo de Hidrogênio mais leve e com um tempo de vida finito. O positrônio é um objeto de grande interesse em pesquisas atuais. Por exemplo, há interesse em investigar o espalhamento de positrônio por moléculas, que exibe similaridades com o espalhamento de um elétron isolado [21]. Perspectivas futuras incluem a obtenção de um condensado de Bose-Einstein formado com átomos de Ps [22].

Como será explicado mais adiante, hoje sabe-se que o pósitron pode formar estados ligados com sistemas mais complexos, gerando assim átomos e moléculas positrônicas. Por exemplo, já foram produzidos em laboratório o íon de positrônio $\mathrm{Ps}^{-}$[23], o hidreto de positrônio PsH [24] e a molécula de positrônio $\mathrm{Ps}_{2}$ [25]. Vale ainda mencionar que o pósitron possibilitou a formação e detecção de átomos de antihidrogênio (compostos por um antipróton e um pósitron) 
[26], que pode ser utilizado para estudar propriedades da antimatéria.

Os primeiros experimentos a investigar a interação de pósitrons com a matéria foram realizados por volta da metade do século passado (por exemplo, [20]), onde eram realizadas medidas da taxa de aniquilação, isto é, o numéro de eventos de aniquilação por unidade de tempo, de pósitrons em gases atômicos e moleculares. Essa taxa, para um pósitron em um gás de elétrons livres, é dada por

$$
\lambda_{D}=\pi r_{0}^{2} c n,
$$

onde $r_{0}$ é o raio clássico do elétron, $c$ é a velocidade da luz e $n$ a densidade de número de elétrons. Surpreendentemente, as primeiras medidas mostraram que, embora em alguns casos o valor obtido estivesse de acordo com essa equação, para certas moléculas o resultado experimental era muito maior que o previsto por (1.1). Experimentos realizados posteriormente confirmaram esse fato (veja [27] para uma revisão da literatura). Atualmente, os grandes valores das taxas de aniquilação são atribuídos à captura do pósitron em um estado ressonante, o que aumenta consideravelmente a probabilidade dele se aniquilar com um dos elétrons da molécula. Mais especificamente, o pósitron é capturado em uma ressonância de Feshbach vibracional (veja a seção 3.1 para mais detalhes), a qual só é possível caso exista um estado ligado do sistema molécula-pósitron. Isto é uma evidência de que o pósitron pode se ligar a algumas moléculas, formando um composto energéticamente estável. Nestes casos, a medida da taxa de aniquilação também possibilita computar a energia de ligação do pósitron $\varepsilon_{b}$, como será discutido no capítulo 3.

Atualmente, há um número relativamente grande de cálculos e medidas de $\varepsilon_{b}$, entretanto, a interação de pósitrons com moléculas ainda não é completamente entendida. Como mencionado por Gribakin e Swann [28, 29], apenas seis moléculas positrônicas já foram estudadas teórica e experimentalmente, sendo que as energia de ligação calculadas estão sempre abaixo das medidas, como pode ser observado pela tabela 1.1 .

\begin{tabular}{c|c|c|c} 
Molécula & Fórmula & Valor medido & valor calculado \\
\hline Dissulfeto de Carbono & $\mathrm{CS}_{2}$ & $75^{a}$ & não há ligação \\
Acetaldeído & $\mathrm{C}_{2} \mathrm{H}_{4} \mathrm{O}$ & $90^{a}$ & $55^{c}$ \\
Acetonitrila & $\mathrm{CH}_{3} \mathrm{CN}$ & $180^{a}$ & $135^{c}$ \\
Propanal & $\mathrm{C}_{2} \mathrm{H}_{5} \mathrm{CHO}$ & $118^{b}$ & $58^{d}$ \\
Acetona & $\left(\mathrm{CH}_{3}\right)_{2} \mathrm{CO}$ & $173^{a}$ & $96^{c}$ \\
Proprionitrila & $\mathrm{C}_{2} \mathrm{H}_{5} \mathrm{CN}$ & $245^{b}$ & $164^{f}$
\end{tabular}

Tabela 1.1: Valores medidos e calculados de energias de ligação de pósitrons em moléculas. Todos os valores apresentados estão em meV.

${ }^{a}$ Ref. [1], ${ }^{b}$ Ref. [2], ${ }^{c}$ Ref. [3], ${ }^{d}$ Ref. [4], ${ }^{e}$ Ref. [5], ${ }^{f}$ Ref. [6]

Vale ainda ressaltar que existe uma relação empírica entre a energia de ligação do pósitron e certas propriedades da molécula [30]. Essa relação, que fornece a energia de ligação em meV, é dada por 


$$
\varepsilon_{b}=12,4\left(\alpha+1,6 \mu+2,4 N_{\pi}-5,6\right)
$$

onde $\alpha$ é a polarizabilidade (medida em $\AA^{3}$ ), $\mu$ é o momento de dipolo (medido em debye), e $N_{\pi}$ é o numero de ligações $\pi$ da molécula. Tal equação pode ser útil no estudo de pósitrons em meios biólogicos, o que é de grande interesse, como já mencionado. Em alguns casos, essa fórmula produz resultados próximos às medidas experimentais, mas ainda há discrepâncias (veja novamente [27] para mais detalhes).

\subsection{Motivação e objetivos}

As aplicações de pósitrons na medicina têm motivado o estudo das interações dessa antipartícula com moléculas cada vez maiores. Os métodos numéricos que mais obtiveram sucesso na descrição de moléculas positrônicas (como CI e Monte Carlo) possuem um alto custo computacional e são em geral aplicáveis apenas a sistemas pequenos e médios (veja [31] e as referências citadas neste artigo). Uma alternativa a eles é o método das funções de Green (propagadores).

Recentemente, esse método, que usualmente é aplicado apenas a sistemas eletrônicos, foi generalizado com o uso da teoria APMO (Any Particle Molecular Orbital Theory) [32], permitindo assim aplicá-lo para sistemas contendo qualquer quantidade e tipo de partículas. Tal teoria foi desenvolvida pelo grupo do professor Andres Reyes, da Universidade Nacional da Colômbia, e implementada no código LOWDIN [33]. O grupo do prof. Reyes possui colaboração com o nosso grupo do IF-USP, que também possui interesse no estudo de moléculas positrônicas.

Como será explicado em detalhes nos capítulos seguintes, energias de ligação de pósitrons a átomos e moléculas podem ser determinadas conhecendo as energias dos orbitais Hartee-Fock (HF) do pósitron e outra quantidade chamada auto-energia, denotada por $\Sigma$. Como as energias HF são supostas conhecidas, o problema passa a ser calcular $\Sigma$, que, infelizmente, não pode ser obtida de forma exata. Porém, é possível expandi-la perturbativamente, escrevendo-a como a soma de infinitos termos

$$
\Sigma=\Sigma^{(2)}+\Sigma^{(3)}+\Sigma^{(4)}+\ldots
$$

O termo de primeira ordem não aparece na expressão acima pois, como veremos, ele é nulo. Entretanto, devido à complexidade das expressões desses termos, e das limitações dos computadores atuais, na prática apenas os termos de ordem dois e três podem ser calculados numericamente. Porém, desprezar os termos de ordens mais altas em geral não leva a boas aproximações para a auto-energia. Para contornar esse problema, existem métodos que permitem estimar a contribuição parcial dos termos de ordens superiores. Um deles, que foi generalizado e implementado no LOWDIN, é o método OVGF [34, 35, 36], o qual possibilita melhorar a aproximação para $\Sigma$ apenas usando os termos que podem ser calculados. 
Com tal método, já foram computadas energias de ligação positrônicas para vários sistemas atômicos e moleculares [37, 31]. Os resultados para algumas moléculas orgânicas são compilados na tabela abaixo, adaptada de [31]. Na primeira coluna é mostrada a energia de ligação obtida pelo método Hartree-Fock, que não leva em consideração a auto-energia. Em seguida são apresentados os resultados com a auto-energia calculada até a segunda e a terceira ordem, e a com o método OVGF (na verdade, esse método possui quatro versões diferentes implementadas no LOWDIN, sendo que apenas a versão denominada REN-PP3, que apresenta os melhores resultados, é considerada aqui). Nas últimas duas colunas são mostrados resultados de outros cálculos numéricos e os valores medidos experimentalmente.

\begin{tabular}{c|c|c|c|c|c|c} 
Molécula & $\mathrm{HF}$ & $\Sigma^{(2)}$ & $\Sigma^{(2)}+\Sigma^{(3)}$ & OVGF (REN-PP3) & outros cálculos & medidas \\
\hline $\mathrm{H}_{2} \mathrm{CO}$ & 1 & 2 & 3 & 3 & $19^{a}$ & - \\
$\mathrm{CH}_{3} \mathrm{COH}$ & -20 & 5 & 16 & 16 & 55 & 90 \\
$\mathrm{CH}_{3} \mathrm{COCH}$ & -10 & 21 & 35 & 36 & 96 & 173 \\
$\mathrm{HCN}$ & 2 & 6 & 8 & 8 & $35^{b}$ & - \\
$\mathrm{CH}_{3} \mathrm{CN}$ & 15 & 49 & 65 & 65 & 135 & 180
\end{tabular}

Tabela 1.2: Energias de ligação de pósitrons a moléculas orgânicas (em meV), com diversas aproximações. Os valores calculados e medidos para as molécuas que possuem resultados experimentais foram retirados das mesmas referências que os dados apresentados na tabela 1.1. ${ }^{a}$ Ref. [7], ${ }^{b}$ Ref. [8]

Fica então evidente a importância da auto-energia para o cálculo de energias de ligação. Por exempo, de acordo com os cálculos $\mathrm{HF}$ o pósitron não poderia ligar às moléculas de $\mathrm{CH}_{3} \mathrm{COH}$ e $\mathrm{CH}_{3} \mathrm{COCH}_{3}$, isso só ocorre quando o termo de segunda ordem é levado em consideração. Entretanto, ainda há uma diferença considerável entre os resultados da versão REN-PP3 e os medidos e calculados. Além disso, os resultados dessa versão, que deveria conter contribuições de termos de ordens mais altas, quase não diferem dos obtidos usando a auto-energia de terceira ordem neste caso.

O método das funções de Green também já foi utilizado por vários outros autores para o estudo da interação de pósitrons com átomos. Por exemplo, G. Gribakin e J. Ludlow o aplicaram tanto para estados ligados [38] quanto de espalhamento [39] de pósitrons e átomos, calculando energias de ligação e taxas de aniquilação. Para obter estas duas quantidades, também é necessário computar a auto-energia do pósitron, o que eles fazem com o uso de diagramas de Feynman, que serão muito utilizados neste trabalho. Como antes, a auto-energia não pode ser calculada de forma exata, e é necessário recorrer a aproximações e métodos que permitam obter a contribuição de termos de ordens maiores.

Na colisão de um pósitron com um átomo ou molécula, se a energia do pósitron incidente for maior que $I+E_{P s}$, onde $I$ é o potencial de ionização do átomo e $E_{P s}$ é a energia do estado fundamental do Ps ( $\left.E_{P s} \approx-6,8 \mathrm{eV}\right)$, o pósitron pode capturar um elétron, resultando assim na formação de um átomo de positrônio e um cátion, 


$$
e^{+}+X \rightarrow P s+X^{+}
$$

Caso a energia esteja abaixo desse valor, porém próxima, o átomo de positrônio resultante da captura do elétron não tem energia suficiente para escapar. Neste caso, o sstema é melhor descrio como um átomo de Ps ligado a um cátion. Tal efeito recebe o nome de formação de Ps virtual, e deve ser de grande importância para átomos (veja [39] e as referências citadas neste artigo). Utilizando os diagramas de Feynman para a auto-energia do pósitron é possível levar sua contribuição em consideração, fazendo somas de certos tipos de diagramas, como será explicado de forma mais detalhada no capítulo 3.

Existem diferenças entre a abordagem implementada no LOWDIN e a de Gribakin e Ludlow, que não aplicam o método OVGF. Na primeira parte deste trabalho, o objetivo é comparar ambas as aproximações para a auto-energia e tentar determinar se a contribuição do efeito da formação do Ps virtual está de alguma forma contida no método OVGF, e caso não esteja, como incluí-la.

Há um segundo objetivo, que é o cálculo das taxas de aniquilação de pósitron em átomos e moléculas, ainda não implementado no LOWDIN. Tendo como base os trabalhos de Gribakin e Ludlow e outros autores [40,41], pretende-se desenvolver um método que permita computar essas taxas, que possa ser futuramente incluído no LOWDIN. Para isso, usa-se teoria quântica de muitos corpos (MBPT) e diagramas similares aos utilizados para a auto-energia. A mesma técnica também é aplicada para o cálculo da energia de correlação do sistema, que possibilita outra maneira de calcular energias de ligação.

\subsection{Organização da dissertação}

Esta dissertação está organizada da seguinte forma: No capítulo 2, será feita uma revisão da parte principal da teoria utilizada ao longo do trabalho, o que inclui o método HartreeFock e a aproximação Born-Oppenheimer, o formalismo da segunda-quantização e o método das funções de Green e sua expansão perturbativa utilizando diagramas de Feynman. Nesse capítulo, será considerado um sistema composto apenas por partículas idênticas (de spin 1/2). A generalização para sistemas que contém dois tipos de férmions, elétrons e pósitrons, será explicada no capítulo seguinte, onde também serão descritos os métodos de Gribakin e Ludlow e o obtido pelo uso da teoria APMO, implementado no LOWDIN.

No capítulo 3, serão apresentadas a derivação original das chamadas versões A e B do método OVGF original e a sua generalização para a auto-energia do pósitron. A versão REN/PP3 também será discutida. Será mostrado que os termos relacionados à formação do Ps virtual são despresados pelas aproximações feitas, e correções para as fórmualas finais serão propostas.

No último capítulo é explicado como as taxas de aniquilação de pósitron em moléculas ( e átomos) podem ser calculadas através de MBPT. O método empregado aqui é semelhante ao 
utilizado na expansão da função de Green, e também ao utilizado por Gribakin e Ludlow para o cálculo de taxas de aniquilação de pósitrons em átomos, porém há diferenças. A taxa de aniquilação será escrita como a soma de infinitos termos que podem ser representados através de diagramas. As expressões associadas a cada diagrama podem ser obtidas empregando certas regras, que serão apresentadas e deduzidas nesse capítulo. Também será discutido como somar diagramas, melhorando assim a aproximação. Por fim, o mesmo método é aplicado para o cálculo da energia de correlação do sistema, que também pode ser expandida e computada através de diagramas. 


\section{Capítulo 2}

\section{Fundamentos Teóricos}

\subsection{Sistema de férmions idênticos}

Considere um sistema formado por $N$ partículas idênticas de spin 1/2. Será assumido que essas partículas interagem entre si através de um potencial $V$ que só depende da distância entre elas, e que estão sujeitas a um potencial externo $v$. Adotando um sistema de unidades tal que a massa dessas partículas e a constante de Planck reduzida $\hbar$ são iguais a 1 , a hamiltoniana de um sistema assim pode ser escrita como

$$
\hat{H}=-\frac{1}{2} \sum_{i=1}^{N} \nabla_{i}^{2}+\sum_{i=1}^{N} v\left(\boldsymbol{r}_{i}\right)+\frac{1}{2} \sum_{\substack{i, j=1 \\ i \neq j}}^{N} V\left(\left|\boldsymbol{r}_{i}-\boldsymbol{r}_{j}\right|\right),
$$

onde $\boldsymbol{r}_{i}$ é o vetor posição da $i$-ésima partícula. É conveniente escrever a hamiltoniana como a soma de duas parcelas, $\hat{H}=\hat{H}_{0}+\hat{H}_{I}$, em que $\hat{H}_{0}$ é usualmente chamada de hamiltoniana não perturbada do sistema e é igual a soma dos operadores de uma partícula presentes na equação acima

$$
\hat{H}_{0}=\sum_{i=1}^{N}\left[-\frac{1}{2} \nabla_{i}^{2}+v\left(\boldsymbol{r}_{i}\right)\right] \equiv \sum_{i=1}^{N} \hat{h}_{0}(i) .
$$

Em geral, o potencial $V$ torna o problema de diagonalizar $\hat{H}$ muito difícil. Se essa interação fosse desconsiderada, então a função de onda do sistema poderia ser construída utilizando as autofunções de $\hat{h}_{0}$,

$$
\hat{h}_{0}(i) \phi_{j}\left(\boldsymbol{r}_{i}\right)=\varepsilon_{j} \phi_{j}\left(\boldsymbol{r}_{i}\right)
$$

O estado de cada partícula individual do sistema é descrito pelo produto de uma dessas autofunções, que está relacionada à probabilidade de encontrar tal partícula em uma determinada região do espaço, por uma outra função que descreve o seu spin. Com isso se obtém uma terceira função chamada de spin-orbital $\varphi(\boldsymbol{x})$, que especifica tanto o spin quanto a distribuição espacial da 
partícua. Aqui, $\boldsymbol{x}$ representa as coordenadas de posição e de spin. Como as funções $\phi$ podem ser escolhidas como sendo ortonormais, o mesmo vale para os spins-orbitais

$$
\left\langle\varphi_{i} \mid \varphi_{j}\right\rangle=\int d \boldsymbol{x} \varphi_{i}(\boldsymbol{x})^{*} \varphi_{j}(\boldsymbol{x})=\delta_{i j}
$$

Na expressão acima, deve-se somar sobre as coordenadas de spin e integrar sobre as coordenadas espaciais.

A mecânica quântica exige que a função de onda de um sistema de férmions idênticos seja antissimétrica, ou seja, que seu sinal seja trocado sempre que as coordenadas de duas partículas são permutadas. Para satisfazer esse requerimento, a função de onda (no caso não interagente) deve ser escrita como um determinante formado por spins-orbitais

$$
\psi_{0}\left(\boldsymbol{x}_{1}, \ldots, \boldsymbol{x}_{m}\right)=\frac{1}{\sqrt{N !}}\left|\begin{array}{cccc}
\varphi_{1}\left(\boldsymbol{x}_{1}\right) & \varphi_{2}\left(\boldsymbol{x}_{1}\right) & \cdots & \varphi_{N}\left(\boldsymbol{x}_{1}\right) \\
\varphi_{1}\left(\boldsymbol{x}_{2}\right) & \varphi_{2}\left(\boldsymbol{x}_{2}\right) & \cdots & \varphi_{N}\left(\boldsymbol{x}_{2}\right) \\
\vdots & \vdots & \ddots & \vdots \\
\varphi_{1}\left(\boldsymbol{x}_{N}\right) & \varphi_{2}\left(\boldsymbol{x}_{N}\right) & \cdots & \varphi_{N}\left(\boldsymbol{x}_{N}\right)
\end{array}\right|
$$

que recebe o nome de determinante de Slater. Assim, a exigência da antissimetria é satisfeita, pois trocar as coordenadas de duas partículas equivale a trocar duas linhas do determinante, o que altera o seu sinal. Além disso, essa função também está de acordo com o princípio de exclusão de Pauli, segundo o qual dois desses férmions não poderiam ocupar o mesmo estado (ou seja, possuir o mesmo spin-orbital). Se esse fosse o caso, o determinante teria duas colunas iguais, e portanto seu resultado seria zero.

É possível verificar que (2.5) também é uma autofunção do operador $\hat{H}_{0}$, com autovalor $\varepsilon_{1}+\ldots+\varepsilon_{N}$. Para descrever o estado fundamental do sistema, os $N$ spins-orbitais com os $N$ menores autovalores $\varepsilon$ devem ser escolhidos. Esses spins-orbitais são geralmente chamados de ocupados ou de orbitais buracos, enquanto os restantes (com maiores $\varepsilon$ ) são referidos como orbitais virtuais ou de partículas.

\subsection{Segunda Quantização}

O formalismo da segunda quantização $[42,43]$ pode ser muito útil para sistemas que possuem um número grande de partículas. A partir de agora, será conveniente adotar uma nova notação e passar a representar spins-orbitais com letras como índices. As letras $a, b, c, \ldots$ serão utilizadas para representar spin-orbitais ocupados no estado fundamental, e $i, j, k, \ldots$ para spinorbitais virtuais, enquanto as letras $p, q, r, \ldots$ indicarão um spin-orbital qualquer.

No que se segue, também será útil empregar a notação de Dirac, então à cada determinante de Slater formado pelos spin-orbitais $\varphi_{p_{1}}, \ldots, \varphi_{p_{N}}$ associamos um ket $\left|p_{1}, \ldots, p_{N}\right\rangle$. Com isso, é definido um novo operador, chamado de operador de criação e representado por $\hat{a}_{p}^{\dagger}$, que quando aplicado a um determinante adiciona um spin-orbital $\varphi_{p}$ a ele 


$$
\hat{a}_{p}^{\dagger}\left|p_{1}, \ldots, p_{N}\right\rangle=\left|p, p_{1}, \ldots, p_{N}\right\rangle
$$

Caso o orbital $p$ já esteja presente, então o resultado será zero, pois assim o determinante terá duas colunas iguais. Dessa forma, $\hat{a}_{p}^{\dagger}$ transforma um estado de $N$ partículas em um estado de $N+1$ partículas. O conjugado adjunto desse operador, $\hat{a}_{p}$, faz o oposto, levando o estado de um sistema de $N$ partículas para um de $N-1$. De fato, é possível mostrar que [44]

$$
\hat{a}_{p}\left|p_{1}, \ldots, p_{N}\right\rangle=\sum_{j=1}^{N}(-1)^{j-1}\left\langle\varphi_{p} \mid \varphi_{p_{j}}\right\rangle\left|p_{1}, \ldots, p_{j-1}, p_{j+1}, \ldots, p_{N}\right\rangle .
$$

Portanto, se $p=p_{j}, \hat{a}_{p_{j}}\left|p_{1}, \ldots, p_{N}\right\rangle=(-1)^{j-1}\left|p_{1}, \ldots, p_{j-1}, p_{j+1}, \ldots, p_{N}\right\rangle$. O operador $\hat{a}_{p}$ elimina um dos spin-orbitais do determinante, e por isso é chamado de operador de aniquilação. Se não existe nenhum orbital $p$ no determinante no qual esse operador atua, o resultado será zero.

Decorre das propriedades da função de onda que eeses operadores satisfazem as seguintes relações de anticomutação

$$
\left\{\hat{a}_{p}, \hat{a}_{q}\right\}=\left\{\hat{a}_{p}^{\dagger}, \hat{a}_{q}^{\dagger}\right\}=0,\left\{\hat{a}_{p}, \hat{a}_{q}^{\dagger}\right\}=\delta_{p q}
$$

Qualquer operador pode ser escrito através dos operadores de criação e aniquilação. Por exemplo, a hamiltoniana não perturbada do sistema pode ser expressa como

$$
\hat{H}_{0}=\sum_{i=1}^{N} \hat{h}_{0}(i)=\sum_{p, q}\left\langle p\left|\hat{h}_{0}\right| q\right\rangle \hat{a}_{p}^{\dagger} \hat{a}_{q}=\sum_{p} \varepsilon_{p} \hat{a}_{p}^{\dagger} \hat{a}_{p},
$$

enquanto a soma de operadores de duas partículas, como é o caso da soma das interações entre os férmions, se torna

$$
\hat{H}_{I}=\frac{1}{2} \sum_{\substack{i, j=1 \\ i \neq j}}^{N} V\left(\left|\boldsymbol{r}_{i}-\boldsymbol{r}_{j}\right|\right)=\frac{1}{2} \sum_{p, q, r, s}\langle p, q|V| r, s\rangle \hat{a}_{p}^{\dagger} \hat{a}_{q}^{\dagger} \hat{a}_{s} \hat{a}_{r}
$$

onde

$$
\langle p, q|V| r, s\rangle=\int d \boldsymbol{x} d \boldsymbol{x}^{\prime} \varphi_{p}^{*}(\boldsymbol{x}) \varphi_{q}^{*}\left(\boldsymbol{x}^{\prime}\right) V\left(\left|\boldsymbol{r}-\boldsymbol{r}^{\prime}\right|\right) \varphi_{r}(\boldsymbol{x}) \varphi_{s}\left(\boldsymbol{x}^{\prime}\right)
$$

\subsection{Função de Green}

Supondo que o sistema considerado aqui tem um estado fundamental $\Psi_{0}$ exato não degenerado, a função de Green de uma partícula pode ser definida como

$$
G_{p q}\left(t, t^{\prime}\right)=-i\left\langle\Psi_{0}\left|T\left[\hat{a}_{p}(t) \hat{a}_{q}^{\dagger}\left(t^{\prime}\right)\right]\right| \Psi_{0}\right\rangle
$$


onde os operadores $\hat{a}$ e $\hat{a}^{\dagger}$ estão na representação de Heisemberg, ou seja, $\hat{a}_{p}(t)=e^{i \hat{H} t} \hat{a}_{p} e^{-i \hat{H} T}$, e $T$ é um operador que altera a ordem dos operadores de criação e aniquilação de modo que aquele calculado no maior instante de tempo fique à esquerda, trocando o sinal sempre que uma permutação é feita:

$$
T\left[\hat{a}_{p}(t) \hat{a}_{q}^{\dagger}\left(t^{\prime}\right)\right]=\left\{\begin{array}{ll}
\hat{a}_{p}(t) \hat{a}_{q}^{\dagger}\left(t^{\prime}\right) & , t>t^{\prime} \\
-\hat{a}_{q}^{\dagger}\left(t^{\prime}\right) \hat{a}_{p}(t) & , t \leq t^{\prime}
\end{array} .\right.
$$

Será útil definir também a função de Green para o sistema não-interagente $G^{0}$, onde no lugar de $\Psi_{0}$ é utilizado o estado fundamental do sistema sem as interações entre as partículas $\psi_{0}$,

$$
G_{p q}^{0}\left(t, t^{\prime}\right)=-i\left\langle\psi_{0}\left|T\left[\hat{a}_{p}(t) \hat{a}_{q}^{\dagger}\left(t^{\prime}\right)\right]\right| \psi_{0}\right\rangle,
$$

Nesse caso, os operadores de criação e aniquilação passam a estar na representação de interação. Essa função possui uma forma muito simples: quando $p$ e $q$ forem orbitais virtuais

$$
G_{i j}^{0}\left(t, t^{\prime}\right)=\left\{\begin{array}{ll}
-i \delta_{i j} e^{-i \varepsilon_{i}\left(t-t^{\prime}\right)} & , t>t^{\prime} \\
0 & , t \leq t^{\prime}
\end{array},\right.
$$

e quando forem orbitais buracos

$$
G_{a b}^{0}\left(t, t^{\prime}\right)=\left\{\begin{array}{ll}
0 & , t>t^{\prime} \\
i \delta_{a b} e^{-i \varepsilon_{a}\left(t-t^{\prime}\right)} & , t \leq t^{\prime}
\end{array} .\right.
$$

\subsubsection{Representação Espectral}

Como a hamiltoniana do sistema não depende do tempo, $G$ será uma função apenas da diferença $\tau \equiv t-t^{\prime}$. Assim, é possível calcular a sua transformada de Fourier com respeito a variável $\tau$, obtendo desse modo a chamada representação de Lehmann (ou espectral) da função de Green

$$
G_{p q}(E)=\int_{-\infty}^{\infty} d \tau G_{p q}(\tau) e^{i E \tau}
$$

Realizando a integração e utilizando as relações de completeza, pode-se demonstrar que

$$
\begin{aligned}
G_{p q}(E)= & \sum_{m} \frac{\left\langle\Psi_{0}\left|\hat{a}_{p}\right| \Psi_{m}^{N+1}\right\rangle\left\langle\Psi_{m}^{N+1}\left|\hat{a}_{q}^{\dagger}\right| \Psi_{0}\right\rangle}{E+E_{0}-E_{m}^{N+1}+i \eta}+ \\
& +\sum_{n} \frac{\left\langle\Psi_{0}\left|\hat{a}_{q}^{\dagger}\right| \Psi_{n}^{N-1}\right\rangle\left\langle\Psi_{n}^{N-1}\left|\hat{a}_{p}\right| \Psi_{0}\right\rangle}{E+E_{n}^{N-1}-E_{0}-i \eta}
\end{aligned}
$$

onde $E_{0}$ é a energia do estado fundamental do sistema, $\Psi_{l}^{N \pm 1}$ são os estados do sistema com 
um férmion a mais ou a menos, $E_{l}^{N \pm 1}$ são as suas respectivas energias e $\eta$ é um infinitesimal positivo: $\eta \rightarrow 0^{+}$.

Uma propriedade importante da representação de Lehmann da função de Green é o fato de que seus polos ocorrem nas afinidades eletrônicas (quando os férmions considerados forem elétrons) $A_{m}=E_{0}-E_{m}^{N+1}$ e nos potenciais de ionização $I_{n}=E_{n}^{N-1}-E_{0}$ do sistema. Se for possível calcular esses polos, essas duas quantidades podem ser obtidas sem a necessidade de computar as energias totais. Isso pode ser feito com a ajuda da equação de Dyson e da auto-energia, que serão introduzidas mais adiante.

De forma análoga, também é possível definir uma representação de Lehmann para a função de Green não interagente $G_{p q}^{0}\left(t, t^{\prime}\right)$, que assim como $G$ depende apenas da diferença dos instantes de tempo $t$ e $t^{\prime}$. O resultado da sua transformada de Fourier é

$$
G_{p q}^{0}(E)=\frac{\delta_{p q} \bar{n}_{p}}{E-\varepsilon_{p}+i \eta}+\frac{\delta_{p q} n_{p}}{E-\varepsilon_{p}-i \eta}
$$

em que $n_{p}$ é o número de ocupação do spin-orbital $p$, isto é, $n_{p}=1$ se $p$ está ocupado no estado fundamental $\psi_{0}$ e $n_{p}=0$ caso contrário, e $\bar{n}_{p}=1-n_{p}$.

\subsubsection{Expansão da Função de Green}

A função de Green pode ser expandida perturbativamente, o que permitirá obter os polos de sua transformada de Fourier, como ficará claro a seguir. Nesta seção e nas duas seguintes, será discutido, de maneira sucinta, de que forma essa expansão pode ser realizada e a maneira como pode ser simplificada com o uso de diagramas de Feynman.

Para tanto, em geral utiliza-se o teorema de Gell-Mann e Low [45, 42, 43], o qual permite relacionar o estado exato de um sistema, que será denotado por $\Psi_{0}^{\prime}$, com o estado fundamental do sistema não-interagente $\psi_{0}$. Mais especificamente, o teorema estabelece que

$$
\left|\Psi_{0}^{\prime}\right\rangle=\frac{\hat{U}_{\eta}(0,-\infty)\left|\psi_{0}\right\rangle}{\left\langle\psi_{0}\left|\hat{U}_{\eta}(0,-\infty)\right| \psi_{0}\right\rangle} .
$$

Aqui, $\Psi_{0}^{\prime}$ está normalizado de modo que $\left\langle\psi_{0} \mid \Psi_{0}^{\prime}\right\rangle=1$, e o operador $\hat{U}_{\eta}$ é dado por

$$
\hat{U}_{\eta}\left(t, t^{\prime}\right)=\sum_{n=0}^{\infty} \frac{(-i)^{n}}{n !} \int_{t^{\prime}}^{t} d t_{1} \cdots \int_{t^{\prime}}^{t} d t_{n} e^{-\eta\left(\left|t_{1}\right|+\ldots+\left|t_{n}\right|\right)} T\left[\hat{H}_{I}\left(t_{1}\right) \cdots \hat{H}_{I}\left(t_{n}\right)\right]
$$

onde o termo de ordem zero dessa série deve ser entendido como sendo o operador identidade. Mais uma vez, o operador $T$ troca a ordem das interações $\hat{H}_{I}$, que estão todas escritas na representação de interação $\left(\hat{H}_{I}(t)=e^{i \hat{H}_{0} t} \hat{H}_{I} e^{-i \hat{H}_{0} t}\right)$, de forma que seus respectivos instantes de tempo fiquem em ordem decrescente da esquerda para a direita ${ }^{1}$.

\footnotetext{
${ }^{1}$ Agora não se deve trocar o sinal a cada permutação feita (veja a generalização da definição de $T$ na seção sobre o teorema de Wick). Cada operador $\hat{H}_{I}$ pode ser escrito usando dois operadores de criação e dois de aniquilação, e
} 
Na verdade, o teorema de Gell-Mann e Low garante que o estado dado por (2.20) é um autoestado da hamiltoniana exata do sistema $\hat{H}$, mas não necessariamente o estado fundamental. Entretanto, aqui será assumido que $\Psi_{0}^{\prime}$ é de fato o estado com a menor energia. Se $\Psi_{0}^{\prime}$ é não degenerado, também é possível escrever

$$
\left|\Psi_{0}^{\prime}\right\rangle=\frac{\hat{U}_{\eta}(0,+\infty)\left|\psi_{0}\right\rangle}{\left\langle\psi_{0}\left|\hat{U}_{\eta}(0,+\infty)\right| \psi_{0}\right\rangle} .
$$

Considerando um operador qualquer $\hat{O}$, e combinando as equações (2.20) e (2.22), pode-se expressar o valor esperado desse operador quando escrito na representação de Heisenberg como [45]

$$
\begin{aligned}
\left\langle\Psi_{0}\left|\hat{O}_{H}(t)\right| \Psi_{0}\right\rangle=\sum_{n=0}^{\infty} \frac{(-i)^{n}}{n !} & \int_{-\infty}^{\infty} d t_{1} \cdots \int_{-\infty}^{\infty} d t_{n} e^{-\eta\left(\left|t_{1}\right|+\ldots+\left|t_{n}\right|\right)} \\
& \frac{\left\langle\psi_{0}\left|T\left[\hat{H}_{I}\left(t_{1}\right) \cdots \hat{H}_{I}\left(t_{n}\right) \hat{O}_{I}(t)\right]\right| \psi_{0}\right\rangle}{\left\langle\psi_{0}\left|\hat{U}_{\eta}(\infty,-\infty)\right| \psi_{0}\right\rangle}
\end{aligned}
$$

em que $\left|\Psi_{0}\right\rangle=\left\langle\psi_{0} \mid \Psi_{0}\right\rangle\left|\Psi_{0}^{\prime}\right\rangle$ é o estado fundamental do sistema interagente normalizado, e $\hat{O}_{I}(t)$ é o mesmo operador escrito na representação de interação. Essa relação possibilita escrever a função de Green na forma

$$
\begin{aligned}
i G_{p q}\left(t, t^{\prime}\right)=\sum_{n=0}^{\infty} \frac{(-i)^{n}}{n !} & \int_{-\infty}^{\infty} d t_{1} \cdots \int_{-\infty}^{\infty} d t_{n} e^{-\eta\left(\left|t_{1}\right|+\ldots+\left|t_{n}\right|\right)} \\
& \frac{\left\langle\psi_{0}\left|T\left[\hat{H}_{I}\left(t_{1}\right) \cdots \hat{H}_{I}\left(t_{n}\right) \hat{a}_{p}(t) \hat{a}_{q}^{\dagger}\left(t^{\prime}\right)\right]\right| \psi_{0}\right\rangle}{\left\langle\psi_{0}\left|\hat{U}_{\eta}(\infty,-\infty)\right| \psi_{0}\right\rangle}
\end{aligned}
$$

Apesar de não indicado, os operadores de criação e aniquilação no lado direito da expressão acima também estão na representação de interação. Dessa maneira, a função de Green está sendo escrita como a soma de infinitos termos

$$
i G_{p q}\left(t, t^{\prime}\right)=i G_{p q}^{(0)}\left(t, t^{\prime}\right)+i G_{p q}^{(1)}\left(t, t^{\prime}\right)+\ldots
$$

Para calcular cada um deles, é necessário utilizar o teorema de Wick, que será enunciado a seguir.

portanto permutar dois $\hat{H}_{I}$ é equivalente a fazer um total de 16 permutações de operadores de criação e aniquilação. Já que o número total de permutações dos operadores $\hat{a}$ e $\hat{a}^{\dagger}$ é par, o sinal não é alterado. 


\subsection{O Teorema de Wick}

Este teorema é fundamental para o cálculo da expansão da função de Green, pois através dele é possível introduzir os diagramas de Feynmann para $G$, que serão muito úteis neste trabalho. Entretanto, antes de enunciá-lo, é preciso fazer algumas definições.

Primeiro, é necessário generalizar a definição do operador T: Quando aplicado a um produto de operadores de criação e aniquilação que dependem do tempo, $T$ permuta esses operadores de tal forma que aqueles com os maiores instantes de tempo fiquem à esquerda dos operadores com os menores, multiplicando o resultado por $(-1)^{P}$, onde $P$ é o número de permutações feitas para obter o ordenamento correto (só é permitido permutar operadores vizinhos). Por exemplo, se $t_{1}>t_{2}>t_{3}$

$$
T\left[\hat{a}\left(t_{2}\right) \hat{a}^{\dagger}\left(t_{1}\right) \hat{a}\left(t_{3}\right)\right]=-\hat{a}^{\dagger}\left(t_{1}\right) \hat{a}\left(t_{2}\right) \hat{a}\left(t_{3}\right) .
$$

Nesse caso, é necessário permutar apenas $\hat{a}^{\dagger}\left(t_{1}\right)$ e $\hat{a}\left(t_{2}\right)$, então o sinal é negativo. Por definição, esse é um operador linear e, se dois ou mais desses operadores possuem o mesmo instante de tempo, então os de criação são sempre colocados à esquerda dos de aniquilação.

Em seguida, também é importante introduzir um novo tipo de operadores de criação e de aniquilação $\hat{b}^{\dagger}$ e $\hat{b}$, definidos através de

$$
\hat{a}_{a}=\hat{b}_{a}^{\dagger}, \quad \hat{a}_{a}^{\dagger}=\hat{b}_{a} .
$$

$\hat{b}^{\dagger}$ e $\hat{b}$ são chamados operadores de criação e aniquilação de buracos, enquanto $\hat{a}_{i}$ e $\hat{a}_{j}^{\dagger}$ passarão a ser referidos como operadores de criação e aniquilação de partículas. Nesse contexto, o termo "partícula" se refere apenas a férmions em orbitais virtuais. Um buraco pode ser entendido como a ausência de um férmion. A definição feita acima diz que aniquilar um férmion em um orbital ocupado no estado de referência $\psi_{0}$ é equivalente a criar um buraco, e aniquilar um buraco equivale a criar um férmion em um orbital ocupado.

Como no estado fundamental do sistema não-interagente $\psi_{0}$ todos os orbitais buracos estão "preenchidos" por um férmion e os virtuais estão todos desocupados, segue das definições acima que

$$
\hat{a}_{i}\left|\psi_{0}\right\rangle=\hat{b}_{a}\left|\psi_{0}\right\rangle=0
$$

Em termos desses novos operadores, pode-se definir o operador $N$, similar a $T$, que reorganiza um produto de operadores de criação e aniquilação de modo que os de criação de buracos e partículas fiquem à esquerda dos de aniquilação, multiplicando o resultado por $(-1)^{P}$ (para isso, os operadores devem ser permutados entre si. Novamente, apenas permutações entre vizinhos são permitidas). Por exemplo

$$
N\left[\hat{a}_{i} \hat{a}_{a} \hat{a}_{b}^{\dagger}\right]=N\left[\hat{a}_{i} \hat{b}_{a}^{\dagger} \hat{b}_{b}\right]=-\hat{b}_{a}^{\dagger} \hat{a}_{i} \hat{b}_{b}=-\hat{a}_{a} \hat{a}_{i} \hat{a}_{b}^{\dagger}
$$


Decorre dessa definição e da relação (2.28) que o valor esperado calculado usando o estado $\psi_{0}$ de qualquer "produto $N$ " é sempre zero:

$$
\left\langle\psi_{0}|N[\cdots]| \psi_{0}\right\rangle=0
$$

Por fim, a contração de dois operadores de criação e aniquilação $\hat{A}$ e $\hat{B}$ é definida como

$$
\widehat{A(t) B}\left(t^{\prime}\right)=T\left[\hat{A}(t) \hat{B}\left(t^{\prime}\right)\right]-N\left[\hat{A}(t) \hat{B}\left(t^{\prime}\right)\right] .
$$

A contração de dois operadores será sempre um número, pois é igual a zero ou a mais ou menos o anticomutador desses operadores. Após realizar os cálculos, é possível verificar que apenas duas contrações são não nulas, sendo elas

$$
\vec{a}_{i}(t) a_{j}^{\dagger}\left(t^{\prime}\right)= \begin{cases}\delta_{i j} e^{-i \varepsilon_{i}\left(t-t^{\prime}\right)} & , t>t^{\prime} \\ 0 & , t \leq t^{\prime}\end{cases}
$$

$\mathrm{e}$

$$
\vec{a}_{a}(t) a_{b}^{\dagger}\left(t^{\prime}\right)=\left\{\begin{array}{ll}
0 & , t>t^{\prime} \\
-\delta_{a b} e^{-i \varepsilon_{a}\left(t-t^{\prime}\right)} & , t \leq t^{\prime}
\end{array} .\right.
$$

Então, para que a contração seja diferente de zero, os operadores devem ser um de criação e outro de aniquilação (nunca ambos podem ser do mesmo tipo) e também devem ter o mesmo índice, isto é, criar e aniquilar o mesmo spin-orbital. Comparando essas expressões com as (2.15) e (2.16), pode-se constatar que essas contrações estão relacionadas à função de Green não interagente

$$
\stackrel{\Gamma}{a_{p}(t)} a_{q}^{\dagger}\left(t^{\prime}\right)=i G_{p q}^{0}\left(t, t^{\prime}\right)
$$

Em alguns casos, podem etar presentes no produto $N$ operadores contraídos entre si. Como uma contração é só um número, ela pode ser "removida" desse produto, entretanto, para isso, primeiro é necessário permutar os operadores que estão sendo contraídos com seus vizinhos de modo que a contração fique à esquerda de todos os outros operadores, trocando o sinal cada vez que uma permutação é feita. Por exemplo

$$
N[\widehat{A \hat{B} \hat{C} D}]=-N[\widehat{A \hat{B} D} \hat{C}]=+N[\overparen{A D} \hat{B} \hat{C}]=+\overparen{A D} N[\hat{B} \hat{C}]
$$

Com essas definições feitas, o teorema de Wick pode ser enfim enunciado. Ele afirma que o produto $T$ de um conjunto de operadores de criação e aniquilação é igual ao produto $N$ desses operadores somado aos produtos $N$ com esses operadores contraídos entre si de todas as formas possíveis. Ou seja, devemos considerar o caso em que apenas dois deles estão contraídos, o em que há dois pares de contrações, etc. Por exemplo, quando há apenas quatro operadores, o 
teorema estabelece que

$$
\begin{aligned}
& T[\hat{A} \hat{B} \hat{C} \hat{D}]=N[\hat{A} \hat{B} \hat{C} \hat{D}]+N[\widehat{A B} \hat{C} \hat{D}]+N[\widehat{A \hat{B} C} \hat{D}]+N[\overparen{A \hat{B} \hat{C} D}] \\
& +N[\hat{A} B C \hat{D}]+N[\hat{A} \overrightarrow{B C} D]+N[\hat{A} \hat{B} \vec{C} D]+N[\overrightarrow{A B C D}] \\
& +N[\overparen{\overparen{A B C} D}]+N[\overparen{A B C D}] \text {, }
\end{aligned}
$$

onde a dependência temporal dos operadores não está sendo escrita por simplicidade.

O teorema de Wick pode agora ser aplicado à expansão da função de Green (2.24), ao escrever os operadores $\hat{H}_{I}$ que aparecem nessa expressão usando segunda quantização, de acordo com (2.10). São obtidos assim um número muito grande de termos, pois a cada ordem aumenta o número de operadores de criação e aniquilação dentro do produto $T$ e com isso as possibilidades de contrações. Entretanto, muitos desses termos serão na verdade nulos, pois, devido a (2.30), apenas aqueles em que todos os operadores dentro do produto $N$ estão contraídos entre si de alguma maneira devem ser diferentes de zero. No caso de quatro operadores, por exemplo, apenas três termos devem ser mantidos:

$$
\begin{aligned}
\left\langle\psi_{0}|T[\hat{A} \hat{B} \hat{C} \hat{D}]| \psi_{0}\right\rangle= & \left\langle\psi_{0}|N[\overrightarrow{A B C D}]| \psi_{0}\right\rangle+\left\langle\psi_{0}|N[\overrightarrow{A B C D}]| \psi_{0}\right\rangle+ \\
& +\left\langle\psi_{0}|N[\overrightarrow{A B C D}]| \psi_{0}\right\rangle \\
= & \neg B C D-\neg \overrightarrow{A C B D}+\neg D B C .
\end{aligned}
$$

Ainda assim haverá muitos termos que devem ser considerados em ordens maiores, porém, com o método dos diagramas, é possível obtê-los e representá-los de uma maneira mais simples, como é explicado a seguir.

\subsection{Diagramas de Feynman}

A técnica dos diagramas de Feynman se baseia em construir figuras (diagramas) para representar graficamente os vários termos obtidos pela aplicação do teorema de Wick. Primeiro será explicado como isso pode ser feito para o denominador da expansão da função de Green (2.24), dado por

$$
\sum_{n=0}^{\infty} \frac{(-i)^{n}}{n !} \int_{-\infty}^{\infty} d t_{1} \cdots \int_{-\infty}^{\infty} d t_{n} e^{-\eta\left(\left|t_{1}\right|+\ldots+\left|t_{n}\right|\right)}\left\langle\psi_{0}\left|T\left[\hat{H}_{I}\left(t_{1}\right) \cdots \hat{H}_{I}\left(t_{n}\right)\right]\right| \psi_{0}\right\rangle .
$$

Escrevendo os operadores utilizando o formalismo da segunda quantização, a equação acima envolverá várias somatórias com produtos de elementos de matriz do potencial $V$ multiplicados 
por integrais sobre coordenadas temporais, com os operadores de criação e aniquilação dentro do produto $T$. Nos diagramas, são usados símbolos para representar partes dessa expressão. A interação entre as partículas dada por (2.10) será representada por uma linha ondulada com uma linha orientada (ou seta) entrando e outra saindo de cada um dos seus vértices, como mostrado na figura 2.1.

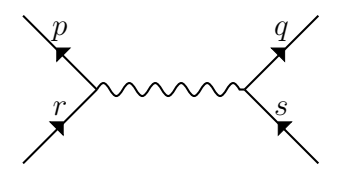

Figura 2.1: Representação da interação em um diagrama.

As linhas (setas) que saem da linha ondulada representam os operadores de criação, e as que entram, os de aniquilação. Em um termo de ordem $n$, haverá $n$ operadores $\hat{H}_{I}$, e para representá-los graficamente são desenhadas $n$ linhas onduladas como a acima dispostas umas sobre as outras (ou lado a lado), como indicado na figura 2.2.

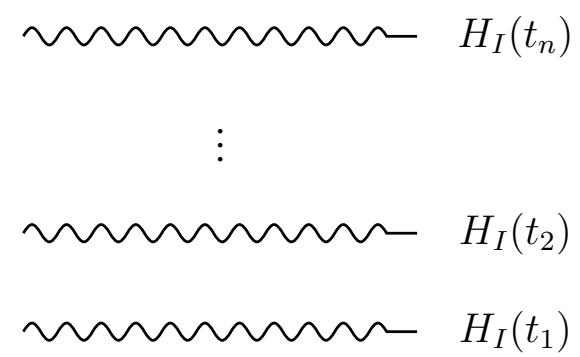

Figura 2.2: Representação de um diagrama do denominador da função de Green de ordem $n$. As linhas onduladas representam os $n$ operadores $\hat{H}_{I}$ que aparecem no produto $T$ nesse termo. Por simplicidade, as setas que entram e saem das linhas onduladas não são mostradas.

Um determinado termo de ordem $n$ que surge após a aplicação do teorema de Wick pode ser representado conectando as setas que entram e saem das linhas onduladas. Como já foi dito, essas setas representam operadores de criação e aniquilação, e as suas conexões irão representar as contrações entre eles. Desenhando então vários diagramas diferentes, com as linhas conectadas de todas as maneiras possíveis, todos os termos decorrentes do teorema de Wick são obtidos. Um exemplo é mostrado na figura 2.3, onde é considerado um termo de segunda ordem. O primeiro diagrama dessa figura representa as duas interações que aparecem nesse termo. Existem várias maneiras de conectar as suas linhas. Por exemplo, uma possibilidade é ligar $p_{1}$ com $r_{2}, p_{2}$ com $r_{1}, q_{1}$ com $s_{2}$ e $q_{2}$ com $s_{1}$ e assim obter o segundo diagrama mostrado nessa figura. Uma outra opção seria ligar $q_{2} \operatorname{com} r_{1}$ e $p_{2} \operatorname{com} s_{1}$, o que gera o terceiro diagrama. Há muitas outras maneiras de fazer essas conexões, e cada uma representa uma possibilidade de contração diferente dos operadores.

De maneira mais geral, ligar a linha $p_{i}$ que sai de uma linha ondulada com a linha $r_{j}$ que entra em outra significa dizer que nesse termo o operador $\hat{a}_{p_{i}}^{\dagger}$ está contraído com o operador $\hat{a}_{r_{j}}$. 

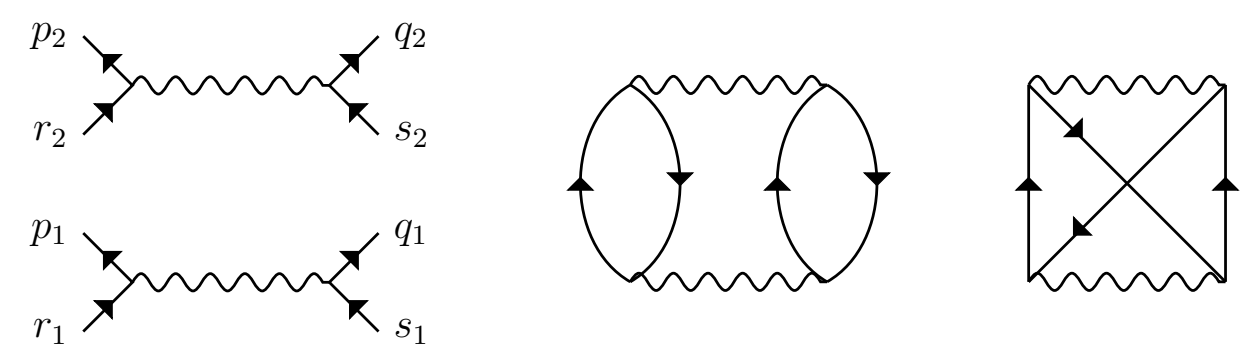

Figura 2.3: Um exemplo de como construir diagramas. Primeiro desenha-se as linhas onduladas umas sobre as outras, e depois suas setas são conectadas. O segundo e o terceiro diagramas desta imagem representam diferentes maneiras de fazer essas ligações.

Entretanto, não é permitido conectar linhas que possuem sentidos opostos, pois isso seria equivalente a contrair operadores de um mesmo tipo (ambos de criação ou ambos de aniquilação), e tal contração é igual a zero. Assim, deve-se ligar as linhas que possuem o mesmo sentido. Dessa forma, cada diagrama está então associado a um termo da expansão da função de Green.

Um melhor entendimento desse procedimento pode ser obtido analisando o termo de primeira ordem. Como há apenas uma interação, ele é representado por apenas uma linha ondulada, como a da figura 2.1. Existe apenas duas maneiras diferentes de conectar as setas: ligando $p \operatorname{com} s$ e $r \operatorname{com} q$ ou $p \operatorname{com} r$ e $s \operatorname{com} q$. Os dois diagramas formados por essas conexões são mostradas na figura 2.4, junto com as respectivas contrações que eles representam.

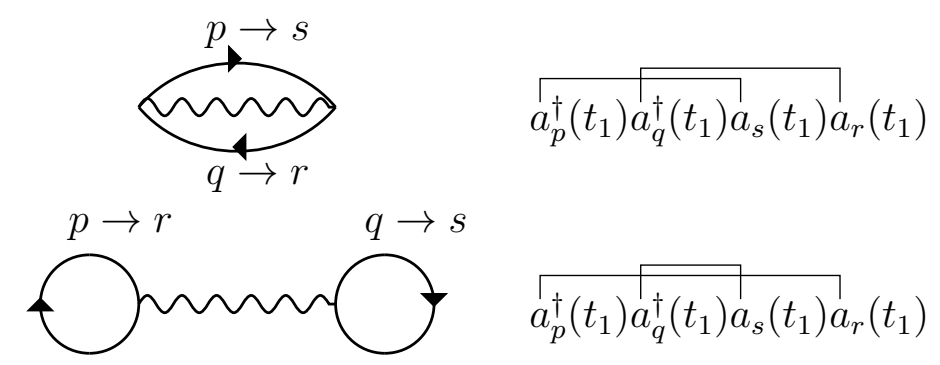

Figura 2.4: Diagramas de primeira ordem para o denominador da função de Green.

Cada diagrama representa um dos termos da equação (2.38) de maneira única, portanto a cada diagrama está associada uma única expressão matemática. É possível deduzir regras que permitam obter tal expressão apenas observando a maneira como as linhas do diagrama estão conectadas. Assim, os termos da função de Green até uma dada ordem podem ser calculados desenhando os diagramas e aplicando essas regras. Essa é uma das vantagens do uso de diagramas.

Os diagramas que representam o numerador de $G$ podem ser obtidos de maneira semelhante, a única diferença sendo o fato de que agora há dois operadores a mais dentro do produto $T$ :

$$
\begin{aligned}
\sum_{n=0}^{\infty} \frac{(-i)^{n}}{n !} & \int_{-\infty}^{\infty} d t_{1} \cdots \int_{-\infty}^{\infty} d t_{n} e^{-\eta\left(\left|t_{1}\right|+\ldots+\left|t_{n}\right|\right)} \\
& \left\langle\psi_{0}\left|T\left[\hat{H}_{I}\left(t_{1}\right) \cdots \hat{H}_{I}\left(t_{n}\right) \hat{a}_{p}(t) \hat{a}_{q}^{\dagger}\left(t^{\prime}\right)\right]\right| \psi_{0}\right\rangle
\end{aligned}
$$


Esses operadores podem ser representados desenhado dois pontos, com as linhas onduladas colocadas entre eles. Um dos pontos terá uma linha que sai, que representa o operador $\hat{a}_{q}^{\dagger}$, enquanto o outro uma linha que entra, representando o operador $\hat{a}_{p}$, como é indicado na figura 2.5 .

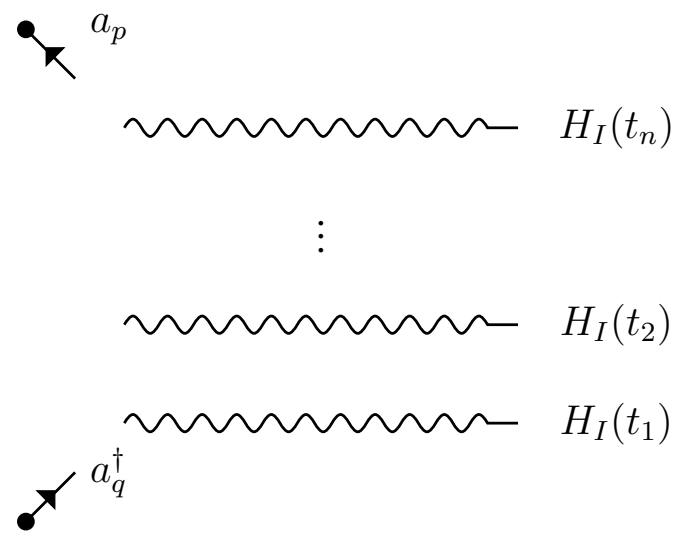

Figura 2.5: Representação de um diagrama do numerador da função de Green de ordem $n$. Novamente, as setas que entram e saem das linhas onduladas não são mostradas.

Mais uma vez, para representar todas as contrações possíveis, é necessário conectar as setas que têm o mesmo sentido de todas as maneiras possíveis. Considere o termo de ordem zero ( $n=0)$, onde não há nenhuma interação. Neste caso, só há uma contração possível, a entre $\hat{a}_{p}(t)$ e $\hat{a}_{q}^{\dagger}\left(t^{\prime}\right)$, o que gera um diagrama representado apenas por uma linha. Porém, de acordo com a equação (2.34), as contrações são iguais à função de Green não interagente (multiplicada pela unidade imaginária) $i G^{0}$. Assim, em ordem zero, $G_{p q}\left(t, t^{\prime}\right)=G_{p q}^{0}\left(t, t^{\prime}\right)$, o que explica a notação utilizada para $G^{0}$.

Já os diagramas para o termo de primeira ordem terão uma linha ondulada aparecendo, e alguns exemplos são mostrados na figura abaixo.
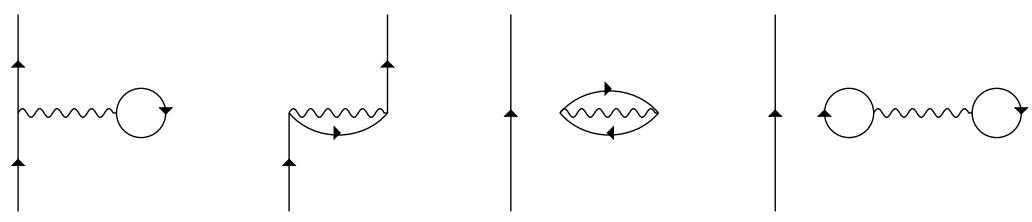

Figura 2.6: Alguns dos diagramas de primeira ordem possíveis para o numerador da função de Green.

Quando as conexões das setas são feitas, podem surgir diagramas desconectados, que são aqueles contendo duas ou mais partes que não estão ligadas entre si por nenhuma linha. Esse é o caso do terceiro e quarto diagramas da figura 2.6, enquanto os dois primeiros são diagramas conectados. Os diagramas desconectados acima representam os termos em que os dois operadores $\hat{a}_{p}(t)$ e $\hat{a}_{q}^{\dagger}\left(t^{\prime}\right)$ estão contraídos entre si, enquanto os diagramas conectados representam termos em que eles aparecem contraídos com os operadores vindos das interações.

Cada diagrama desconectado (de qualquer ordem) é composto por diagramas conectados de ordens mais baixas, sendo que um deles será igual a um dos diagramas conectados do numera- 
dor da função de Green, e os outros serão iguais a diagramas conectados do denominador de $G$. Por exemplo, o primeiro diagrama que aparece na equação (2.40) é um diagrama desconectado de segunda ordem, composto pelo primeiro diagrama da figura 2.6 e pelo segundo da figura 2.4. Um diagrama desconectado é proporcional ao produto dos diagramas conectados que o formam:

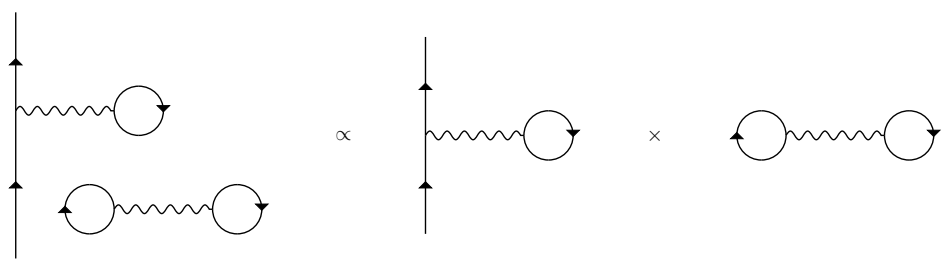

Pode-se demonstrar que os diagramas desconectados do numerador da função de Green se cancelam com os diagramas do seu denominador [45] (uma prova será apresentada no capítulo 5), e portanto a sua expansão completa é dada apenas pelos diagramas conectados do numerador. Como a função $G^{0}$ é representada apenas por um linha orientada, é usual representar a função de Green multiplicada pela unidade imaginária $i G_{p q}\left(t, t^{\prime}\right)$ da mesma forma, porém usando uma linha mais grossa. Assim, é possível escrever

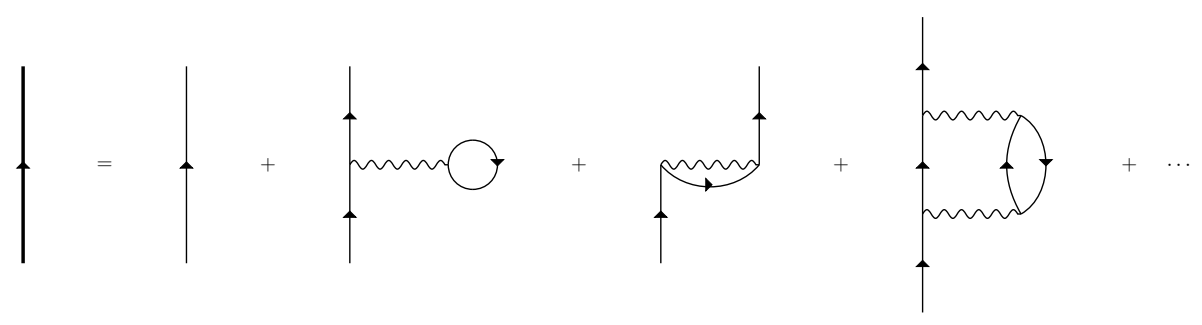

Ao conectar as linhas de todas as maneiras possíveis, muitas vezes surgem diagramas que, apesar de representarem diferentes tipos de contrações, possuem a mesma contribuição. Um exemplo é mostrado na figura 2.7. Esses diagramas, embora resultem de conexões distintas, podem ser transformados um no outro, "girando" uma das linhas onduladas em 180 graus. Todos os diagramas assim, que diferem apenas pela inversão de uma ou mais de suas linhas onduladas têm o mesmo valor numérico, e apenas um deles precisa ser mantido, o que permite cancelar o fator $1 / 2$ que aparece na expressão de $\hat{H}_{I}$ [46].
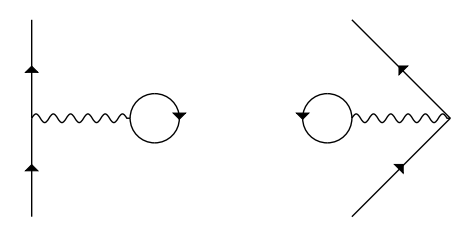

Figura 2.7: Dois diagramas diferentes que têm a mesma contribuição. Apenas um deles precisa ser considerado.

Além disso, diagramas que podem ser transformados uns nos outros pela permutação da ordem de suas linhas onduladas também são numericamente iguais (um exemplo de dois diagramas assim é mostrado na figura 2.8). Novamente, só um deles precisa ser desenhado. 


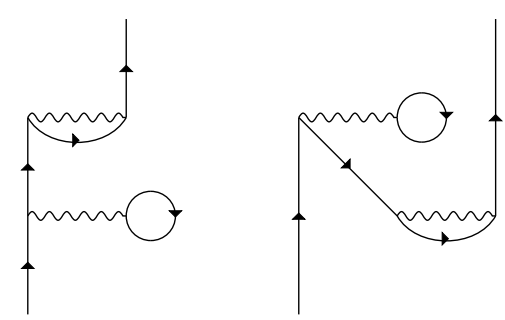

Figura 2.8: Dois diagramas com o mesmo valor numérico. Trocando a ordem das linhas ondulas no segundo, o primeiro é obtido. Novamente, apenas um deles precisa ser considerado.

Levando em conta essas observações, é possível deduzir regras simples que permitem obter a expressão associada a um dado diagrama. Para isso, primeiro é necessário associar à cada linha ondulada um instante de tempo $t_{i}$, com $i$ variando de 1 até $n$, a ordem do diagrama. Aos dois vértices do diagrama, são associados os instantes de tempo $t$ e $t^{\prime}$. Como já mencionado, as linhas representam contrações, mas cada contração é igual a uma função de Green nãointeragente (vezes a unidade imaginária). Assim, uma linha orientada indo de uma interação com instante de tempo $t_{i}$ até outra com um instante de tempo $t_{j}$ contribuirá com $i G_{r r}^{0}\left(t_{j}, t_{i}\right)$, onde $r$ é um spin-orbital qualquer. Desse modo, também é necessário associar spins-orbitais $r, s, u, \ldots$ a cada linha orientada do diagrama. Às duas linhas "externas", que só estão ligadas a uma linha ondulada, são associados os orbitais $p$ e $q$, dos quais a função de Green depende.

Já cada linha ondulada contribui para a expressão do diagrama com um elemento de matriz $\langle r, s|V| u, v\rangle$, em que $r$ e $u$ são os orbitais associados às linhas que entram e saem de um dos vértices da linha ondulada, respectivamente, e $s$ e $v$ são os orbitais das linhas que entram e saem do outro vértice. Por fim, se deve adicionar um fator $e^{-\eta\left(\left|t_{1}\right|+\ldots+\left|t_{n}\right|\right)}$, integrar sobre todos os instantes de tempo (exceto $t$ e $t^{\prime}$ ), somar sobre todos os índices (exceto $p$ e $q$ ), e multiplicar a expressão final por $(-i)^{n}(-1)^{L}$, onde $L$ é o número de loops do diagrama. Um loop é um caminho fechado formado por linhas orientadas. ${ }^{2}$

Um exemplo de aplicação dessas regras é mostrado abaixo, para um diagrama de segunda ordem.

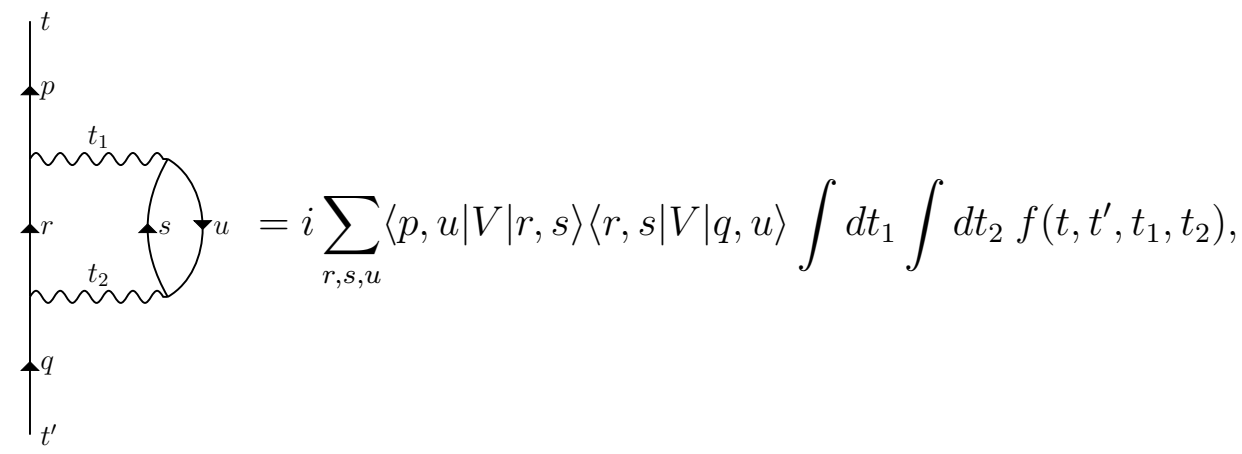

\footnotetext{
${ }^{2} \mathrm{O}$ motivo de multiplicar a expressão por $(-i)^{n}$ é simplesmente porque esse fator aparece na expansão da função de Green, já a razão de multiplicar por $(-1)^{L}$ está relacionada ao sinal dos termos vindos do teorema de Wick e é mais difícil de justificar. Uma dedução dessa regra, para outro tipo de diagrama, é apresentada no capítulo 5 .
} 
onde

$$
f\left(t, t^{\prime}, t_{1}, t_{2}\right)=e^{-\eta\left(\left|t_{1}\right|+\left|t_{2}\right|\right)} G_{p p}^{0}\left(t, t_{2}\right) G_{q q}^{0}\left(t_{1}, t^{\prime}\right) G_{r r}^{0}\left(t_{2}, t_{1}\right) G_{s s}^{0}\left(t_{2}, t_{1}\right) G_{u u}^{0}\left(t_{1}, t_{2}\right) .
$$

\subsection{A equação de Dyson}

Com o uso dos diagramas para a expansão da função de Green, é possível obter uma relação que envolve $G, G^{0}$ e uma nova quantidade que recebe o nome de auto-energia $\Sigma$. Essa equação é chamada de equação de Dyson, e é através dela que os polos de $G$ podem ser calculados.

Para deduzí-la, é necessário primeiro notar que alguns dos diagramas da função de Green podem ser pensados como a junção de diagramas de ordens menores por uma linha orientada. Um exemplo é mostrado na figura 2.9, em que o primeiro diagrama (que é de terceira ordem) pode ser obtido "ligando" o segundo e terceiro, que são de ordens um e dois, respectivamente. Os diagramas com essa propriedade serão chamados de diagramas separáveis. Entretanto, podese observar que o quarto diagrama dessa figura não pode ser gerado pela simples união de diagramas de ordens menores, e portanto esse diagrama é dito ser não separável.
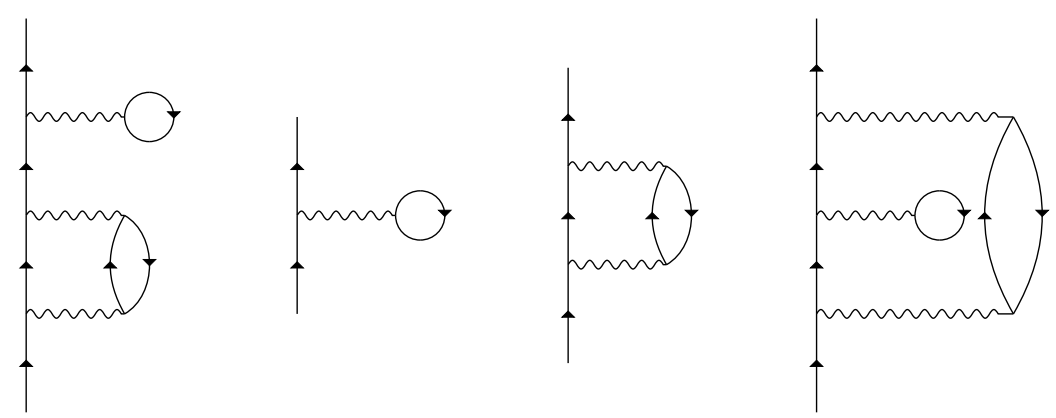

Figura 2.9: Alguns diagramas da função de Green. O primeiro pode ser separado no segundo e terceiro "cortando-o" ao meio, já o quarto não.

Defini-se que a soma de todos os diagramas como esse último, que não são separáveis em diagramas menores, sem as duas linhas externas, é igual a $-i \Sigma_{r s}\left(t, t^{\prime}\right)$, onde $\Sigma$ é a já mencionada auto-energia. Aqui, $r$ e $s$ são os índices dos operadores com os quais $\hat{a}_{p}$ e $\hat{a}_{q}^{\dagger}$ estão contraídos, respectivamente. Graficamente, a auto-energia pode ser representada como

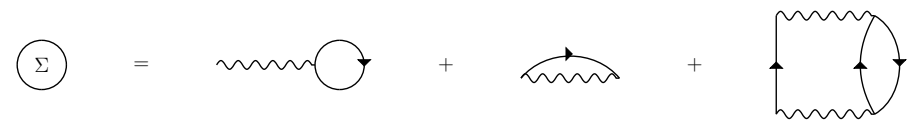

Ligando dois ou mais dos diagramas da auto-energia usando linhas orientadas, obtemos os diagramas separáveis da função de Green. Isso significa que $G$ pode ser escrita usando apenas a auto-energia e a função não interagente $G^{0}$ : 


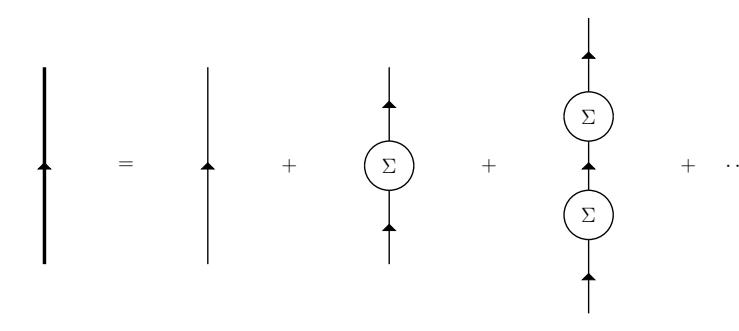

A primeira linha do lado direito da equação acima representa simplesmente $i G_{p q}^{0}\left(t, t^{\prime}\right)$, que é o termo de ordem zero. O segundo termo, obtido pela adição de duas linhas orientadas à autoenergia, é a soma de todos os diagramas não-separáveis da função de Green. O terceiro é igual a soma de todos os diagramas separáveis de $G$ que podem ser decompostos em dois diagramas menores "cortando" uma linha. Um quarto termo, que não aparece nessa representação, seria obtido unindo três auto-energias (2.44) usando quatro linhas orientadas, e representaria a soma de todos os diagramas separáveis que podem ser divididos em três diagramas menores, e assim por diante.

Considere novamente essa mesma equação, reescrita abaixo.

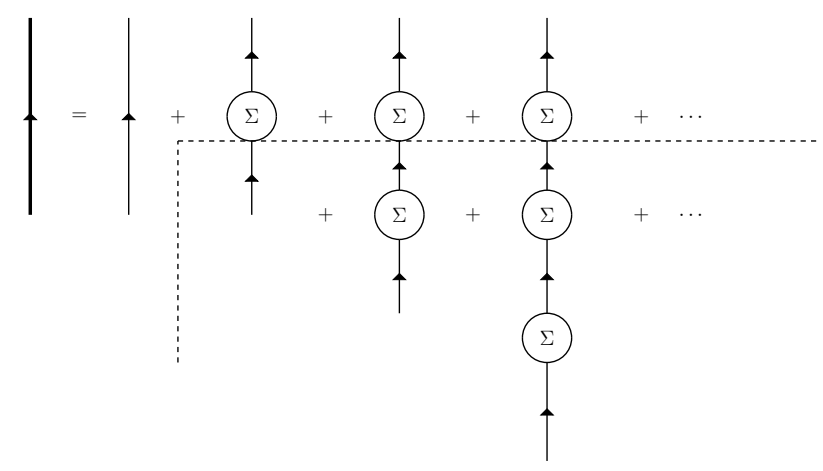

A soma de diagramas que aparece dentro da região delimitada pelas linhas tracejadas é igual a própria função de Green, e portanto é possível reescrever a equação acima como

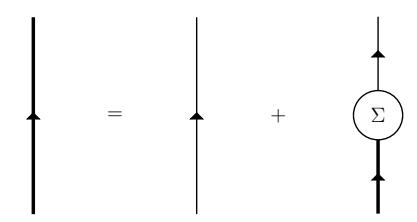

Essa é a chamada Equação de Dyson. Algebricamente, usando as regras para os diagramas, ela equivale a

$$
G_{p q}\left(t, t^{\prime}\right)=G_{p q}^{0}\left(t, t^{\prime}\right)+\sum_{r, s} \int_{-\infty}^{\infty} d t_{1} \int_{-\infty}^{\infty} d t_{2} G_{p r}^{0}\left(t, t_{1}\right) \Sigma_{r s}\left(t_{1}, t_{2}\right) G_{r q}\left(t_{2}, t^{\prime}\right)
$$

Pode-se mostrar que a auto-energia, assim como a função de Green, é uma função da diferença dos dois instantes de tempo dos quais depende [47]. Assim, é possível calcular sua transformada de Fourier em relação a essa diferença 


$$
\Sigma(E)=\int_{-\infty}^{\infty} d t e^{i E t} \Sigma(t, 0)
$$

Usando as transformadas de Fourier das duas funções de Green e da auto-energia, a equação de Dyson passa a ser

$$
G_{p q}(E)=G_{p q}^{0}(E)+\sum_{r, s} G_{p r}^{0}(E) \Sigma_{r s}(E) G_{r q}(E)
$$

A auto-energia também pode ser escrita como uma série infinita: $\Sigma=\Sigma^{(1)}+\Sigma^{(2)}+\ldots$ Mais adiante será explicado como esses termos podem ser calculados usando diagramas, mas antes é necessário discutir de que forma $\Sigma$ pode ser utilizada para obter os polos de $G$. Definindo matrizes $\boldsymbol{G}, \boldsymbol{G}^{0}$ e $\Sigma$, cujos coeficientes são $G_{p q}(E), G_{p q}^{0}(E)$ e $\Sigma_{p q}(E)$, a equação (2.50) fica, em forma matricial

$$
\mathbf{G}(E)=\mathbf{G}^{0}(E)+\mathbf{G}^{0}(E) \boldsymbol{\Sigma}(E) \mathbf{G}(E) .
$$

Multiplicando à direita pela inversa de $G$ e à esquerda pela inversa de $G^{0}$, obtém-se

$$
\mathbf{G}(E)=\left[\mathbf{G}^{0}(E)^{-1}-\mathbf{\Sigma}(E)\right]^{-1} .
$$

Para obter os polos de $G$, é necessário determinar os valores de $E$ para os quais a matriz $G^{0}(E)^{-1}-\Sigma(E)$ não é inversível, ou seja, os valores de $E$ que tornam o determinante dessa matriz nulo. De acordo com a equação (2.19), $G^{0}$ é uma matriz diagonal e sua inversa é dada por $\boldsymbol{G}^{0}(E)^{-1}=E \boldsymbol{I}-\boldsymbol{\varepsilon}$, onde $\boldsymbol{I}$ é a matriz identidade e $\boldsymbol{\varepsilon}$ uma matriz também diagonal que tem como coeficientes as energias dos orbitais $\varepsilon_{p}$. Adotando a aproximação de quase-partícula, que consiste em desprezar os termos não-diagonais da auto-energia, $\Sigma$ também se torna uma matriz diagonal e o objetivo passa a ser resolver

$$
\operatorname{det}\left[\mathbf{G}^{0}(E)^{-1}-\Sigma(E)\right] \approx \prod_{p}\left(E-\varepsilon_{p}-\Sigma_{p p}(E)\right)=0 .
$$

Assim, deve-se encontrar os valores de $E$ tais que

$$
E=\varepsilon_{p}+\Sigma_{p p}(E)
$$

Essa equação pode ser resolvida de forma iterativa.

\subsection{Função de Green na física atômica e molecular}

Nesta seção será mostrado como a função de Green definida nas seções anteriores pode ser aplicada para átomos e moléculas. Primeiro, entretanto, algumas aproximações utilizadas para 
esses sistemas serão revisadas, como a aproximação Born-Oppenheimer e o método HartreeFock, que serão fundamentais ao longo deste trabalho.

\subsubsection{Aproximação Born-Oppenheimer}

A função de onda que descreve o estado de uma molécula deve obedecer a equação de Schrodinger independente do tempo: $\hat{H} \Psi(\boldsymbol{r}, \boldsymbol{R})=E \Psi(\boldsymbol{r}, \boldsymbol{R})$, onde $\boldsymbol{r}=\left(\boldsymbol{r}_{1}, \ldots, \boldsymbol{r}_{N}\right)$ e $\boldsymbol{R}=$ $\left(\boldsymbol{R}_{1}, \ldots, \boldsymbol{R}_{M}\right)$ representam os conjuntos das coordenados dos $N$ elétrons e dos $M$ núcleos da molécula, respectivamente (por simplicidade, a dependência com os spins das partículas não está sendo mostrada). Desprezando efeitos relativísticos e utilizando unidades atômicas, a hamiltoniana do sistema pode ser escrita como

$$
\begin{aligned}
\hat{H}= & -\frac{1}{2} \sum_{i=1}^{N} \nabla_{i}^{2}-\sum_{i=1}^{M} \frac{1}{2 m_{j}} \nabla_{i}^{2}+\frac{1}{2} \sum_{\substack{i, j=1 \\
i \neq j}}^{N} \frac{1}{\left|\boldsymbol{r}_{i}-\boldsymbol{r}_{j}\right|}-\sum_{i=1}^{N} \sum_{j=1}^{M} \frac{Z_{j}}{\left|\boldsymbol{r}_{i}-\boldsymbol{R}_{j}\right|} \\
& +\frac{1}{2} \sum_{\substack{i, j=1 \\
i \neq j}}^{M} \frac{Z_{i} Z_{j}}{\left|\boldsymbol{R}_{i}-\boldsymbol{R}_{j}\right|} \\
& =\hat{T}_{e}+\hat{T}_{N}+\hat{V}_{e e}+\hat{V}_{e N}+\hat{V}_{N N},
\end{aligned}
$$

sendo $Z_{i}$ e $m_{i}$ o número atômico e a massa do $i$-ésimo núcleo. Aqui, $\hat{T}_{e}\left(\hat{T}_{N}\right)$ representa a soma das energias cinéticas dos elétrons (núcleos), $\hat{V}_{e e}$ é a soma das interações de Coulomb entre os elétrons, $\hat{V}_{N N}$ a soma das interações de Coulomb entre os núcleos e $\hat{V}_{e N}$ a soma das interações elétron-núcleo.

Para facilitar a solução dessa equação, é comum utilizar a aproximação Born-Oppenheimer (BO). Aqui, o seu resultado será apresentado de maneira sucinta e pouco formal (uma descrição mais rigorosa e matemática pode ser encontrada na maioria dos livros sobre química quântica e física molecular, como por exemplo [48]). Essa aproximação é baseada no fato de que os elétrons possuem uma massa muito menor do que a dos núcleos, e portanto devem se movimentar muito mais rapidamente. Pode-se então considerar que do ponto de vista dos elétrons os núcleos estão fixos e assim a princípio desprezar o termo correspondente a sua energia cinética na (2.55). Passa-se então a buscar uma solução para a equação

$$
\left(\hat{H}_{e}+\hat{V}_{N}\right) \psi_{e}(\boldsymbol{r}, \boldsymbol{R})=U(\boldsymbol{R}) \psi_{e}(\boldsymbol{r}, \boldsymbol{R})
$$

em que foi definida a hamiltoniana eletrônica $\hat{H}_{e}=\hat{T}_{e}+\hat{V}_{e e}+\hat{V}_{e N}$. Essa equação pode ser resolvida para cada configuração possível de núcleos fixos, assim $\psi_{e}$ e $U$ dependem parametricamente das coordenadas $\boldsymbol{R}$. Como na equação acima $\hat{V}_{N N}$ é uma constante, é suficiente solucionar 


$$
\hat{H}_{e} \psi_{e}(\boldsymbol{r}, \boldsymbol{R})=E_{e}(\boldsymbol{R}) \psi_{e}(\boldsymbol{r}, \boldsymbol{R})
$$

onde $U=E_{e}+V_{N}$. Considerando agora o movimento nuclear, $U$ pode ser interpretado como a energia potencial sentida pelos núcleos, e a equação de Schrodinger que sua função de onda deve obedecer se torna

$$
\left[-\sum_{i=1}^{M} \frac{1}{2 m_{i}} \nabla_{i}^{2}+U(\boldsymbol{R})\right] \phi(\boldsymbol{R})=E_{N} \phi(\boldsymbol{R}),
$$

sendo que a função $U(\boldsymbol{R})$ recebe o nome de superfície de energia potencial. Assim, a aproximação BO permite separar os movimentos eletrônicos e nucleares, e será adotada daqui em diante.

\subsubsection{O Método Hartree-Fock}

A partir de agora, os núcleos serão considerados cargas pontuais fixas e a atenção será voltada para a solução do problema eletrônico. A hamiltoniana eletrônica tem a mesma forma da hamiltoniana (2.1) considerada no início do capítulo, com o potencial $V$ sendo o potencial de Coulomb entre os elétrons e $v$ a interação dos elétrons com os núcleos. Essa equação não pode ser resolvida analiticamente para sistemas com mais de um elétron, devido ao termo correspondente à repulsão de Coulomb entre eles ${ }^{3}$. Uma opção seria desprezar as interações entre os elétrons, o que levaria a um problema solúvel, em que a função de onda do sistema é um determinante de Slater. Essa escolha, que em geral não é uma boa aproximação, pode ser melhorado com o método Hartree-Fock. Ele é baseado no teorema variacional [49], que pode ser enunciado da seguinte forma: Seja $E_{0}$ a energia exata do estado fundamental do sistema, e $\phi$ uma função normalizada, chamada de função tentativa. Se $\hat{H}$ é a hamiltoniana do sistema (o índice $e$ não será mais utilizado para se referir à hamiltoniana eletrônica), então

$$
E_{0} \leq\langle\phi|\hat{H}| \phi\rangle
$$

O método HF consiste em utilizar um determinante de Slater como função tentativa, sendo que seus spin-orbitais devem ser escolhidos de modo que esse determinante forneça o menor valor de $\left\langle\psi_{0}|\hat{H}| \psi_{0}\right\rangle$ possível, enquanto continuam sendo ortonormais. Pode-se demonstrar (veja, por exemplo [50]) que tais spins-orbitais são autofunções de um determinado operador $\hat{f}$ (chamado operador de Fock):

$$
\hat{f}(i) \varphi_{p}\left(\boldsymbol{x}_{i}\right)^{H F}=\left[\hat{h}_{0}(i)+\sum_{a}\left(\hat{J}_{a}(i)-\hat{K}_{a}(i)\right)\right] \varphi_{p}\left(\boldsymbol{x}_{i}\right)^{H F}=\varepsilon_{p}^{H F} \varphi_{p}\left(\boldsymbol{x}_{i}\right)^{H F} .
$$

\footnotetext{
${ }^{3}$ Na verdade, a DFT (Density Functional Theory) permite obter uma solução formal exata, porém para aplicá-la ainda deve-se recorrer a aproximações.
} 
Aqui, $\hat{h}(i)$ é a soma da energia cinética do $i$-ésimo elétron com a sua interação com os núcleos da molécula, e $\hat{J}$ e $\hat{K}$ são os operadores de Coulomb e Troca, definidos por

$$
\begin{aligned}
& \hat{J}_{a}(i) \varphi_{p}\left(\boldsymbol{x}_{i}\right)^{H F}=\int d \boldsymbol{x}^{\prime} \frac{\varphi_{a}^{*}\left(\boldsymbol{x}^{\prime}\right)^{H F} \varphi_{a}\left(\boldsymbol{x}^{\prime}\right)^{H F}}{\left|\boldsymbol{r}_{i}-\boldsymbol{r}^{\prime}\right|} \varphi_{p}\left(\boldsymbol{x}_{i}\right)^{H F}, \\
& \hat{K}_{a}(i) \varphi_{p}\left(\boldsymbol{x}_{i}\right)^{H F}=\int d \boldsymbol{x}^{\prime} \frac{\varphi_{a}^{*}\left(\boldsymbol{x}^{\prime}\right)^{H F} \varphi_{p}\left(\boldsymbol{x}^{\prime}\right)^{H F}}{\left|\boldsymbol{r}_{i}-\boldsymbol{r}^{\prime}\right|} \varphi_{a}\left(\boldsymbol{x}_{i}\right)^{H F} .
\end{aligned}
$$

Os autovalores do operador $\hat{f}$ podem ser interpretados como as energias dos elétrons nos spinsorbitais $\varphi_{p}^{H F}$.

O operador de Fock terá um número infinito de autofunções [50], e para construir o determinante de Slater para o estado fundamental do sistema deve-se utilizar os $N$ spin-orbitais com as $N$ menores energias $\varepsilon^{H F}$. Como antes, esses spins-orbitais são chamados de ocupados (ou buracos) e os demais de partículas (ou virtuais), para os quais usamos os índices $a, b, c, \ldots \mathrm{e}$ $i, j, k, \ldots$, respectivamente.

Também é possível definir operadores de criação e aniquilação que atuam em determinantes de Slater construídos com esses novos spins-orbitais, que têm as mesmas propriedades dos operadores apresentados anteriormente. Até o final do capítulo, todos os spins-orbitais (e suas respectivas energias) que aparecerão serão spins-orbitais Hartree-Fock, então não usaremos mais o índice $H F$ para se referir a eles nem aos seus autovalores.

\subsubsection{Partição de Moller-Plesset}

No início deste capítulo, a hamiltoniana foi dividida em duas partes, uma que só envolvia a soma de operadores de uma partícula $\hat{H}_{0}$ e outra igual a soma dos operadores de duas partículas $\hat{H}_{I}$. Entretanto, muitas vezes é conveniente definir o potencial de Fock

$$
\hat{v}_{H F}(i)=\sum_{a}\left(\hat{J}_{a}(i)-\hat{K}_{a}(i)\right) .
$$

e reescrever a hamiloniana na forma

$$
\hat{H}=\hat{H}_{0}+\sum_{i=1}^{N} \hat{v}_{H F}(i)-\sum_{i=1}^{N} \hat{v}_{H F}(i)+\hat{H}_{I},
$$

e, com isso, redefinir a hamiltoniana não perturbada do sistema $\hat{H}_{0}$ como sendo

$$
\hat{H}_{0}=\sum_{i=1}^{N} \hat{h}_{0}(i)+\sum_{i=1}^{N} \hat{v}_{H F}(i)=\sum_{i=1}^{N} \hat{f}(i) .
$$

Consequentemente 


$$
\hat{H}_{I}=\frac{1}{2} \sum_{\substack{i, j=1 \\ i \neq j}}^{N} \frac{1}{\left|\boldsymbol{r}_{i}-\boldsymbol{r}_{j}\right|}-\sum_{i=1}^{N} \hat{v}_{H F}(i) .
$$

Com essas definições, a nova hamiltoniana $\hat{H}_{0}$ passa a ser a soma dos operadores de Fock, e assim os spins-orbitais do determinante de Slater que é autofunção de $\hat{H}_{0}$ passam a ser os orbitais Hartree-Fock do sistema. Essa partição da hamiltoniana é chamada de partição de Moller-Plesset (MP), e é muito útil para o estudo de átomos e moléculas, e também será adotada a partir de agora.

\subsubsection{Função de Green para átomos e moleculas}

Considere um átomo ou uma molécula, com a aproximação BO adotada para essa última. Se o sistema é de camada fechada, pode-se definir uma função de Green da mesma maneira que foi feita anteriormente:

$$
G_{p q}\left(t, t^{\prime}\right)=-i\left\langle\Psi_{0}\left|T\left[a_{p}(t) a_{q}^{\dagger}\left(t^{\prime}\right)\right]\right| \Psi_{0}\right\rangle,
$$

onde aqui $\Psi_{0}$ é o estado fundamental da hamiltoniana eletrônica. Também podemos definir uma função de Green não interagente para o sistema sem as interações entre os elétrons

$$
G_{p q}^{0}\left(t, t^{\prime}\right)=-i\left\langle\psi_{0}\left|T\left[a_{p}(t) a_{q}^{\dagger}\left(t^{\prime}\right)\right]\right| \psi_{0}\right\rangle,
$$

que também é dada por (2.15) e (2.16). A única diferença reside no fato de que agora os orbitais que aparecem nessas funções são spins-orbitais HF.

Ainda é possível expandir a função de Green, aplicar o teorema de Wick e representar os termos através de diagramas. Entretanto, agora $\hat{H}_{I}$ não é mais simplesmente a soma das interações entre as partículas, mas contém termos extras, como pode ser visto por (2.66). A princípio, isto significaria que são necessários mais diagramas para representar a expansão de $G$ quando a partição de MP é adotada, entretanto, na verdade os termos extras em $\hat{H}_{I}$ irão cancelar-se com alguns dos diagramas da expansão original [51]. Então na prática o uso da partição de Moller-Plesset diminui o número de diagramas que precisa ser considerado. Apenas os diagramas em que nenhuma de suas linhas onduladas está ligada a ela mesma devem ser considerados. Assim, não há mais termos de ordem 1 e a expansão começa em segunda ordem.

No caso de sistemas de camada aberta, a situação é um pouco mais complexa, devido a degenerescência das autofunções da hamiltoniana em relação ao spin. Ainda é possível definir uma função de Green e expandí-la usando diagramas, porém esse caso não será considerado aqui. Para uma discussão sobre isso, veja as referências [52, 35]. 


\subsubsection{Cálculo da auto-energia}

Os diagramas da auto-energia podem ser obtidos diretamente dos diagramas para a função de Green. Para isso, os diagramas não separáveis devem ter duas de suas linhas removidas, que passarão a ser referidas como linhas externas. Mais alguns diagramas para $\Sigma$ são mostrados na figura 2.10. Os dois primeiros são diagramas de segunda ordem, enquanto o último é um diagrama de terceira ordem.
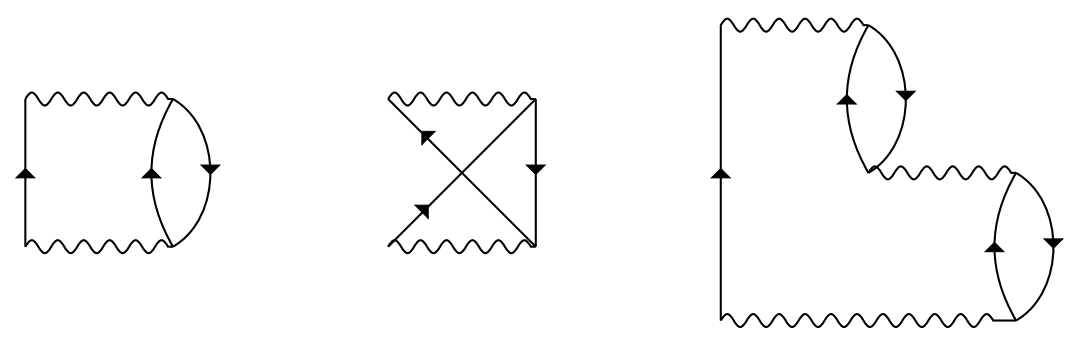

Figura 2.10: Mais alguns diagramas da auto-energia.

Esses diagramas são válidos tanto para a expansão de $\Sigma(\tau)$ quanto a de sua transformada de Fourier $\Sigma(E)$, a qual pretende-se calcular nesse trabalho. Como já mencionado, cada diagrama está associado a uma expressão matemática, e é possível deduzir regras para obtê-las, que serão enunciadas a seguir. Tais regras podem ser encontradas em vários artigos e livros [53, 35, 54], e uma dedução detalhada para as regras dos diagramas da função de Green, que são semelhantes às da auto-energia, está disponível no apêndice de [42]. Essas deduções são similares às apresentadas no capítulo 5.

Porém, antes de aplicá-las, é necessário dividir os diagramas de Feynman para a autoenergia nos chamados diagramas temporalmente ordenados. Para isso, primeiro deve-se associar à cada linha ondulada (que a partir de agora será referida como uma "interação") um instante de tempo. Às interações que estavam ligadas às linhas externas que foram removidas são associados os instante de tempo $t$ e $t^{\prime}$ ( $t$ para a que está acima e $t^{\prime}$ para a que está mais abaixo). Enquanto isso, para as outras interações são utilizados os instantes de tempo $t_{i}, i=1, \ldots, n-2$, onde $n$ é a ordem do diagrama em questão. Um exemplo de como essa associação é feita é mostrado na figura 2.11, para um diagrama de terceira ordem.

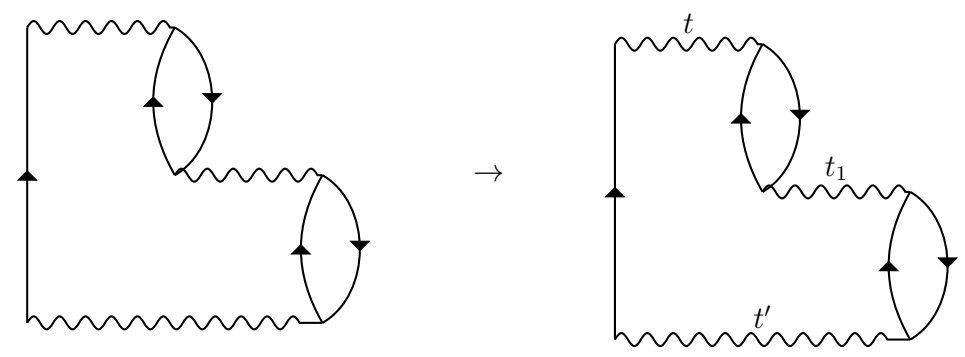

Figura 2.11: Exemplo de como associar instantes de tempo a cada uma das interações de um diagrama.

Em seguida, escolhe-se um dado ordenamento desses instantes de tempo, por exemplo, 
$t^{\prime}<t_{1}<t_{2}<\ldots<t_{n-2}<t$, e as linhas onduladas do diagrama são movidas de modo que uma linha com um maior instante de tempo fique acima de uma com um menor, gerando assim um novo diagrama, que é um diagrama temporalmente ordenado, também chamado de diagrama de Goldstone. Depois, uma outra forma de ordenar os instantes de tempo deve ser escolhida, e o processo repetido, até que todas as possibilidades tenham sido consideradas. Um exemplo é mostrado na figura 2.12, onde são apresentados alguns dos diagramas temporalmente ordenados obtidos a partir do diagrama de Feynman da figura 2.11. Um diagrama de ordem $n$ dá origem a $n$ ! diagramas de Goldstone.

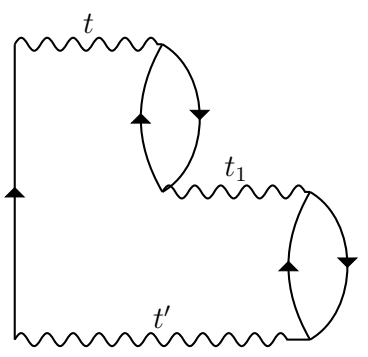

(a) $t>t_{1}>t^{\prime}$

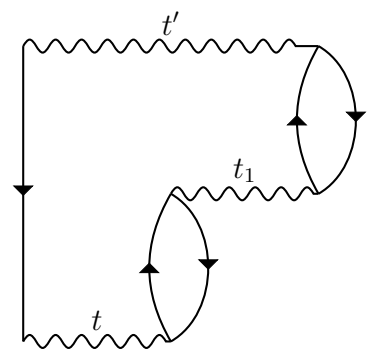

(b) $t^{\prime}>t_{1}>t$

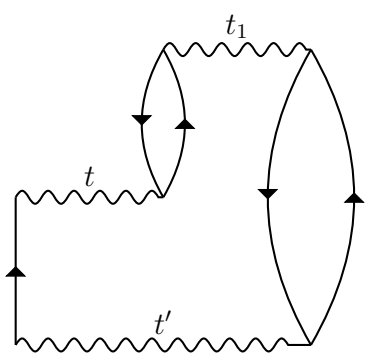

(c) $t_{1}>t>t^{\prime}$

Figura 2.12: Alguns diagramas temporalmente ordenados obtidos a partir do diagrama de Feynman na figura 2.11, e as respectivas ordens dos instantes de tempo de cada um.

As regras são aplicáveis apenas a diagramas temporalmente ordenados, então cada um deles deve ser considerado separadamente. Elas podem ser enunciadas da seguinte forma: Primeiro, cada uma das linhas orientadas que ligam as interações são associadas à orbitais eletrônicos. As linhas que apontam para cima são associadas a orbitais partículas, e nomeadas com as letras $i, j, k, \ldots$ (deve-se utilizar uma letra diferente para cada linha). Já as linhas que apontam para baixo representam orbitais buracos, e são nomeadas usando as letras $a, b, c, \ldots$. A figura 2.13 (a) mostra como essa associação pode ser feita.

Cada interação $t_{i}$ possui duas linhas que entram e duas que saem dela. No diagrama da figura 2.13 (a), as linhas $j$ e $k$ estão entrando na interação $t_{1}$ e as $a$ e $b$ saindo. Para cada uma dessas interações, deve-se multiplicar a expressão do diagrama pelo elemento de matriz $\langle p, q|V| r, s\rangle$, onde $p$ e $q$ são as linhas que saem da interação, e $r$ ( $s$ ) é a linha que entra no mesmo vértice do qual $p(q)$ sai. Por exemplo, a interação mencionada acima contribui com $\langle a, b|V| j, k\rangle$. Porém, as interações associadas aos instantes $t$ e $t^{\prime}$ têm uma linha a menos. Essas interações contribuem com $\langle u, q|V| r, s\rangle$ e $\langle p, q|V| v, s\rangle$, respectivamente, onde $u$ e $v$ são os índices dos quais a auto-energia depende: $\Sigma_{u v}(E)$.

Em seguida, desenha-se uma linha tracejada horizontal entre cada par de interações consecutivas. Para cada uma dessas linhas tracejadas, deve ser adicionado ao denominador da expressão um fator igual à soma das energias dos orbitais das linhas de buracos menos as energias dos orbitais das linhas de partículas que cruzam a linha tracejada em questão. Se essa linha estiver entre as interações $t$ e $t^{\prime}$, então também é preciso somar a esse fator a energia $E$ se $t>t^{\prime}$, e $-E$ caso $t^{\prime}>t$. Um exemplo de como traçar essas linhas e os fatores que surgem através delas é 
apresentado na figura 2.13 (b).

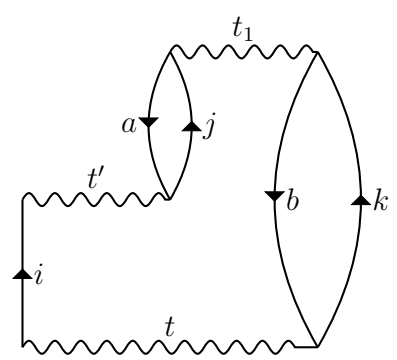

$(a)$

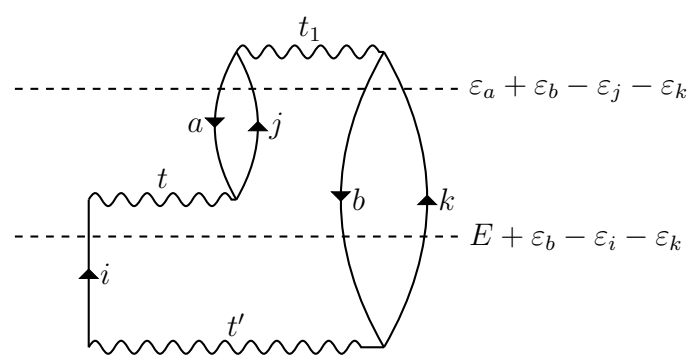

(b)

Figura 2.13: A figura (a) mostra como nomear as linhas do diagrama 2.12 (c), enquanto a (b) mostra como obter os fatores que aparecem no denominador da expressão do diagrama.

Por fim, soma-se sobre todos os índices (exceto os dois índices dois quais a auto-energia depende, denotados por $u$ e $v$ ) e multiplica-se o resultado por $(-1)^{L+B}$, onde $B$ é o número de linhas representado orbitais ocupados e $L$ é o número de loops do diagrama. Por exemplo, o diagrama 2.13 (a) possui dois loops, um formado pelas linhas $a$ e $j$ e outro formado pelas $b$ e $k$. Aplicando essas regras para esse diagrama, obtem-se que sua contribuição para $\Sigma_{p q}(E)$ é (note que houve uma mudança de notação nos índices da auto-energia)

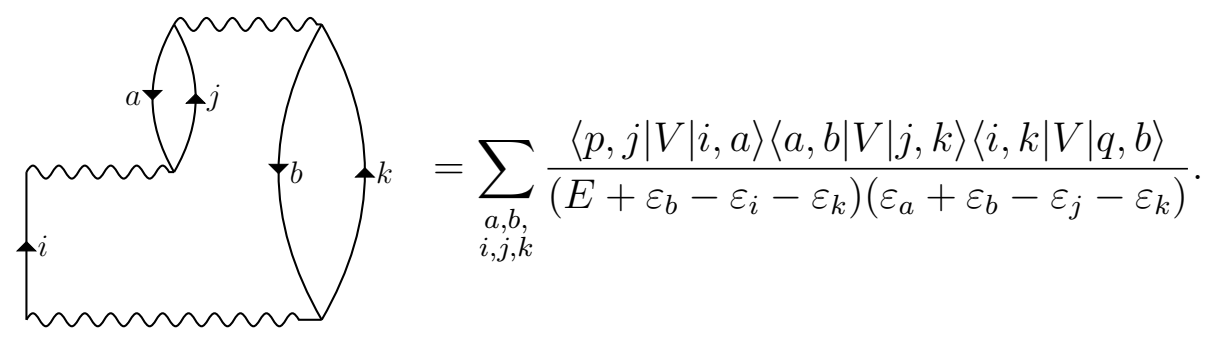

O denominador desse diagrama é formado pelo produto de dois fatores, um que depende da energia e outro que não. Alguns dos diagramas terão a energia aparecendo em todos os fatores no seu denominador, enquanto outros em apenas alguns deles. Também haverá diagramas que são independentes da energia. Esse é o caso dos diagramas em que as duas linhas externas que foram removidas pertenciam a mesma interação. Um diagrama de Feynman da auto-energia desse tipo é apresentado na figura 2.14 (b), junto com o respectivo diagrama da função de Green que o gerou (a). Nesses casos, não há uma interação $t^{\prime}$, apenas uma interação $t$, e as demais linhas onduladas devem ser nomeadas com $t_{1}, \ldots, t_{n-1}$, sendo $n$ a ordem do diagrama.

Isso significa que a auto-energia pode ser escrita como a soma de dois termos, um que depende da energia, e é chamado de parte dinâmica $M$, e outro que é independente de $E$, denotado por $\Sigma(\infty)$ :

$$
\Sigma_{p q}(E)=\Sigma_{p q}(\infty)+M_{p q}(E) .
$$

É possível mostrar que $\Sigma(\infty)$ pode ser determinada de forma auto-consistente conhecendo a 


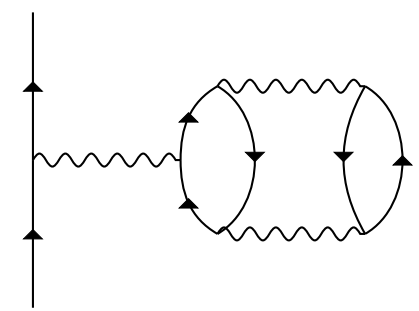

$(a)$

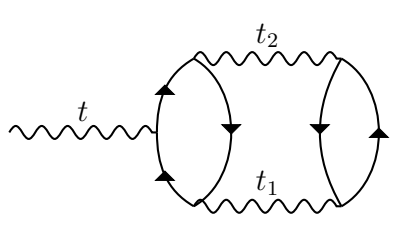

(b)

Figura 2.14: Um diagrama da função de Green (a) e o diagrama da auto-energia obtido ao remover as suas linhas externas (b). Este diagrama da auto-energia não dependerá da energia E.

parte dinâmica da auto-energia (veja [34] e as referências citadas nesse artigo), então na pratica é necessário apenas obter $M(E)$. Uma propriedade importante da auto-energia dinâmica é que ela possui uma forma espectral assim como a função de Green, podendo ser escrita como [55]

$$
M_{p q}(E)=\sum_{m} \frac{f_{p q m}}{E-A_{m}+i \eta}+\sum_{n} \frac{g_{p q n}}{E-B_{n}-i \eta},
$$

onde $f$ e $g$ são números reais não-negativos. 


\section{Capítulo 3}

\section{Energias de Ligação}

Neste capítulo, que trata de átomos e moléculas que podem formar estados ligados com pósitrons, primeiro será feita uma breve revisão sobre o assunto e em seguida se discutirá como o formalismo apresentado no capítulo anterior pode ser generalizado para obter energias de ligação do pósitron. Como dito na introdução, o objetivo é comparar a aproximação implementada no LOWDIN com a obtida em outros trabalhos.

\section{1 Átomos e moléculas que podem ligar pósitrons}

A interação repulsiva entre um pósitron e o núcleo de um átomo dificulta a formação de estados ligados, porém, o pósitron pode polarizar o átomo, atraindo a nuvem eletrônica para si e afastando o núcleo, originando assim um potencial de polarização atrativo. Além disso, também é possível que o pósitron capture um dos elétrons do alvo com que interage, criando um átomo de positrônio, que é polarizado pelo cátion restante. Esses efeitos possibilitam que o pósitron vença o potencial repulsivo e se ligue ao átomo. Atualmente, sabe-se que o pósitron não pode se ligar aos átomos de $\mathrm{H}, \mathrm{He}, \mathrm{Ne}$ e $\mathrm{N}$ [56], entretanto, cálculos numéricos realizados para todos os elementos da tabela periódica [57] sugerem que cerca de 50 deles podem formar estados ligados com o pósitron (quando em seus estados fundamentais).

Se o átomo possui uma energia de ionização $I$ maior que a energia de ligação do Ps no estado fundamental, então o pósitron pode se ligar a ele se o mesmo tiver uma afinidade positrônica maior que zero. Aqui, a afinidade positrônica é definida de forma análoga à eletrônica, sendo a diferença entre as energias do sistema com e sem o pósitron. Se $I<\left|E_{P s}\right| \approx 6,8 \mathrm{eV}$, então a energia de ligação do pósitron deve ser maior que $\left|E_{P s}\right|-I$, caso contrário o sistema se dissociará em um positrônio e um cátion [58].

Infelizmente, nenhum átomo positrônico foi detectado experimentalmente, exceto os já mencionados na introdução. Para moléculas, a situação é diferente. Além de vários trabalhos teóricos em que a energia de ligação de pósitrons é computada para sistemas moleculares, há também muitas medidas experimentais (veja [29] e as referências citadas nesse artigo). A 
ligação entre o pósitron e uma molécula pode ser facilitada se a mesma possuir um momento de dipolo permanente. Já foi demonstrado teoricamente que qualquer molécula em que o momento de dipolo é maior que um valor crítico possui um número infinito de estados positrônicos ligados [59].

O que permite medir essas energias de ligação é o fato de que, em uma colisão entre um pósitron e uma molécula, o pósitron pode ser capturado em uma ressonância de Feshbach vibracional (RFV). Em um processo de espalhamento, uma ressonância consiste na captura temporária do projétil (neste caso, o pósitron) pelo alvo (aqui, a molécula), formando o que é chamado de estado metaestável, havendo diferentes tipos de ressonâncias. A RFV ocorre quando existe um estado ligado da molécula e do pósitron e a energia do estado fundamental do sistema molécula-pósitron é menor do que a energia do estado fundamental da molécula isolada, sendo o único tipo de ressonância que deve ocorrer para colisões de pósitrons em baixas energias [60]. Essa ressonância recebe o nome de vibracional pois a energia cinética do pósitron é transferida para o movimento vibracional da molécula, gerando assim um composto vibracionalmente excitado, que pode decair pela emissão do pósitron e sua desexcitação vibracional.

O pósitron capturado eventualmente poderá se aniquilar com um dos elétrons da molécula. Medindo a taxa de aniquilação em função da energia do pósitron incidente (mais sobre taxas de aniquilação será explicado no capítulo 5), pode-se determinar as energias $\varepsilon_{\text {res }}$ em que ocorrem as ressonâncias e, conhecendo as energias dos modos vibracionais da molécula $\varepsilon_{\nu}$, a energia de ligação do pósitron pode ser calculada de acordo com a relação $\varepsilon_{b}=\varepsilon_{\nu}-\varepsilon_{\text {res }}$.

Um exemplo de aplicação desse método é ilustrado na figura 3.1, retirada da referência [2], onde são mostradas medidas do parâmetro $Z_{\text {eff }}$ (proporcional à taxa de aniquilação) em função da energia do pósitron incidente $\varepsilon$ para a molécula de butano $\mathrm{C}_{4} \mathrm{H}_{10}$. $\mathrm{O}$ pico pronunciado na forma de $Z_{\text {eff }}$ seria devido a captura do pósitron pela molécula, formando a RFV [9]. Nessa figura também é apresentado o espectro de absorção da molécula no infravermelho. Considerando a diferença entre as energias nas quais ocorrem os picos, é possível obter a energia de ligação do pósitron.

Por fim, deve-se mencionar que recentemente surgiram evidências da existência de outro tipo de molécula positrônica. Cálculos numéricos mostram que o sistema formados por um pósitron e dois ânions de hidrogênio $e^{+} \mathrm{H}^{-} \mathrm{H}^{-}$é eletronicamente estável [61, 62], assim como os sistemas formados por $e^{+} \mathrm{X}^{-} \mathrm{Y}^{-}$, com $\mathrm{X}, \mathrm{Y}=\mathrm{F}, \mathrm{Br}, \mathrm{Cl}$ [63]. Nesses casos, a densidade do pósitron está acumulada na região entre os dois núcleos, evidenciando que há uma espécie de ligação covalente positrônica que mantém os ânions unidos.

\subsection{Sistemas contendo elétrons e um pósitron}

A teoria desenvolvida no capítulo 2 é aplicável a um sistema formado por apenas um tipo de férmion. Como o objetivo deste trabalho é estudar a interação de pósitrons com átomos e moléculas, será necessário considerar sistemas contendo dois tipos diferentes de partículas. A 


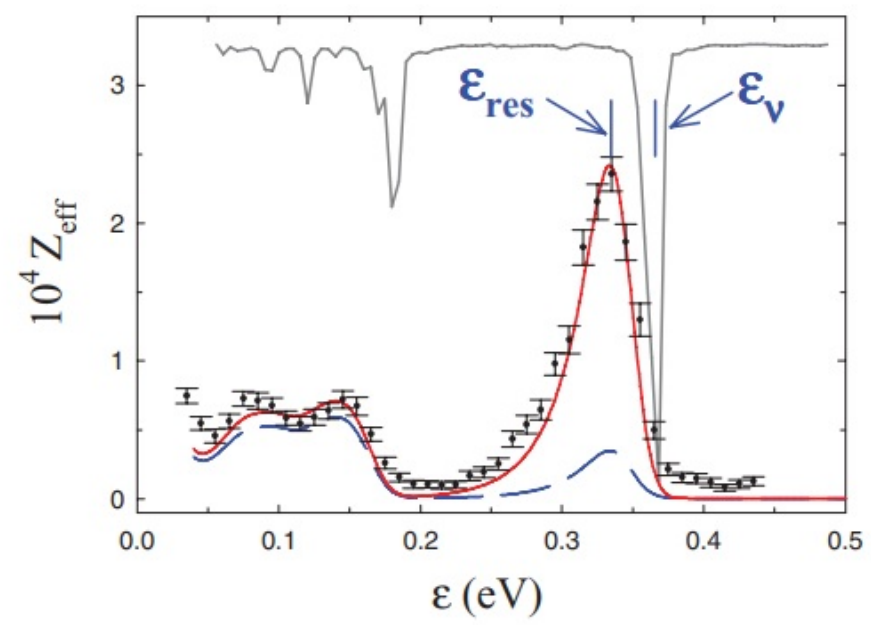

Figura 3.1: Círculos pretos são medidas do parâmetro de aniquilação; as linhas tracejadas representam uma predição teórica para $Z_{e f f}$ [9]; a linha contínua vermelha é um ajuste aos dados; a linha mais acima é o espectro de absorção da molécula.

teoria apresentada anteriormente pode ser generalizada para esse caso.

Considerando a validade da aproximação Born-Oppenheimer, a hamiltoniana de um sistema composto por uma molécula e um pósitron, com os núcleos sendo tratados como cargas pontuais fixas, pode ser escrita como

$$
\begin{aligned}
\hat{H} & =\sum_{i=1}^{N} \hat{h}_{0}^{(-)}(i)+\hat{h}_{0}^{(+)}+\frac{1}{2} \sum_{\substack{i, j=1 \\
i \neq j}}^{N} \frac{1}{\left|\boldsymbol{r}_{i}-\boldsymbol{r}_{j}\right|}-\sum_{i=1}^{N} \frac{1}{\left|\boldsymbol{r}_{i}-\boldsymbol{r}\right|} \\
& =\hat{H}_{0}+\hat{H}_{I},
\end{aligned}
$$

em que $r$ é a posição do pósitron, $\hat{H}_{I}$ é a soma das insterações de Coulomb elétron-elétron e elétron-pósitron e

$$
\begin{gathered}
\hat{h}_{0}^{(-)}(i)=-\frac{1}{2} \nabla_{i}^{2}-\sum_{j=1}^{M} \frac{Z_{j}}{\left|\boldsymbol{r}_{i}-\boldsymbol{R}_{j}\right|}, \\
\hat{h}_{0}^{(+)}=-\frac{1}{2} \nabla_{p}^{2}+\sum_{j=1}^{M} \frac{Z_{j}}{\left|\boldsymbol{r}-\boldsymbol{R}_{j}\right|} .
\end{gathered}
$$

Por enquanto, a partição de MP não será adotada. Desprezando as interações de Coulomb entre as partículas, a hamiltoniana se reduz a $\hat{H}=\hat{H}_{0}$, e o estado fundamental do sistema pode ser escrito como um produto de um determinante de Slater construído com spins-orbitais eletrônicos e um spin-orbital positrônico 


$$
\psi_{0}\left(\boldsymbol{x}_{1}, \ldots, \boldsymbol{x}_{m}, \boldsymbol{x}\right)=\phi_{0}\left(\boldsymbol{x}_{1}, \ldots, \boldsymbol{x}_{m}\right) \varphi(\boldsymbol{x}),
$$

com $\phi_{0}$ sendo dado por (2.5). Os spins-orbitais agora são construídos pelo produto das autofunções dos operadores $\hat{h}_{0}^{( \pm)}$por funções que descrevem o spin da partícula em questão.

É possível definir operadores de criação e aniquilação para elétrons e pósitrons. Novamente, as letras $a, b, c, \ldots$ irão representar orbitais ocupados, $i, j, k, \ldots$ representarão orbitais virtuais e $p, q, r, \ldots$ qualquer tipo de orbital. Entretanto, daqui em diante, serão utilizadas letras minúsculas para os orbitais de pósitrons e maiúsculas para os de elétrons. Assim, por exemplo, $\hat{a}_{i}$ é um operador que aniquila um pósitron em um orbital virtual $\varphi_{i}$, e $\hat{a}_{A}^{\dagger}$ um operador que cria um elétron em um orbital ocupado $\varphi_{A}$. Os operadores de pósitrons comutam com os de elétrons

$$
\left[\hat{a}_{p}, \hat{a}_{P}\right]=\left[\hat{a}_{p}^{\dagger}, \hat{a}_{P}\right]=\left[\hat{a}_{p}, \hat{a}_{P}^{\dagger}\right]=\left[\hat{a}_{p}^{\dagger}, \hat{a}_{P}^{\dagger}\right]=0,
$$

e obedecem as relações de anticomutação usuais (2.8) entre si.

Utilizando segunda quantização, as duas parcelas da hamiltoniana podem ser escritas como

$$
\begin{gathered}
\hat{H}_{0}=\sum_{p} \varepsilon_{p} \hat{a}_{p}^{\dagger} \hat{a}_{p}+\sum_{P} \varepsilon_{P} \hat{a}_{P}^{\dagger} \hat{a}_{P}, \\
\hat{H}_{I}=\frac{1}{2} \sum_{P, Q, R, S}\langle P, Q|V| R, S\rangle \hat{a}_{P}^{\dagger} \hat{a}_{Q}^{\dagger} \hat{a}_{S} \hat{a}_{R}-\sum_{p, Q, r, S}\langle p, Q|V| r, S\rangle \hat{a}_{p}^{\dagger} \hat{a}_{Q}^{\dagger} \hat{a}_{S} \hat{a}_{r} .
\end{gathered}
$$

O primeiro termo de $\hat{H}_{I}$ representa a repulsão Coulombiana entre os elétrons e o segundo a atração entre eles e o pósitron.

\subsection{Função de Green para o pósitron}

Uma generalização da teoria da função de Green para sistemas contendo tanto elétrons quanto pósitrons foi proposta por L. Cederbaum e M. Müller em 1990 [51], onde são definidas duas funções de Green, uma para cada tipo de partícula. Seguindo esses autores, a função de Green para um pósitron interagindo com um sistema eletrônico é

$$
G_{p q}\left(t, t^{\prime}\right)=-i\left\langle\Phi_{0}\left|T\left[\hat{a}_{p}(t) \hat{a}_{q}^{\dagger}\left(t^{\prime}\right)\right]\right| \Phi_{0}\right\rangle
$$

onde $\Phi_{0}$ é o estado fundamental da molécula (ou átomo) isolado, ou seja, sem o pósitron. Assim, $G$ só será não nula para $t>t^{\prime}$. Novamente pode-se calcular a sua transformada de Fourier e obter a representação de Lehmann, que possui polos nas afinidades positrônicas do sistema:

$$
G_{p q}(E)=\sum_{m} \frac{\left\langle\Phi_{0}\left|\hat{a}_{p}\right| \Psi_{m}^{N+1}\right\rangle\left\langle\Psi_{m}^{N+1}\left|\hat{a}_{q}^{\dagger}\right| \Phi_{0}\right\rangle}{E+E_{0}-E_{m}^{N+1}+i \eta} .
$$

Aqui, $\Psi_{m}^{N+1}$ é o $m$-ésimo estado do sistema molécula-pósitron, $E_{m}^{N+1}$ é a sua respectiva energia 
e $E_{0}$ é a energia da molécula no estado fundamental sem o pósitron. Analogamente, também é possível definir uma função de Green não interagente através de

$$
G_{p q}^{0}\left(t, t^{\prime}\right)=-i\left\langle\phi_{0}\left|T\left[\hat{a}_{p}(t) \hat{a}_{q}^{\dagger}\left(t^{\prime}\right)\right]\right| \phi_{0}\right\rangle,
$$

onde $\phi_{0}$ é o estado fundamental da molécula/átomo sem as interações de Coulomb entre os elétrons, que para sistemas de camada fechada é simplesmente um determinante de Slater. Novamente, essa função também só será não nula para $t>t^{\prime}$. Nesse caso, ela pode ser escrita como

$$
G_{p q}^{0}\left(t, t^{\prime}\right)=-i \delta_{p q} e^{-i \varepsilon_{p}\left(t-t^{\prime}\right)}
$$

e sua representação espectral é dada por

$$
G_{p q}^{0}(E)=\frac{\delta_{p q}}{E-\varepsilon_{p}+i \eta}
$$

A função de Green (3.8) também pode ser expandida em uma série infinita cujos termos envolvem integrais do produto $T$ de vários operadores $\hat{H}_{I}$, de acordo com (2.24). A diferença é que, após escrever as interações usando segunda quantização, agora haverá operadores de criação e aniquilação de elétrons e pósitrons aparecendo no produto $T$. Porém, como esses dois tipos de operadores comutam entre si, é possível separar o produto $T$ em dois, um apenas para os operadores de elétrons e outro para os de pósitrons, e aplicar o teorema de Wick separadamente para cada um deles, o que leva a expressões matemáticas que, mais uma vez, podem ser representadas por diagramas. Nesses novos diagramas haverá dois tipos de interações de Coulomb, uma entre os elétrons e outra entre elétrons e o pósitron. Como antes, essas interações serão representadas por linhas onduladas, cada uma tendo duas linhas que entram e duas que saem, que representam seus respectivos operadores de criação e aniquilação. Linhas contínuas representarão os operadores de elétrons e descontínuas os de pósitrons, como é indicado na figura 3.2.
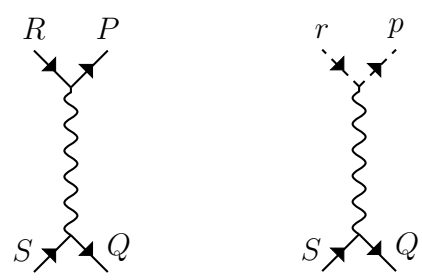

Figura 3.2: Representação das interações de Coulomb entre elétrons e elétrons e entre elétrons e o pósitron, respectivamente. A primeira (segunda) figura representa o primeiro (segundo) termo da equação (3.7).

Para construir os diagramas da função de Green, as linhas onduladas devem ser colocadas lado a lado e suas setas conectadas, para representar as contrações dos operadores. Como o produto $T$ foi separada em dois, um para elétrons e outro para pósitrons, os operadores de 
elétrons não podem ser contraídos com os de pósitrons, e portanto não é possível conectar uma linha contínua com uma descontínua.

Uma diferença importante em relação ao que foi apresentado no capítulo anterior é que, como não há pósitrons no estado usado na definição da função de Green, não há orbitais ocupados do pósitron e todos os orbitais positrônicos devem ser vistos como virtuais, portanto não há operadores de buracos $\hat{b}$ e $\hat{b}^{\dagger}$ para pósitrons. Consequentemente, todas as linhas referentes a pósitrons devem ser linhas de partículas e apontar para a direita (aqui, diferente do que foi feito no capítulo 2, os diagramas serão escritos com as linhas onduladas na vertical, então as linhas que apontarem para a direita representarão orbitais virtuais e as que apontarem para a esquerda orbitais buracos).

De forma análoga, pode-se também definir uma auto-energia para o pósitron como a soma de partes de diagramas da sua função de Green e assim obter uma equação de Dyson, o que permite calcular os polos de $G_{p q}(E)$ da maneira que foi descrita anteriormente. Generalizando o método Hartree-Fock para incluir o pósitron, e adotando uma espécie de partição de MP generalizada, muitos dos diagramas da função de Green e da auto-energia se cancelam [51]. Novamente, o termo de primeira ordem da auto-energia se torna nulo. Para a segunda ordem, haverá apenas um diagrama, que é mostrado abaixo.

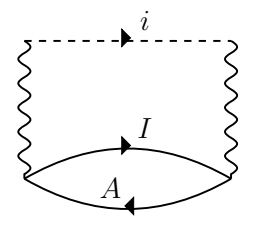

Figura 3.3: Diagrama de segunda ordem para a auto-energia do pósitron.

Além disso, nesses diagramas não é permitido ligar duas linhas de pósitrons que pertencem a uma mesma interação, pois isso equivaleria a contrair um operador de criação com um de aniquilação com os mesmos instantes de tempo, o que pela (2.32) é igual a zero.

As regras para obter expressões desses diagramas também são dadas em [51]. Basicamente, elas são quase idênticas às regras já citadas no capítulo anterior, a única diferença sendo que agora deve-se multiplicar o resultado por $(-1)^{v}$, onde $v$ é o número de interações entre elétrons e pósitrons, pois a interação entre essas partículas é atrativa, e portanto possui um sinal negativo. Então, para qualquer diagrama da auto-energia do pósitron, aplica-se as regras convencionais e multiplica-se a expressão obtida pelo fator extra mencionado acima. Por exemplo, a expressão associada ao diagrama de segunda ordem de $\Sigma_{p q}(E)$ é

$$
\Sigma_{p q}^{(2)}(E)=\sum_{i, A, I} \frac{\langle p, I|V| i, A\rangle\langle i, A|V| q, I\rangle}{E+\varepsilon_{A}-\varepsilon_{i}-\varepsilon_{I}} .
$$

Para a terceira ordem, haverá 8 diagramas para a parte dinâmica da auto-energia, que são mostrados na figura 3.4 .

Esses diagramas também são utilizados por Gribakin e Ludlow na expansão da auto-energia[39, 

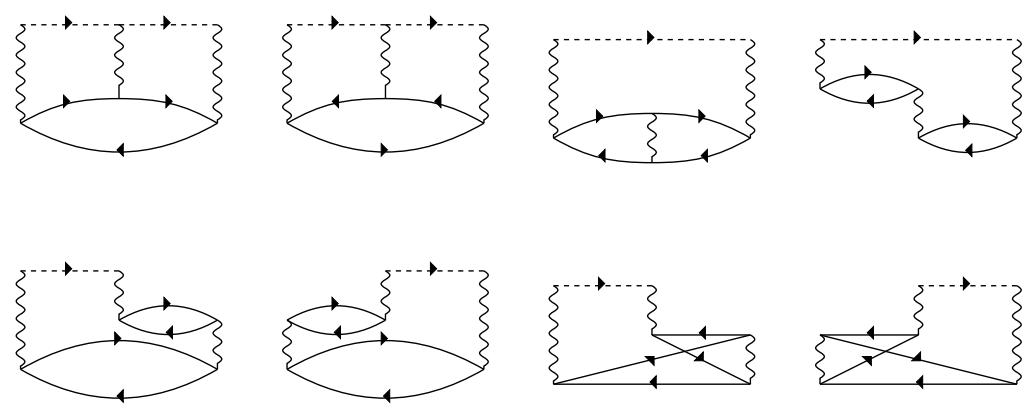

Figura 3.4: Diagramas de terceira para a auto-energia do pósitron que dependem da energia.

38]. Como no caso eletrônico, a auto-energia é calculada apenas até a terceira ordem, e para incluir contribuições de ordens mais altas, são realizadas somas infinitas de alguns tipos de diagramas. Para entender como isso pode ser feito, considere o primeiro diagrama de terceira ordem mostrado acima. A interação que aparece no centro do diagrama é uma interação de Coulomb entre o pósitron e um elétron em um estado excitado. Na quarta ordem, haverá um diagrama semelhante, todavia contendo duas interações de Coulomb como essa aparecendo no interior do diagrama. Na quinta ordem, há outro diagrama similar, mas com três dessas interações, e assim por diante. A soma de todos os diagramas deste tipo, de todas as ordens, será indicada na forma
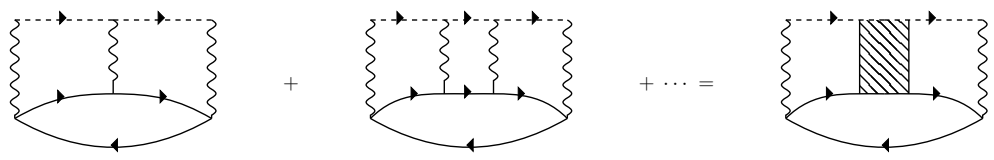

A região hachurada representa a soma de todas as interações de Coulomb que aparecem no interior dos diagramas que estão sendo somadas, ou seja, é dada por
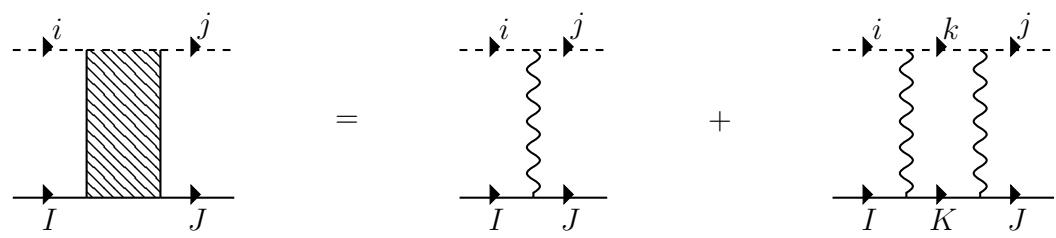

Assim como as linhas onduladas representam elementos de matriz da interação de Coulomb, pode-se pensar na região hachurada como a representação de elementos de matriz de uma nova interação, que será denotada por $\Gamma_{E}$, seguindo a notação de Gribakin e Ludlow. Aplicando as regras já mencionadas ao último diagrama da equação (3.14), sua expressão é

$$
\sum_{i, j, A, I, J} \frac{\langle p, A|V| j, J\rangle\left\langle j, J\left|\Gamma_{E}\right| i, I\right\rangle\langle i, I|V| q, A\rangle}{\left(E+\varepsilon_{A}-\varepsilon_{i}-\varepsilon_{I}\right)\left(E+\varepsilon_{A}-\varepsilon_{j}-\varepsilon_{J}\right)} .
$$

Esse termo representa a contribuição do efeito da formação do Ps virtual para a auto-energia [39], portanto deve ser levado em consideração para uma melhor descrição dos efeitos de correlação. A seguir, será explicado como ele pode ser calculado. 
Segue das regras para diagramas que a equação (3.15) representa a seguinte soma

$$
\left\langle j, J\left|\Gamma_{E}\right| i, I\right\rangle=-\langle j, J|V| i, I\rangle+\sum_{k, K} \frac{\langle j, J|V| k, K\rangle\langle k, K|V| i, I\rangle}{E+\varepsilon_{A}-\varepsilon_{k}-\varepsilon_{K}}+\cdots
$$

Devido ao fato da interação de Coulomb entre o pósitron e o elétron contribuir com um sinal negativo, os termos da série acima alternam de sinal. Apesar de não indicado, $\Gamma$ também depende do índice $A$, que é a única linha representando um orbital ocupado que aparece nos diagramas sendo somados. O elemento de matriz $\langle j, J|V| k, K\rangle$ estará presente em todos os termos da série (exceto o primeiro), e pode ser colocado em evidência, obtendo assim uma equação que pode ser representada diagramaticalmente por

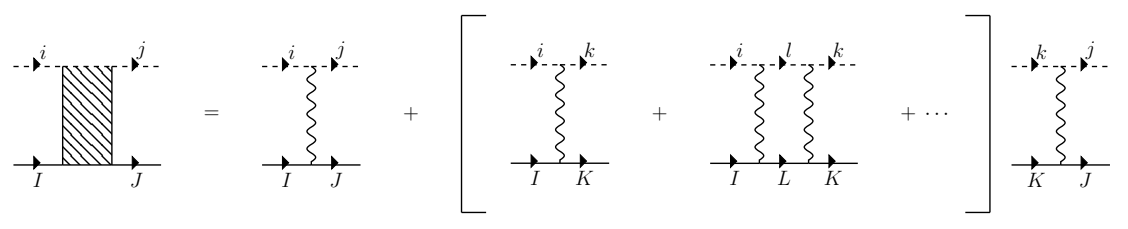

A soma infinita que aparece dentro do colchetes na expressão acima é igual a soma (3.15), então pode-se escrever

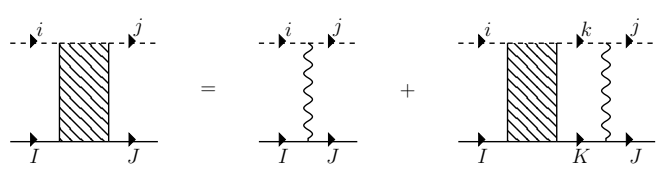

Matematicamente, isso equivale à expressão

$$
-\left\langle j, J\left|\Gamma_{E}\right| i, I\right\rangle=\langle j, J|V| i, I\rangle+\sum_{k, K} \frac{\langle j, J|V| k, K\rangle\left\langle k, K\left|\Gamma_{E}\right| i, I\right\rangle}{E+\varepsilon_{A}-\varepsilon_{k}-\varepsilon_{K}} .
$$

Essa relação permite calcular numericamente os elementos de matriz de $\Gamma_{E}$. Denotando o par de índices $i, I$, onde $i$ é um orbital positrônico e $I$ um orbital virtual eletrônico, utilizando apenas um índice $\lambda$, é conveniente definir matrizes $\boldsymbol{V}$ e $\boldsymbol{\Gamma}$, que têm como coeficientes $V_{\lambda, \lambda^{\prime}}=$ $\left\langle\lambda|V| \lambda^{\prime}\right\rangle$ e $\left\langle\lambda\left|\Gamma_{E}\right| \lambda^{\prime}\right\rangle$, e também uma matriz diagonal $\boldsymbol{E}$ tal que $E_{\lambda, \lambda^{\prime}}=\delta_{\lambda, \lambda^{\prime}} /\left(E+\varepsilon_{A}-\varepsilon_{i}-\varepsilon_{I}\right)$. Com isso, a equação (3.20) pode ser escrita em forma matricial

$$
-\Gamma=V+V E \Gamma
$$

o que leva a

$$
\boldsymbol{\Gamma}=-(\boldsymbol{I}+\boldsymbol{V} \boldsymbol{E})^{-1} \boldsymbol{V}
$$

Então, conhecendo os elementos de matriz da interação de Coulomb e as energias dos orbitais, é possível calcular os elementos da matriz $\Gamma$. 


\subsection{A teoria APMO}

A teoria APMO (Any Particle Molecular Orbital Theory) permite generalizar o método da função de Green descrito no capítulo 2 para um sistema que a princípio pode conter diferentes tipos de partículas, sendo elas bósons, férmions e ou partículas clássicas. Sua versão para os propagadores não utiliza uma expansão em diagramas como a que foi descrita, mas um método diferente baseado no formalismo de super-operadores [64]. Aqui, primeiro será apresentada a teoria de forma geral, e depois será considerado o caso em que há apenas dois tipos de férmions, elétrons e pósitrons.

As diferentes espécies ou tipos de partículas de um sistema serão denotadas por letras gregas (por exemplo, $\alpha$ poderá indicar elétrons, $\beta$ prótons, etc), e o número de partículas de uma dada espécie será $N_{\alpha}$, enquanto $N_{Q}$ denotará o número total de partículas quânticas no sistema e $N_{C}$ o de partículas clássicas. Admitindo que todas as partículas sendo consideradas interagem entre si através da interação de Coulomb, a hamiltoniana de tal sistema pode ser escrita como

$$
H=-\sum_{i=1}^{N_{Q}} \frac{1}{2 m_{i}} \nabla_{i}^{2}+\sum_{i=1}^{N_{Q}} \sum_{j>i}^{N_{Q}} \frac{Q_{i} Q_{j}}{r_{i j}}+\sum_{i=1}^{N_{Q}} \sum_{j=1}^{N_{C}} \frac{Q_{i} Q_{j}}{r_{i j}}+\sum_{i=1}^{N_{C}} \sum_{j>i}^{N_{C}} \frac{Q_{i} Q_{j}}{r_{i j}},
$$

onde $Q$ representa as cargas das partículas, $m$ suas massas e $r$ a distância entre duas delas. A função de onda exata do sistema $\Psi_{0}$ é aproximada pela função de onda APMO/HF, construída como o produto das funções de onda de cada espécie quântica, que por sua vez são aproximadas como produtos dos orbitais moleculares $\phi^{\alpha}$, autofunções do operador de Fock generalizado dado abaixo

$$
\hat{f}^{\alpha}(i)=\hat{h}_{0}^{\alpha}(i)+Q_{\alpha}^{2} \sum_{a \in \alpha}\left[\hat{J}_{a}^{\alpha}(i) \mp \hat{K}_{a}^{\alpha}(i)\right]+\sum_{a \in \beta \neq \alpha} Q_{\alpha} Q_{\beta} \hat{J}_{a}^{\beta}(i) .
$$

O sinal negativo é usado para férmions e o positivo para bósons, e $\hat{J}$ e $\hat{K}$ são generalizações dos operadores de Coulomb e Troca apresentados no capítulo anterior, com os orbitais moleculares aparecendo no lugar dos spins-orbitais (para suas definições precisas, veja [31]).

Na teoria APMO, a representação espectral da função de Green (para a espécie $\alpha$ ) é

$$
\begin{aligned}
G_{p q}^{\alpha}(E)= & \sum_{m} \frac{\left\langle\Psi_{0}\left|\hat{a}_{p}^{\alpha}\right| \Psi_{m}^{N_{\alpha}+1}\right\rangle\left\langle\Psi_{m}^{N_{\alpha}+1}\left|\hat{a}_{q}^{\alpha \dagger}\right| \Psi_{0}\right\rangle}{E+E_{0}-E_{m}^{N_{\alpha}+1}}+ \\
& +\sum_{n} \frac{\left\langle\Psi_{0}\left|\hat{a}_{q}^{\alpha \dagger}\right| \Psi_{n}^{N_{\alpha}-1}\right\rangle\left\langle\Psi_{n}^{N_{\alpha}-1}\left|\hat{a}_{p}^{\alpha}\right| \Psi_{0}\right\rangle}{E+E_{n}^{N_{\alpha}-1}-E_{0}}
\end{aligned}
$$

onde $E_{0}$ é a energia do sistema, $\Psi_{m}^{N_{\alpha} \pm 1}$ é o m-ésimo estado do sistema com uma partícula da espécie $\alpha$ a mais ou a menos, e $E_{m}^{N_{\alpha} \pm 1}$ é a sua respectiva energia.

Aqui será descrito brevemente como a função de Green é expandida usando o formalismo dos superoperadores. Mais detalhes podem ser encontrados nas referências [65, 66, 64]. À cada 
operador $\hat{A}$ atuando no espaço de Hilbert do sistema associa-se um superoperador $\hat{\mathcal{A}}$ tal que

$$
\hat{\mathcal{A}} \hat{B}=[\hat{B}, \hat{A}],
$$

onde $\hat{B}$ é algum outro operador qualquer. Também é necessário definir o seguinte produto de operadores

$$
(\hat{A} \mid \hat{B})=\left\langle\Psi_{0}\left|\left\{\hat{A}^{\dagger}, \hat{B}\right\}\right| \Psi_{0}\right\rangle .
$$

A função de onda na expressão acima pode ser expandida através de teoria de perturbação de Rayleigh-Schrodinger, e assim pode-se escrevê-la utilizando a função de onda APMO definida anteriormente. Com isso, se obtém uma expansão para esse produto de operadores

$$
(\hat{A} \mid \hat{B})=(\hat{A} \mid \hat{B})^{(0)}+(\hat{A} \mid \hat{B})^{(1)}+(\hat{A} \mid \hat{B})^{(2)}+\ldots
$$

Usando essas definições, é possível mostrar que a função de Green (3.25) pode ser escrita como

$$
G_{p q}^{\alpha}(E)=\left(\hat{a}_{p}^{\alpha} \mid(E \hat{\mathcal{I}}-\hat{\mathcal{H}})^{-1} \hat{a}_{q}^{\alpha}\right),
$$

em que $\hat{\mathcal{I}}$ e $\hat{\mathcal{H}}$ são os superoperadores associados aos operadores identidade e hamiltoniana, respectivamente. Como essa função de Green tem a forma de (3.27), pode-se expandí-la como (3.28). Mais uma vez, é útil definir uma função de Green $G_{p q}^{0}$, calculada usando a função de onda APMO no lugar da função de onda exata, o que leva a uma equação de Dyson para a espécie $\alpha$ análoga à apresentado no capítulo 2 e à uma auto-energia $\Sigma_{p q}^{\alpha}(E)$, a qual pode ser expandida assim como $G$. Essa auto-energia, computada com o formalismo APMO, possui muitos termos além dos que aparecem na teoria usual, onde é considerado um sistema composto apenas por férmions idênticos. Cada espécie de partícula terá uma auto-energia, que pode ser expandida perturbativamente, com o termo de primeira ordem sendo nulo quando adotada a partição de MP. O termo de segunda ordem da auto-energia para uma determinada espécie $\alpha$ pode ser escrito como a soma de duas contribuições, uma que só envolve orbitais de partículas dessa mesma espécie e outra onde haverá tanto orbitais de partículas $\alpha$ quanto orbitais de uma segunda espécie $\beta$

$$
\Sigma_{p p}^{\alpha}(E)^{(2)}=\Sigma_{p p}^{\alpha \alpha}(E)^{(2)}+\sum_{\beta \neq \alpha} \Sigma_{p p}^{\alpha \beta}(E)^{(2)}
$$

onde

$$
\begin{gathered}
\Sigma_{p p}^{\alpha \alpha}(E)^{(2)}=\sum_{a, i, j} \frac{|\langle p, a|| i, j\rangle|^{2}}{E+\varepsilon_{a}-\varepsilon_{i}-\varepsilon_{j}}+\sum_{a, b, i} \frac{|\langle p, i|| a, b\rangle|^{2}}{E+\varepsilon_{i}-\varepsilon_{a}-\varepsilon_{b}}, \\
\Sigma_{p p}^{\alpha \beta}(E)^{(2)}=\sum_{i, A, I} \frac{|\langle p, A|V| i, I\rangle|^{2}}{E+\varepsilon_{A}-\varepsilon_{i}-\varepsilon_{I}}+\sum_{a, A, I} \frac{|\langle p, I|V| a, A\rangle|^{2}}{E+\varepsilon_{I}-\varepsilon_{a}-\varepsilon_{A}},
\end{gathered}
$$


em que $\langle p, q|| r, s\rangle \equiv\langle p, q|V| r, s\rangle-\langle p, q|V| s, r\rangle$. Na terceira ordem da auto-energia APMO, os termos são mais numerosos e complexos. Expressões para eles não serão apresentadas aqui, mas podem ser encontradas em [31, 66]. Tais termos podem conter um, dois e três tipos de orbitais de espécies diferentes de partículas, sendo então possível dividir a auto-energia em três partes

$$
\Sigma_{p p}^{\alpha}(E)^{(3)}=\Sigma_{p p}^{\alpha \alpha}(E)^{(3)}+\sum_{\beta \neq \alpha} \Sigma_{p p}^{\alpha \beta}(E)^{(3)}+\sum_{\beta \neq \gamma \neq \alpha} \Sigma_{p p}^{\alpha \beta \gamma}(E)^{(3)} .
$$

As expressões mostradas até aqui são gerais, e válidas para um sistema contendo quaisquer quantidades e tipos de partículas. Agora o foco será voltado para o sistema de interesse desse trabalho, formado por vários elétrons e um único pósitron. Denotando por $\alpha \mathrm{e} \beta$ as espécies positrônica e eletrônica, respectivamente, o termo $\Sigma_{p p}^{\alpha \beta \gamma}(E)^{(3)}$ desaparece, pois não há uma terceira espécie de partícula presente. Os termos $\Sigma_{p p}^{\alpha \alpha}(E)^{(2)}$ e $\Sigma_{p p}^{\alpha \alpha}(E)^{(3)}$ também devem ser excluídos, pois neles há elementos de matriz com interações entre dois pósitrons, o que não deve ocorrer, pois há apenas um no sistema. Alguns dos termos de $\Sigma_{p p}^{\alpha \beta}(E)^{(3)}$ também possuem interações entre pósitrons, e devem ser ignorados pelo mesmo motivo. Por conta desses cancelamentos, deve-se notar que a auto-energia de segunda ordem se reduz simplesmente a equação (3.32).

Deve-se notar que o termo de segunda ordem APMO é diferente daquele obtido na expansão da auto-energia usando diagramas (veja a equação (3.13)). Isso ocorre porque há uma diferença na definição da função de Green feita na abordagem da teoria APMO e a usada nos trabalhos de Gribakin e Ludlow [39] e Cederbaum e Müller [51]. Na teoria APMO, a função de onda utilizada para calcular $G$ é a do sistema completo, incluindo o pósitron, enquanto os autores citados utilizam a função de onda do sistema eletrônico com o qual o pósitron interage. A inclusão do pósitron nessa função implica na existência de um orbital ocupado positrônico, e portanto, se fossem construídos diagramas para a auto-energia APMO, haveria linhas tracejadas apontando tanto para a direita quanto para a esquerda, diferente do que ocorre nos diagramas apresentados na seção anterior. Por esse motivo, há algumas diferenças nas expressões das duas auto-energias. Ainda assim, ambas podem ser utilizadas para computar a energia de ligação do pósitron. 


\section{Capítulo 4}

\section{O método OVGF}

A cada ordem da auto-energia aumenta o número de termos e sua complexidade. Na prática, é muito difícil calculá-la numericamente para ordens altas. No caso da teoria APMO, em que há muito mais termos, que envolvem a interação entre partículas de diferentes tipos, o custo computacional é ainda maior. Devido a isso, é importante empregar métodos que permitam levar em consideração contribuições de termos de ordens maiores sem precisar calculá-los diretamente. Um exemplo é o método OVGF (Outer Valence Green Function) [36, 35, 34], originalmente desenvolvido para obter uma melhor aproximação para a auto-energia de moléculas e átomos de camada fechada, sendo generalizado posteriormente com o uso da teoria APMO.

No método original, só é necessário calcular os termos de segunda e terceira ordens da autoenergia, que são usados para estimar as contribuições dos termos de ordens mais altas. Há três versões desse método. Na versão A, que é a mais simples, a auto-energia é aproximada como

$$
\Sigma(E) \approx \Sigma^{(2)}(E)+\frac{1}{1+F} \Sigma^{(3)}(E)
$$

onde $F$ é calculado como a razão entre alguns dos termos de terceira ordem e o termo de segunda ordem (a definição precisa de $F$ pode ser encontrada nas referências citadas anteriormente). A contribuição das ordens mais altas é incluída por meio do fator que multiplica o termo de terceira ordem na expressão acima.

No LOWDIN, cada uma das três versões do método (A, B e C) é generalizada para sistemas contendo mais de um tipo de partícula. A versão A se torna

$$
\begin{aligned}
\Sigma_{p p}(E)_{A P M O}^{\alpha}= & \sum_{\beta} \Sigma_{p p}^{(2)}(E)^{\alpha \beta}+\frac{1}{1+X_{p}^{\alpha}} \Sigma_{p p}^{(3)}(E)^{\alpha \alpha}+ \\
& +\sum_{\beta \neq \alpha}\left[\frac{1}{1+X_{p}^{\beta}} \Sigma_{p p}^{(3)}(E)_{1}^{\alpha \beta}+\frac{1}{1+Y_{p}^{\beta}} \Sigma_{p p}^{(3)}(E)_{2}^{\alpha \beta}\right]+ \\
& +\sum_{\beta \neq \gamma \neq \alpha} \Sigma_{p p}^{(3)}(E)^{\alpha \beta \gamma} .
\end{aligned}
$$


Aqui, os termos de terceira ordem $\Sigma^{\alpha \beta}(E)^{(3)} \operatorname{com} \beta \neq \alpha$ são divididos em dois tipos, para os quais são utilizados os índices 1 e 2, enquanto os coeficientes $X$ e $Y$, que fazem o papel de $F$ na expressão acima, também são calculados como razões de alguns dos termos de terceira ordem e o termo de segunda ordem (expressões exatas podem ser encontradas em [31]). Como já discutido, quando há apenas um pósitron e vários elétrons no sistema, muitos desses termos devem ser desconsiderados. Por exemplo, $\Sigma^{\alpha \beta}(E)_{1}^{(3)}$ deve ser excluído pois contém interações pósitron-pósitron (assim como alguns termos de $\Sigma^{\alpha \beta}(E)_{2}^{(3)}$, mas não todos). No caso de interesse, a equação acima se reduz a

$$
\Sigma_{p p}^{e^{+}}(E)_{A P M O}=\Sigma_{p p}^{e^{+} e^{-}}(E)^{(2)}+\frac{1}{1+Y_{p}^{e^{-}}} \Sigma_{p p}^{e^{+} e^{-}}(E)_{2}^{(3)} .
$$

Por esse resultado, não é claro quais termos de ordens mais altas estão incluídos nessa aproximação. O objetivo desta parte do trabalho é determinar se os termos que levam em conta a contribuição da formação do Ps virtual estão contidos (pelo menos parcialmente) nessa expressão para a auto-energia. Como já mencionado, há diferenças na auto-energia calculada pelo LOWDIN e a utilizada por Gribakin e Ludlow, entretanto, será assumido que para a autoenergia APMO há termos de ordens maiores que são análogos àqueles da série (3.14), isto é, termos em que aparecem interações de pósitrons com elétrons em orbitais virtuais e que possuem todos os fatores no denominador dependentes da energia.

Também foi proposta uma quarta versão do método OVGF, denominada de REN-PP3 [31], que no geral apresenta melhores resultados que as outras três, sendo semelhante a versão B. As deduções das versões A e B, e suas generalizações, assim como a versão REN/PP3, serão apresentadas a seguir, junto com uma discussão dos termos tipo Ps virtual presentes no LOWDIN.

\subsection{Versão A}

O termo de segunda ordem para a auto-energia de um sistema contendo apenas elétrons pode ser escrito como

$$
\begin{aligned}
M_{P P}^{(2)}(E)= & \frac{1}{2} \sum_{A, I, J} \frac{\langle P, A \| I, J\rangle\langle I, J \| P, A\rangle}{E+\varepsilon_{A}-\varepsilon_{I}-\varepsilon_{J}}+ \\
& +\frac{1}{2} \sum_{A, B, I} \frac{\langle P, I \| A, B\rangle\langle A, B \| P, I\rangle}{E+\varepsilon_{I}-\varepsilon_{A}-\varepsilon_{B}} .
\end{aligned}
$$

O método original se inicia com a seguinte aproximação para a parte dinâmica da auto-energia: ela é escrita como se fosse o termo de segunda ordem acima, mas com um fator multiplicativo no numerador e um aditivo no denominador: 


$$
\begin{aligned}
M_{P P}(E) \approx & \frac{1}{2} \sum_{A, I, J} \frac{\langle P, A \| I, J\rangle\langle I, J \| P, A\rangle Z_{A, I, J}}{E+\varepsilon_{A}-\varepsilon_{I}-\varepsilon_{J}-X_{A, I, J}}+ \\
& +\frac{1}{2} \sum_{A, B, I} \frac{\langle P, I \| A, B\rangle\langle A, B \| P, I\rangle Z_{A, B, I}}{E+\varepsilon_{I}-\varepsilon_{A}-\varepsilon_{B}-X_{A, B, I}} .
\end{aligned}
$$

Essa auto-energia possui a forma analítica correta (2.71), e as constantes $Z$ e $X$ podem ser vistas como correções para o termo de segunda ordem. Para facilitar os cálculos a seguir, é conveniente reescrever essa aproximação utilizando uma notação mais compacta

$$
M_{p p}(E) \approx \sum_{n} \frac{V_{n} Z_{n}}{E-f_{n}-X_{n}}
$$

A somatória acima representa as duas somatórias da expressão (4.5), onde o índice $n$ está representando os dois conjuntos de índices $A, I, J$ e $A, B, I$. Quando $Z_{n}=1$ e $X_{n}=0$, o termo acima se reduz ao termo de segunda ordem.

Assumindo que

$$
\left|\frac{X_{n}}{E-f_{n}}\right|<1
$$

pelo menos para energias $E$ próximas às do orbital $p$ de interesse, a auto-energia pode ser expandida usando a série geométrica

$$
M_{p p}(E) \approx \sum_{n} \frac{V_{n} Z_{n}}{E-f_{n}}\left[1+\frac{X_{n}}{E-f_{n}}+\left(\frac{X_{n}}{E-f_{n}}\right)^{2}+\ldots\right]
$$

É conveniente reescrever $Z_{n} \equiv 1-A_{n}$, e assim

$$
M_{p p}(E) \approx \sum_{n} \frac{V_{n}}{E-f_{n}}\left[1+\frac{X_{n}}{E-f_{n}}+\ldots\right]-\sum_{n} \frac{V_{n} A_{n}}{E-f_{n}}\left[1+\frac{X_{n}}{E-f_{n}}+\ldots\right]
$$

É possível associar cada termo da expansão acima com as expressões obtidas por teoria de perturbação para $\Sigma$. Por exemplo, é fácil verificar que o primeiro termo da primeira soma é igual ao termo de segunda ordem

$$
\sum_{n} \frac{V_{n}}{E-f_{n}}=\Sigma_{p p}^{(2)}(E)=M_{p p}^{(2)}(E)
$$

Para fazer a associação com os demais termos, é necessário examinar seus denominadores. Como foi dito no capítulo 2, alguns dos termos de terceira ordem possuem dois fatores no denominador que dependem da energia $E$, enquanto outros têm um único fator em que a energia aparece. Esses últimos devem contribuir para 


$$
-\sum_{n} \frac{V_{n} A_{n}}{E-f_{n}}
$$

enquanto os termos que possuem os dois fatores com a energia $E$ contribuem para

$$
\sum_{n} \frac{V_{n} X_{n}}{\left(E-f_{n}\right)^{2}}
$$

Para melhorar a aproximação, no método original as expressões acima (4.11) e (4.12) são substituídas pelos termos de terceira ordem que contribuem parcialmente para elas. Ou seja, denotando por $M_{p p}^{(3)}(E)_{1}$ a soma dos diagramas de terceira ordem que só possuem um fator no denominador com a energia $E$ e por $M_{p p}^{(3)}(E)_{2}$ a soma dos termos de terceira ordem com os dois fatores contendo $E$, deve-se substituir (4.11) por $M_{p p}^{(3)}(E)_{1}$ e (4.12) por $M_{p p}^{(3)}(E)_{2}$.

Antes disso, entretanto, é conveniente definir um novo fator $A$ através de

$$
A \sum_{n} \frac{V_{n}}{E-f_{n}}\left[1+\frac{X_{n}}{E-f_{n}}+\ldots\right]=\sum_{n} \frac{V_{n} A_{n}}{E-f_{n}}\left[1+\frac{X_{n}}{E-f_{n}}+\ldots\right] .
$$

Substituindo (4.13) na (4.9), chega-se a

$$
M_{p p}(E) \approx(1-A) \sum_{n} \frac{V_{n}}{E-f_{n}}\left[1+\frac{X_{n}}{E-f_{n}}+\ldots\right] .
$$

Uma aproximação para $A$ pode ser obtida negligenciando os termos que multiplicam $X_{n}$ em ambos os lados da equação (4.13), e assim

$$
A \approx \frac{\sum_{n} \frac{V_{n} A_{n}}{E-f_{n}}}{\sum_{n} \frac{V_{n}}{E-f_{n}}} .
$$

Substituindo os termos da série pelos termos de segunda e terceira ordem da auto-energia, como já discutido acima, nesta aproximação $A$ pode ser escrita como a razão dos termos de terceira ordem em que a energia só aparece uma vez no denominador e a auto-energia de segunda ordem

$$
A \approx-\frac{M_{p p}^{(3)}(E)_{1}}{M_{p p}^{(2)}(E)} \equiv F .
$$

No método original, uma melhor aproximação para $A$ é obtida usando a relação $[35,36]$

$$
A \approx \frac{F}{1+F} .
$$

Substituindo esse resultado na (4.14), e após algumas manipulações algébricas, chega-se à seguinte aproximação para a auto-energia dinâmica 


$$
\begin{aligned}
M_{p p}(E) \approx & \sum_{n} \frac{V_{n}}{E-f_{n}}-\frac{F}{1+F} \sum_{n} \frac{V_{n}}{E-f_{n}}+ \\
& +\frac{1}{1+F} \sum_{n} \frac{V_{n} X_{n}}{\left(E-f_{n}\right)^{2}}\left[1+\frac{X_{n}}{E-f_{n}}+\ldots\right]
\end{aligned}
$$

Agora é necessário realizar as substituições dos termos dessa série pelos termos de segunda e terceira ordem da auto-energia obtidos por teoria de perturbação. O primeiro termo é igual à auto-energia de segunda ordem, e o segundo é igual a esse mesmo termo de segunda ordem vezes um fator $F /(1+F)$. Entretanto, pela definição de $F$, isso será igual ao produto de $M_{p p}(E)_{1}^{(3)}$ por um fator $(1+F)^{-1}$. Na terceira somatória, despreza-se os termos com $\left(X_{n}\right)^{m}$ para $m>1$, e assim ela passa a ser igual a $(1+F)^{-1}$ multiplicado por $M_{p p}^{(3)}(E)_{2}$. Utilizando o fato de que $M_{p p}^{(3)}(E)=M_{p p}^{(3)}(E)_{1}+M_{p p}^{(3)}(E)_{2}$, a expressão acima se torna

$$
M_{p p}(E) \approx M_{p p}^{(2)}(E)+(1+F)^{-1} M_{p p}^{(3)}(E) .
$$

Apesar da aproximação feita até aqui levar em consideração apenas a parte dinâmica da auto-energia, é possível incluir a parte não-dependente da energia $\Sigma(\infty)$ e assim obter o bem conhecido resultado do método, dado pela equação (4.1) [35].

\subsection{A formação do Ps virtual}

A contribuição da formação do Ps virtual é levada em conta somando os diagramas temporalmente ordenados da auto-energia em que há interações de pósitrons com elétrons em orbitais virtuais aparecendo no centro do diagrama. Devido às diferenças na auto-energia implementada no LOWDIN e na obtida por Gribakin e Ludlow, os termos da série (3.14) não estão implementados no LOWDIN. Porém, na terceira ordem da auto-energia APMO há um termo semelhante ao primeiro diagrama dessa série, dado por

$$
-\sum_{a, i, A, B, I} \frac{\langle p, A|V| i, I\rangle\langle i, I|V| j, J\rangle\langle j, J|V| p, A\rangle}{\left(E+\varepsilon_{A}-\varepsilon_{i}-\varepsilon_{I}\right)\left(E+\varepsilon_{A}-\varepsilon_{j}-\varepsilon_{J}\right)} .
$$

Será assumido que a auto-energia obtida pela teoria APMO em ordens mais altas possui termos análogos aos da série (3.14), e que eles também podem ser interpretados como sendo a contribuição da formação do Ps virtual. A soma de todos esses termos pode ser calculada através de (3.16), seguindo o mesmo procedimento descrito no capítulo anterior. A única diferença se deve ao fato de que agora deve-se usar apenas os spin-orbitais virtuais do pósitron. A soma de todos esses termos será referida como $\Sigma^{(P s)}(E)_{2 p h}$ (o motivo da notação $2 p h$ será explicado mais adiante).

Entretanto, também há um termo de terceira ordem implementado no LOWDIN similar a 


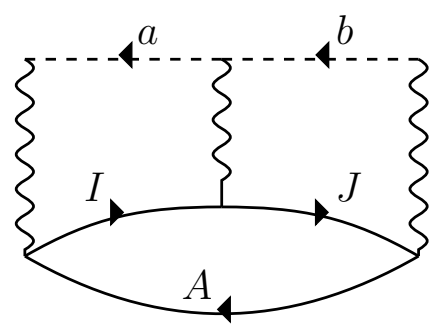

Figura 4.1: Representação do termo (4.21) da auto-energia APMO utilizando um diagrama.

(4.20), com a única diferença de que no lugar dos spin-orbitais virtuais do pósitron aparece o seu spin-orbital ocupado. Esse termo é dado por

$$
-\sum_{a, b, A, I, J} \frac{\langle p, I|V| a, A\rangle\langle a, J|V| b, I\rangle\langle b, A|V| p, J\rangle}{\left(E+\varepsilon_{I}-\varepsilon_{a}-\varepsilon_{A}\right)\left(E+\varepsilon_{J}-\varepsilon_{b}-\varepsilon_{I}\right)},
$$

Se a expressão (4.21) fosse representada por um diagrama, seria o apresentado na figura 4.1. Assume-se novamente que em ordens mais altas da auto-energia APMO há termos similares aos de (3.14), mas com o pósitron estando sempre em um orbital ocupado. A soma desses termos, que também é assumida como estando relacionada à contribuição do Ps virtual, pode ser escrita como

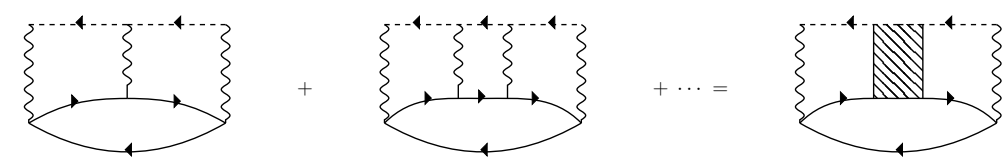

Denotando a somatória (4.22) por $\Sigma^{(P s)}(E)_{2 h p}$, é possível escrever

$$
\Sigma_{p p}^{(P s)}(E)_{2 h p}=\sum_{i, j, A, I, J} \frac{\langle p, I|V| a, A\rangle\left\langle a, J\left|\Gamma_{E}\right| b, I\right\rangle\langle b, A|V| p, J\rangle}{\left(E+\varepsilon_{I}-\varepsilon_{a}-\varepsilon_{A}\right)\left(E+\varepsilon_{J}-\varepsilon_{b}-\varepsilon_{A}\right)} .
$$

Mais uma vez, o motivo da notação 2 hp será explicado adiante. O elemento de matriz $\left\langle a, J\left|\Gamma_{E}\right| b, I\right\rangle$ pode ser calculado usando um procedimento análogo ao apresentado no capítulo 3 . De forma similar
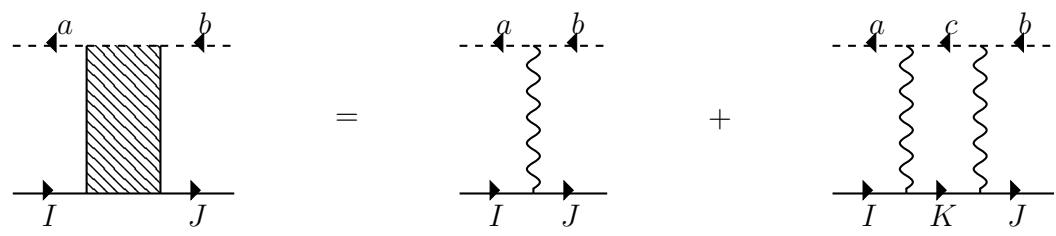

Esta soma equivale a

$$
\left\langle a, J\left|\Gamma_{E}\right| b, I\right\rangle=-\langle a, J|V| b, I\rangle-\sum_{c, K} \frac{\langle a, K|V| c, I\rangle\langle c, J|V| b, K\rangle}{E+\varepsilon_{K}-\varepsilon_{c}-\varepsilon_{A}}+\cdots
$$


o que leva a seguinte relação

$$
\left\langle a, J\left|\Gamma_{E}\right| b, I\right\rangle=-\langle a, J|V| b, I\rangle-\sum_{c, K} \frac{\langle c, J|V| b, K\rangle\left\langle a, K\left|\Gamma_{E}\right| c, I\right\rangle}{E+\varepsilon_{K}-\varepsilon_{c}-\varepsilon_{A}} .
$$

Devido ao fato de que os orbitais calculados pelo LOWDIN são reais, pode-se trocar a ordem dos spin-orbitais positrônicos nos elementos de matriz acima e escrever

$$
\left\langle b, J\left|\Gamma_{E}\right| a, I\right\rangle=-\langle b, J|V| a, I\rangle-\sum_{c, K} \frac{\langle b, J|V| c, K\rangle\left\langle c, K\left|\Gamma_{E}\right| a, I\right\rangle}{E+\varepsilon_{K}-\varepsilon_{c}-\varepsilon_{A}} .
$$

Definindo matrizes $\boldsymbol{\Gamma}^{\prime}, \boldsymbol{V}^{\prime}$ e $\boldsymbol{E}^{\prime}$, com coeficientes $\left\langle\lambda\left|\Gamma_{E}\right| \lambda^{\prime}\right\rangle,\left\langle\lambda|V| \lambda^{\prime}\right\rangle$ e $E_{\lambda, \lambda^{\prime}}^{\prime}=\delta_{\lambda, \lambda^{\prime}} /\left(E+\varepsilon_{I}-\right.$ $\varepsilon_{a}-\varepsilon_{A}$, respectivamente (aqui, $\lambda$ representa o conjunto de índices $a, I$ ), a relação acima passa a ser

$$
\Gamma^{\prime}=-\boldsymbol{V}^{\prime}-\boldsymbol{V}^{\prime} \boldsymbol{E}^{\prime} \boldsymbol{\Gamma}^{\prime}
$$

e assim

$$
\Gamma^{\prime}=-\left(\boldsymbol{V}^{\prime} \boldsymbol{E}^{\prime}+\boldsymbol{I}\right)^{-1} \boldsymbol{V}^{\prime}
$$

As relações (3.16) e (4.23) permitem computar somas de infinitos termos da auto-energia. A soma dessas duas quantidades será denotada por

$$
\Sigma^{(P s)}(E)=\Sigma^{(P s)}(E)_{2 p h}+\Sigma^{(P s)}(E)_{2 h p}
$$

Na próxima seção, se discutirá como incluir essa parcela da auto-energia no método OVGF.

\subsection{O Ps virtual e o método OVGF}

Assumi-se aqui que o análogo ao que foi feito na versão A do método OVGF também pode ser aplicado para a auto-energia do pósitron implementada no LOWDIN. Novamente, se começa com a seguinte aproximação

$$
\begin{aligned}
M_{p p}(E) \approx & \sum_{i, A, I} \frac{\langle p, A|V| i, I\rangle\langle i, I|V| p, A\rangle Z_{p, i, A, I}}{E+\varepsilon_{A}-\varepsilon_{i}-\varepsilon_{I}-X_{i, A, I}}+ \\
& +\sum_{a, A, I} \frac{\langle p, I|V| a, A\rangle\langle a, A|V| p, I\rangle Z_{p, a, A, I}}{E+\varepsilon_{I}-\varepsilon_{a}-\varepsilon_{A}-X_{a, A, I}}
\end{aligned}
$$

que é igual ao termo de segunda ordem com os fatores $Z$ e $X$ adicionados ao numerador e denominador. Como ocorre com a auto-energia do elétron, a do pósitron também possui termos com um e dois fatores no denominador com a energia $E$. Repetindo então o procedimento 
anterior, chega-se a um resultado final com a forma de (4.19). Agora, o fator F é calculado como a razão da soma dos temos de terceira ordem da auto-energia do pósitron em que $E$ só aparece uma vez no denominador e o termo de segunda ordem.

Na passagem da equação (4.18) para a (4.19), foram desprezados todos os termos (exceto o primeiro) da série

$$
\sum_{n} \frac{V_{n} X_{n}}{\left(E-f_{n}\right)^{2}}\left[1+\frac{X_{n}}{E-f_{n}}+\ldots\right] .
$$

Para um sistema contendo apenas elétrons, essa série em geral possui uma contribuição pequena e portanto pode de fato ser ignorada [35]. Isto ocorre pois o sinal dos seus termos alterna, e portanto eles tendem a se cancelar. No caso da auto-energia do pósitron, todos os termos terão o mesmo sinal (pois o potencial de Coulomb entre elétrons é positivo, enquanto o entre um elétron e um pósitron é negativo), então para o pósitron tais termos se somam, e deve ser importante incluí-los na aproximação.

Os termos correspondentes à contribuição da formação do Ps virtual da auto-energia APMO, que podem ser representados pelos diagramas que aparecem nas somas (3.14) e (4.22), devem contribuir para os termos da série (4.32). Para entender o motivo disso, deve-se lembrar que, nesses termos, a energia aparece em todos os fatores em seus denominadores, ou seja, um deles de ordem $m+1$ terá $m$ fatores no denominador com a energia $E$, e portanto no método OVGF ele contribui para

$$
\sum_{n} \frac{V_{n}\left(X_{n}\right)^{m-1}}{\left(E-f_{n}\right)^{n}},
$$

que é justamente um dos termos de (4.32). Então desconsiderar essa série significa desprezar a contribuição dos termos tipo Ps virtual da auto-energia APMO. Porém, seguindo a lógica do método original, sugere-se substituir tal série por $\Sigma_{p p}^{(P s)}$, e assim a versão A do método OVGF para o pósitron se torna

$$
\Sigma_{p p}(E) \approx \Sigma_{p p}^{(2)}(E)+\frac{1}{1+F}\left[\bar{\Sigma}_{p p}^{(3)}(E)+\Sigma_{p p}^{(P s)}(E)\right]
$$

onde $\bar{\Sigma}_{p p}^{(3)}(E)$ é igual a soma dos termos de terceira ordem com exceção de (4.20) e (4.21), que já estão contidos em $\Sigma_{p p}^{(P s)}$.

\subsection{As versões B e REN/PP3}

Das quatro versões do método OVGF, a REN/PP3 é a que no geral apresentou melhores resultados. Por essa versão ser muito semelhante à versão $\mathrm{B}$, primeiro será explicada a derivação dessa última.

Para deduzir a versão A do método OVGF, a auto-energia foi escrita como a soma de duas 
parcelas (veja a equação (4.31)). Na versão B, cada uma dessas parcelas é considerada separadamente, e a auto-energia é expressa como

$$
M_{p p}(E) \approx \sum_{m} \frac{V_{m} X_{m}}{E-f_{m}-X_{m}}+\sum_{n} \frac{V_{n} X_{n}}{E-f_{n}-X_{n}}
$$

onde agora $m$ representa os índices $i, A, I$, e $n$ os índices $a, A, I$. Em seguida, repete-se o procedimento realizado na versão A para cada uma das somatórias acima separadamente. Agora é conveniente adotar uma nova notação para os termos da auto-energia. Alguns desses termos têm no denominador um ou dois fatores na forma $E-\varepsilon_{a}-\varepsilon_{i}-\varepsilon_{I}$, ou seja, onde aparece a energia de um orbital buraco e duas energias de orbitais virtuais. Este é o caso do termo de terceira ordem dado por (4.20). Outros termos, como o (4.21), possuem no denominador fatores na forma $E+\varepsilon_{i}-\varepsilon_{a}-\varepsilon_{A}$, onde estão presentes a energia de um orbital virtual e duas energias de orbitais ocupados. Esses dois tipos de termos serão denotados com os índices $2 p h$ e $2 h p$, respectivamente, onde o $h$ significa hole (buraco) e $p$ particle (partícula). Os termos com $2 p h$ irão contribuir para a primeira somatória de (4.35), e os com $2 h p$ para a segunda. Desta forma, o resultado para o método B pode ser escrito como

$$
\Sigma_{p p}(E) \approx \Sigma_{p p}^{(2)}(E)+\frac{1}{1+F_{2 p h}} M_{p p}^{(3)}(E)_{2 p h}+\frac{1}{1+F_{2 h p}} M_{p p}^{(3)}(E)_{2 h p}+\Sigma^{(3)}(\infty),
$$

onde $F_{2 p h}\left(F_{2 h p}\right)$ é calculado como a razão dos termos de terceira ordem que só possuem um fator no denominador com a energia que contribuem para a primeira (segunda) somatória de (4.35)

$$
F_{2 p h}=\frac{M_{p p}^{(3)}(E)_{1}^{2 p h}}{\Sigma_{p p}^{(2)}(E)_{2 p h}}, \quad F_{2 h p}=\frac{M_{p p}^{(3)}(E)_{1}^{2 h p}}{\Sigma_{p p}^{(2)}(E)_{2 h p}} .
$$

Novamente, os termos da série (4.32) foram desprezados para chegar a este resultado. De maneira análoga ao que foi proposto na versão A, uma correção pode ser obtida através de

$$
\begin{aligned}
\Sigma_{p p}(E) \approx & \Sigma_{p p}^{(2)}(E)+\frac{1}{1+F_{2 p h}}\left[\bar{M}_{p p}^{(3)}(E)_{2 p h}+\Sigma_{p p}^{(P s)}(E)_{2 p h}\right] \\
& +\frac{1}{1+F_{2 h p}}\left[\bar{M}_{p p}^{(3)}(E)_{2 h p}+\Sigma_{p p}^{(P s)}(E)_{2 h p}\right]+\Sigma_{p p}^{(3)}(\infty) .
\end{aligned}
$$

Aqui, $\bar{M}_{p p}^{(3)}(E)_{2 p h}$ significa a soma dos termos de terceira ordem da auto-energia dinâmica do tipo $2 p h$, sem o termo dado por (4.20), enquanto $\bar{M}_{p p}^{(3)}(E)_{2 h p}$ é o análogo para os do tipo $2 h p$, sem o termo (4.21).

Quando a função de Green foi expandida na seção 3.4, utilizou-se teoria de perturbação 
de Rayleigh-Schrodinger para escrever o estado exato do sistema através da função de onda APMO/HF. Uma outra opção seria utilizar o método Coupled Cluster (CC) para expandir a função de onda. Isto leva a uma auto-energia com uma forma semelhante à apresentada no capítulo anterior, mas com duas diferenças: não há a parte independente da energia $\Sigma(\infty)$, e os termos em que $E$ só aparece uma vez no denominador são multiplicados por um fator $1 / 2$. $O$ fato dessa auto-energia só ter a parte dinâmica é vantajoso, pois, como é discutido em [31], é difícil descrever numericamente a parte não dependente da energia devido à sua convergência. Os termos dessa nova auto-energia serão denotados com o índice $P$ antes de sua ordem (por exemplo, usa-se $\Sigma^{(P 2)}$ para o termo de segunda ordem).

A versão REN/PP3 consiste em repetir o procedimento da versão $B$, porém utilizando a auto-energia calculado usando o método CC. O resultado final é muito similar ao de (4.36), porém os fatores $F_{2 p h}$ e $F_{2 h p}$ devem ser divididos por 2 e o termo $\Sigma(\infty)$ precisa ser excluído. Incluindo os termos tipo Ps virtual, a versão REN/PP3 corrigida se torna

$$
\begin{aligned}
\Sigma_{p p}(E)^{R E N / P P 3}= & \Sigma_{p p}^{(P 2)}(E)+\frac{1}{1+F_{2 p h} / 2}\left[\bar{M}_{p p}^{(P 3)}(E)_{2 p h}+\Sigma_{p p}^{(P s)}(E)_{2 p h}\right] \\
& +\frac{1}{1+F_{2 h p} / 2}\left[\bar{M}_{p p}^{(P 3)}(E)_{2 h p}+\Sigma_{p p}^{(P s)}(E)_{2 h p}\right] .
\end{aligned}
$$




\section{Capítulo 5}

\section{Taxas de Aniquilação}

\subsection{Aniquilação em estados ligados}

Como já discutido, alguns átomos e moléculas podem ligar pósitrons e ser eletronicamente estáveis. Entretanto, nenhum desses sistemas é estável frente ao processo de aniquilação. O pósitron poderá se aniquilar com um dos elétrons do composto, produzindo um determinado número $n$ de fótons:

$$
e^{-}+e^{+} \rightarrow n \gamma
$$

O número de fótons gerados depende da configuração de spin do par elétron-pósitron. No átomo de positrônio, quando o elétron e o pósitron estão no estado de singleto (com spin total $S=0$ ), $n$ deve ser um número par maior ou igual a 2 [67]. No estado do tripleto $(S=1)$, o número de fótons deve ser ímpar e maior ou igual a 3. Entretanto, em ambos os casos, os processos que geram o menor número de fótons são os mais prováveis. Assim, a maioria dos pares nos estados de singleto e tripleto produzirão 2 e 3 fótons, respectivamente $[67,68]$. Os casos com $n=0$ e $n=1$ fótons não são permitidos para um único par, porém podem ocorrer em sistemas mais complexos, como a molécula de positrônio $\mathrm{Ps}_{2}$. No íon $\mathrm{Ps}^{-}$, o caso $n=0$ não é permitido, mas o $n=1 \operatorname{sim}[69]$.

Uma quantidade interessante que pode ser calculada para sistemas positrônicos é a sua taxa de aniquilação $\Gamma$, o inverso do tempo de vida de aniquilação. Aqui, serão considerados apenas os casos em que o pósitron está ligado a uma molécula ou átomo com $N$ elétrons, onde a soma dos spins dos elétrons é igual zero. Para o processo em que são gerados dois fótons, o qual é o processo dominante, a taxa de aniquilação pode ser escrita como [28, 68]

$$
\Gamma_{2 \gamma}=\pi r_{0} c^{2} \delta_{e p}
$$

onde $r_{0}$ é o raio clássico do elétron, $c$ é a velocidade da luz no vácuo e $\delta_{e p}$ é dado por 


$$
\delta_{e p}=\sum_{i=1}^{N} \int\left|\Psi_{0}\left(\boldsymbol{r}_{1}, \ldots, \boldsymbol{r}_{N}, \boldsymbol{r}\right)\right|^{2} \delta\left(\boldsymbol{r}-\boldsymbol{r}_{i}\right) d \boldsymbol{r}_{1} \cdots d \boldsymbol{r}_{N} d \boldsymbol{r},
$$

em que $\Psi_{0}$ é o estado fundamental do sistema (incluindo o pósitron), $\boldsymbol{r}_{i}$ é a coordenada do $i$-ésimo elétron e $r$ a do pósitron.

Também é possível calcular as taxas de aniquilação associadas a processos que geram outros números de fótons. Por exemplo, para os casos em que são produzidos um número par de fótons maior que 2, a taxa de aniquilação é diretamente proporcional a do processo de 2 fótons $\Gamma_{2 \gamma}$ (veja [70] para mais detalhes). As taxas de aniquilação para processos que produzem de 0 até 5 fótons também já foram calculadas para alguns sistemas simples, como os já citados $\mathrm{Ps}^{-}$e $\mathrm{Ps}_{2}$ [69], e também alguns hidretos de positrônio [70]. Nesses casos, com exceção das taxas de 0 e 1 fótons, todas elas também são proporcionais a $\delta_{e p}$.

\subsection{Taxas de aniquilação em gases moleculares}

Muitas vezes também há interesse em calcular as taxas de aniquilação de pósitrons incidindo em moléculas em um gás. Neste caso, se $\rho$ é a densidade de número do gás, a taxa de aniquilação pode ser calculada por

$$
\lambda=\pi r_{0}^{2} c \rho Z_{e f f}
$$

onde $Z_{\text {eff }}$ recebe o nome de parâmetro de aniquilação e é dado por

$$
Z_{e f f}=\int\left|\Psi_{\boldsymbol{k}}\left(\boldsymbol{r}_{1}, \ldots, \boldsymbol{r}_{N}, \boldsymbol{r}\right)\right|^{2} \delta\left(\boldsymbol{r}_{i}-\boldsymbol{r}\right) d \boldsymbol{r}_{1} \cdots d \boldsymbol{r}_{N} d \boldsymbol{r}
$$

Aqui, $\Psi_{k}$ é a função de onda que descreve a colisão de um pósitron com momento $\boldsymbol{k}$ com uma das moléculas do gás. A diferença entre $\delta_{e p}$ e $Z_{\text {eff }}$ está no fato de que no primeiro utilizase a função de onda de um estado ligado, enquanto no segundo a de um estado de espalhamento. Entretanto, essas duas grandezas estão relacionadas. Desconsiderando completamente o movimento dos núcleos, pode-se aproximar o parâmetro de aniquilação por [27]

$$
Z_{e f f}(k) \approx \frac{D}{k^{2}+\kappa^{2}},
$$

onde $\kappa$ é o inverso do comprimento de espalhamento e $D$ é uma constante, que pode ser calculada através de $D=\kappa^{2} Z_{\text {eff }}(0)$. Se o pósitron forma um estado ligado com a molécula e a mesma não possui um momento de dipolo permanente, é possível relacionar o parâmetro de aniquilação calculado em $k=0 \operatorname{com} \delta_{e p}[71,27]$ :

$$
Z_{e f f}(0)=\frac{2 \pi \delta_{e p}}{\kappa^{3}}
$$

onde $\kappa$ está relacionado a energia de ligação do pósitron $\varepsilon_{b}$ por $\kappa=\sqrt{2\left|\varepsilon_{b}\right|}$. Assim, apenas co- 
nhecendo $\delta_{e p}$ e $\varepsilon_{b}$ (já computada pelo LOWDIN), é possível calcular o parâmetro de aniquilação nessa aproximação e consequentemente a taxa de aniquilação.

Porém, como foi mencionado no capítulo 3, em uma colisão de um pósitron com uma molécula pode ocorrer uma RFV, e nesses casos o movimento vibracional da molécula deve ser levado em consideração. Para isso, pode-se adotar um modelo proposto por Gribakin e Lee [71, 9], em que a contribuição do parâmetro de aniquilação é dividida em duas, uma que considera apenas os efeitos de correlação eletrônica e é dada por (5.6), sendo chamada de contribuição direta, e outra que recebe o nome de contribuição ressonante. Quando a molécula possui apenas um modo vibracional, essa última pode ser aproximada como [29]

$$
Z_{e f f}^{(r e s)}(T)=\frac{8 \pi^{3} \delta_{e p}}{\left(2 \pi k_{B} T\right)^{3 / 2}} \frac{e^{\varepsilon_{0} / K_{B} T}}{e^{\omega / K_{B} T}-1},
$$

onde $T$ é a temperatura, $K_{B}$ é a constante de Boltzmann e $\omega$ é a frequência do modo vibracional do sistema molécula-pósitron, que é assumida maior que a energia de ligação do pósitron. $\mathrm{O}$ parâmetro de aniquilação total é calculado como a soma da componente direta e a ressonante. Desse resultado pode-se perceber que o cálculo das taxas de aniquilação se resume basicamente ao cálculo de $\delta_{e p}$ (para sistemas que podem formar estados ligados).

\subsection{Cálculo das taxas de aniquilação}

O objeto desta parte do trabalho é obter expressões para calcular as taxas de aniquilação de pósitrons em estados ligados que possam ser implementadas no LOWDIN. Será seguida uma abordagem muito parecida com a de Gribakin e Ludlow [39] e outros autores [41, 40], que utilizaram teoria quântica de muitos corpos (MBPT, na sigla em inglês) para expandir as taxas de aniquilação através de diagramas. Nesses trabalhos foram considerados os casos de espalhamento de pósitrons por átomos. Uma aplicação do método para o cálculo de taxas de aniquilação em estados ligados foi feita por Gribakin e Ludlow em 2010 [38].

De maneira semelhante, a taxa de aniquilação dada por (5.2) e (5.3) será expandida, sendo escrita como a soma de infinitos termos que podem ser representados por diagramas semelhantes àqueles utilizados para a auto-energia e a função de Green. Como será mostrado, esses termos possuem expressões muito parecidas com as da auto-energia calculada pelo LOWDIN, o que deve facilitar a sua implementação numérica.

Os diagramas obtidos neste trabalho são similares aos empregados pelos autores citados acima, mas há algumas diferenças. A vantagem da proposta apresentada aqui é que, além de possuir uma implementação numérica mais simples, pode ser facilmente generalizada para sistemas que contém mais de um pósitron, o que permitiria realizar cálculos para $\mathrm{O}_{2}$, por exemplo.

Para computar a taxa de aniquilação, é necessário calcular o valor esperado $\delta_{e p}$. Analisando a expressão (5.3), percebe-se que a mesma pode ser escrita de maneira mais simplificada como 
o valor esperado de um operador (que será denotado por $\hat{\delta}$ ), calculado usando o estado fundamental do sistema: $\delta_{e p}=\left\langle\Psi_{0}|\hat{\delta}| \Psi_{0}\right\rangle$. Por envolver o estado exato do sistema $\Psi_{0}$, não é possível calcular essa integral de forma analítica, mas pode-se recorrer à teoria de perturbação. Aplicando o teorema de Gell-Mann e Low a $\Psi_{0}$ e usando a equação (2.23), esse valor esperado pode ser escrito como (aqui assume-se que $\Psi_{0}$ é não degenerado)

$$
\sum_{n=0}^{\infty} \frac{(-i)^{n}}{n !} \int_{-\infty}^{\infty} d t_{1} \cdots \int_{-\infty}^{\infty} d t_{n} e^{-\eta\left(\left|t_{1}\right|+\ldots+\left|t_{n}\right|\right)} \frac{\left\langle\psi_{0}\left|T\left[\hat{H}_{I}\left(t_{1}\right) \cdots \hat{H}_{I}\left(t_{n}\right) \hat{\delta}\right]\right| \psi_{0}\right\rangle}{\left\langle\psi_{0}\left|\hat{U}_{\eta}(+\infty,-\infty)\right| \psi_{0}\right\rangle}
$$

o que permite expressar (5.3) como uma série infinita

$$
\delta_{e p}=\delta_{e p}^{(0)}+\delta_{e p}^{(1)}+\delta_{e p}^{(2)}+\ldots,
$$

em que os termos $\delta_{e p}^{(n)}$ podem ser representados por diagramas, após o uso do teorema de Wick, como será mostrado a seguir. Novamente, a hamiltoniana do sistema é dividida em duas partes: $\hat{H}=\hat{H}_{0}+\hat{H}_{I}$, onde $\hat{H}_{0}$ é a soma das energias cinéticas dos elétrons e do pósitron com a adição de algum potencial externo (que no presente caso é igual à soma de suas interações com os núcleos da molécula ou átomo), e $\hat{H}_{I}$ é a soma das interações de Coulomb entre essas partículas. Como antes, $\psi_{0}$ é um autoestado de $\hat{H}_{0}$. Outra opção é adotar a partição de MP generalizada para o pósitron, de modo que $\hat{H}_{0}$ passa a ser a soma dos operadores de Fock para os elétrons e o pósitron dados por (5.37) e (5.38) (mais informações a frente), o que resulta em alguns termos a mais em $\hat{H}_{I}$. Como ocorre com a auto-energia e a função de Green, essa escolha diminui consideravelmente o número de diagramas obtidos, tornando seu cálculo muito mais simples, como será discutido melhor mais adiante.

Este capítulo está organizado da seguinte forma: Primeiro será mostrado como construir esses diagramas para uma ordem qualquer em teoria de perturbação e as regras que devem ser utilizadas para obter as expressões a eles associadas. As deduções e justificativas dessas regras serão apresentadas na seção seguinte, de modo que podem ser ignoradas pelo leitor que não tem interesse nelas; nessa parte também será discutida a generalização do método Hartree-Fock e o uso da partição de MP. Em seguida se abordará como fazer somas infinitas de diagramas e assim tornar o cálculo de $\delta_{e p}$ mais preciso, empregando a mesma ideia explicada nos capítulos anteriores para levar em consideração a formação do Ps virtual. Por fim, seá apresentada uma abordagem parecida para expandir a energia de correlação do sistema molécula-pósitron, também por meio de diagramas. O conhecimento dessa energia possibilita uma outra maneira de calcular energias de ligação do pósitron, sem o uso da auto-energia.

\subsubsection{Construção dos Diagramas e Regras}

Como antes as interações de Coulomb serão representadas através de linhas onduladas com setas entrando e saindo, que estão associadas aos operadores de criação e aniquilação. Porém, 
agora será utilizado um novo símbolo que representará o operador $\hat{\delta}$ : um círculo preto com duas linhas que entram e duas que saem, como na figura 5.1.
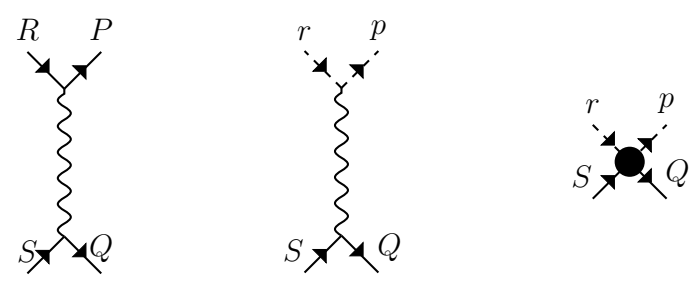

Figura 5.1: Símbolos utilizados nos diagramas da taxa de aniquilação para representar as interações de Coulomb de dois elétrons e um elétron e um pósitron, e o operador $\hat{\delta}$.

Para obter os diagramas que correspondem à ordem $n$, novamente é necessário desenhar $n$ linhas onduladas postas lado a lado e um círculo que representa $\hat{\delta}$. A ordem em que as linhas e o círculo aparecem é importante, então todas devem ser consideradas. Por exemplo, em um diagrama de ordem 2 , as duas linhas onduladas podem ser colocadas à esquerda do circulo, à sua direita ou então de modo que o circulo fique entre elas, como é indicado na figura 5.2.

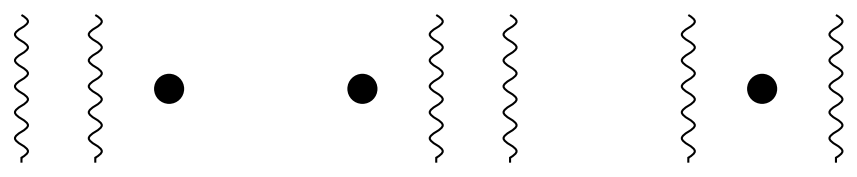

Figura 5.2: Diagramas possíveis para o termo de segunda ordem. A ordem em que os símbolos aparecem é importante e todas as possibilidades devem ser consideradas. As linhas que entram e saem de cada símbolo não estão sendo mostradas por simplicidade.

Devido ao fato de que há dois tipos de interações, a elétron-elétron e a elétron-pósitron, cada linha ondulada pode representar qualquer uma delas. É preciso levar em conta todas as possibilidades e desenhar um diagrama correspondente para cada caso. Voltando ao exemplo anterior, em cada um dos diagramas de segunda ordem acima deve-se considerar o caso em que a primeira dessas duas linhas onduladas é uma interação elétron-elétron e a segunda elétronpósitron, o caso em que a primeira é uma interação elétron-pósitron e a segunda elétron-elétron, o caso em que ambas são elétron-elétron e o em que as duas são elétron-pósitron. Então os três diagramas desenhados na verdade se tornam doze.

Apesar de não aparecerem na figura acima, cada linha ondulada (e o círculo) possui duas linhas orientadas que entram e duas que saem dela. Essas linhas devem ser conectadas umas às outras para representar as contrações dos operadores de criação e aniquilação. Porém, algumas regras precisam ser respeitadas. Como antes, não é permitido ligar uma linha tracejada com uma contínua, pois operadores eletrônicos e positrônicos não podem ser contraídos uns com os outros, e nem linhas que possuem sentidos opostos. Além disso, todos os diagramas devem ser conectados, ou seja, não podem possuir duas ou mais partes não ligadas por linhas.

Na figura 5.3 são mostrados alguns exemplos de diagramas. O primeiro é o único diagrama de ordem zero, em que não há nenhuma interação de Coulomb e que portanto equivale ao caso onde as interações entre as partículas são desprezadas completamente. Há apenas uma maneira 
de conectar as suas linhas. O segundo é um diagrama de primeira ordem e os dois seguintes são diagramas de segunda ordem. À medida que a ordem aumenta, o número de diagramas também aumenta. Uma lista completa dos diagramas de segunda ordem e de suas respectivas expressões pode ser encontrada no apêndice.
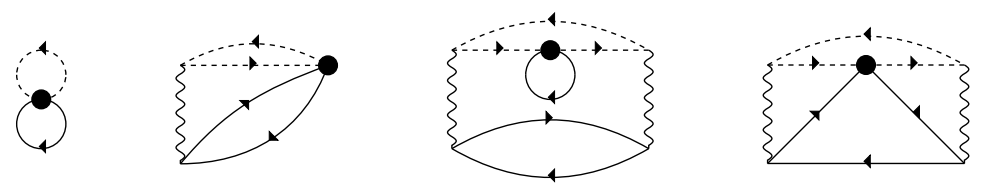

Figura 5.3: Alguns diagramas possíveis em ordens mais baixas. O primeiro é o único diagrama de ordem zero, o segundo é um diagrama de ordem 1 e os dois seguintes são diagramas de segunda ordem.

Entretanto, nem todos os diagramas conectados que podem ser desenhados devem ser mantidos. Este é o caso dos chamados diagramas topologicamente equivalentes. Diz-se que dois diagramas são topologicamente equivalentes se um pode ser transformado no outro distorcendo partes dele, sem alterar a ordem em que as linhas onduladas e o círculo aparecem. Todos os diagramas topologicamente equivalentes possuem a mesma contribuição, e portanto apenas um deles precisa ser considerado. Um exemplo de dois diagramas assim é mostrado na figura 5.4. Apesar de parecerem diferentes, o segundo pode ser transformado no primeiro invertendo uma de duas interações de Coulomb.
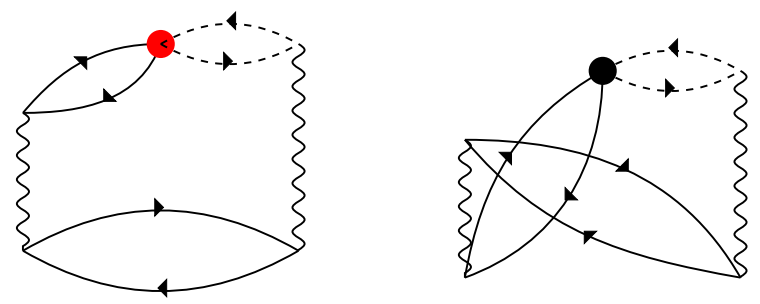

Figura 5.4: Exemplo de dois diagramas topologicamente equivalentes.

Quando utiliza-se a partição de MP, muitos outros diagramas conectados também devem ser excluídos, pois eles serão cancelados pelos termos extras que estarão presentes em $\hat{H}_{I}$. São esses os diagramas nos quais pelo menos uma das interações está ligada a ela mesma, ou seja, os diagramas em que uma ou mais das ligações mostradas na figura 5.5 aparece no mínimo uma vez.
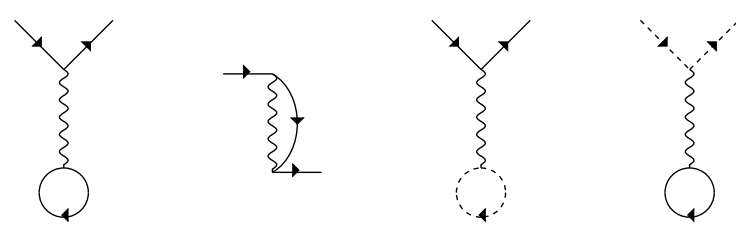

Figura 5.5: Exemplos de algumas ligações que podem ocorrer em alguns diagramas. Os diagramas que contém uma ou mais dessas ligações devem ser excluídos quando utilizada a partição de MP. 
Dois exemplos de diagramas de primeira ordem que poderiam ser construídos com ligações desse tipo são mostrados na figura 5.6.
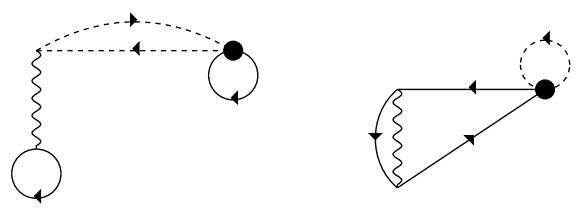

Figura 5.6: Dois diagramas conectados que devem ser excluídos quanto utilizada a partição de MP.

Os diagramas podem ser classificados em dois tipos, os simétricos em relação a uma linha vertical que os divide ao meio e os assimétricos (nesse caso, não leva-se em conta o sentido das linhas). Por exemplo, na figura 5.3, o primeiro, terceiro e quarto diagramas são simétricos, enquanto o segundo é assimétrico. Para cada diagrama assimétrico, sempre haverá um outro diagrama igual a sua imagem espelhada. Esses diagramas terão a mesma contribuição e apenas um deles precisa ser considerado. Assim, na hora de desenhar os diagramas, também é necessário excluir aqueles que podem ser vistos como reflexões de outros diagramas.

As regras para obter expressões dos diagramas podem ser enunciadas da seguinte forma:

1) Nomeia-se as linhas que apontam para a direita com as letras $i, j, k, \ldots$ se forem tracejadas e $I, J, K, \ldots$ se forem contínuas. Para as linhas que apontam para a esquerda, utiliza-se as letras $a, b, c, \ldots$ para as tracejadas e $A, B, C, \ldots$ para as contínuas. Não pode haver mais de uma linha com a mesma letra. Essas linhas representam orbitais positrônicos e eletrônicos. As linhas que apontam para a direita representam orbitais de partículas e as que apontam para a esquerda orbitais ocupados.

2) Cada linha ondulada contribui para a expressão do diagrama com um fator $\langle w, x|V| y, z\rangle$, enquanto o circulo contribui com

$$
\langle w, x|\delta| y, z\rangle=\int d \boldsymbol{x} d \boldsymbol{x}^{\prime} \varphi_{w}^{*}(\boldsymbol{x}) \varphi_{x}^{*}\left(\boldsymbol{x}^{\prime}\right) \delta\left(\boldsymbol{r}-\boldsymbol{r}^{\prime}\right) \varphi_{y}(\boldsymbol{x}) \varphi_{z}\left(\boldsymbol{x}^{\prime}\right),
$$

onde $w$ e $x$ são as linhas que saem da interação e $y$ e $z$ as que entram. No caso das linhas onduladas, $y(z)$ deve ser a linha que entra no mesmo vértice do qual $w(x)$ sai.

3) Para cada par de linhas onduladas sucessivas ou um par formado por uma linha ondulada e o círculo (também sucessivos), adiciona-se ao denominador um fator igual à soma das energias dos orbitais associados às linhas de buracos menos a soma das energias das linhas de partículas que passam entre esse par.

4) Deve-se somar sobre todos os índices dos orbitais e adicionar um fator 2 se o diagrama for assimétrico. o sinal do diagrama é dado por $(-1)^{l+b+v}$, onde $l$ é o número de loops do diagrama, $b$ é o número de linhas de buracos e $v$ o número de interações elétron-pósitron. 
Com essas regras, as expressões dos diagramas de ordem zero e de primeira ordem são, respectivamente

$$
\bigodot_{A}^{\prime-4}=\sum_{a, A}\langle a, A|\delta| a, A\rangle=\sum_{a, A} \int\left|\varphi_{a}(\boldsymbol{r})\right|^{2}\left|\varphi_{A}(\boldsymbol{r})\right|^{2} d \boldsymbol{r}
$$

$\mathrm{e}$

$$
\sum_{A}^{i}=-2 \sum_{a, i, A, I} \frac{\langle i, I|V| a, A\rangle\langle a, A|\delta| i, I\rangle}{\varepsilon_{a}+\varepsilon_{A}-\varepsilon_{i}-\varepsilon_{I}} .
$$

Devido à exclusão de alguns diagramas, o diagrama acima é o único diagrama de primeira ordem.

\subsubsection{Dedução das regras para diagramas}

Inicialmente será considerado apenas o numerador da expansão de $\delta_{e p}$, pois, de forma semelhante à função de Green, o denominador se cancela com os diagramas desconectados, como será mostrado mais adiante. Um termo de ordem $n$ nessa expansão pode ser escrito como

$$
\frac{(-i)^{n}}{n !} \int_{-\infty}^{\infty} d t_{1} \cdots \int_{-\infty}^{\infty} d t_{n} f\left(t_{1}, \ldots, t_{n}\right)
$$

onde $f\left(t_{1}, \ldots, t_{n}\right) \equiv e^{-\eta\left(\left|t_{1}\right|+\ldots+\left|t_{n}\right|\right)} T\left[\hat{H}_{I}\left(t_{1}\right) \cdots \hat{H}_{I}\left(t_{n}\right) \hat{\delta}\right]$. Como antes, os operadores devem ser escritos usando segunda quantização para poder aplicar em seguida o teorema de Wick, mas primeiro é necessário dividir os intervalos de integração da expressão acima de forma a escrevê-la como a soma de vários termos, um em que o intervalo de integração é tal que $t_{1} \leq t_{2} \leq \ldots \leq 0 \leq \ldots \leq t_{n}$, outro onde $t_{2} \leq t_{1} \leq \ldots \leq 0 \leq \ldots \leq t_{n}$, e assim por diante. Todas as maneiras de ordenar os instantes de tempo $t_{1}, \ldots, t_{n}$ e $t=0$ devem ser consideradas, o que gera um total de $(n+1)$ ! novos termos, cada um deles devendo ser analisado separadamente. Um desses novos termos em que $t_{1} \leq t_{2} \leq \ldots \leq t_{m} \leq 0 \leq t_{m+1} \leq \ldots \leq t_{n}$ pode ser expresso como [42]

$$
\begin{aligned}
& \frac{(-i)^{n}}{n !} \int_{-\infty}^{0} d t_{m} \int_{-\infty}^{t_{m}} d t_{m-1} \ldots \int_{-\infty}^{t_{2}} d t_{1} \\
& \quad \int_{0}^{\infty} d t_{m+1} \int_{t_{m+1}}^{\infty} d t_{m+2} \ldots \int_{t_{n-1}}^{\infty} d t_{n} f\left(t_{1}, \ldots, t_{n}\right) .
\end{aligned}
$$

Muitos dos termos obtidos fazendo essas partições terão a mesma contribuição, pois a função $f\left(t_{1}, \ldots, t_{n}\right)$ é simétrica frente a permutação de suas variáveis, isto é, ela é inalterada 
ao trocar os instantes de tempo $t_{i}$ entre si. Então todas as integrais em que os intervalos de integração diferem apenas por permutações desses instantes de tempo na verdade serão idênticas. Por exemplo, em um termo de terceira ordem, este é o caso das integrais com $t_{1} \leq t_{2} \leq 0 \leq t_{3}$ e $t_{2} \leq t_{1} \leq 0 \leq t_{3}$, pois elas só diferem pela permutação dos índices 1 e 2. Para cada ordenamento escolhido, haverá outros $n !-1$ ordenamentos distintos que produzirão o mesmo resultado. Portanto, só é necessário considerar um deles e com isso pode-se eliminar o fator $1 / n$ ! que aparece multiplicando a expressão acima.

Com essa partição feita, pode-se prosseguir com a aplicação do teorema de Wick. Para isso, as interações devem ser escritas de acordo com a equação (3.7) e o operador $\hat{\delta}$ como

$$
\hat{\delta}=\sum_{p, Q, r, S}\langle p, Q|\delta| r, S\rangle \hat{a}_{p}^{\dagger} \hat{a}_{Q}^{\dagger} \hat{a}_{S} \hat{a}_{r}
$$

Desse modo são obtidos muitos outros termos, cada um representando uma possibilidade de contração diferente entre os operadores de criação e aniquilação. Como foi descrito no capítulo anterior, não é possível contrair operadores de pósitron e elétrons. Vale lembrar que os operadores $\hat{H}_{I}$ que aparecem nessa expansão estão na representação de interação, portanto cada um depende de um instante de tempo $t_{i}$, e assim pode-se associar a cada linha ondulada um desses instantes de tempo. Ao desenhar o diagrama, essas linhas devem ser colocadas lado a lado respeitando a ordem temporal escolhida na integral, de modo que o tempo aumente da esquerda para a direita. Por exemplo, em um termo de segunda ordem com o intervalo de integração $t_{1} \leq t_{2} \leq 0$, a linha ondulada que representa $\hat{H}_{I}\left(t_{1}\right)$ deve ser posta à esquerda, seguida pela linha ondulada que representa $\hat{H}_{I}\left(t_{2}\right)$, seguida pelo círculo, que está associado ao instante $t=0$. Já na integral com $t_{1} \leq 0 \leq t_{2}$, coloca-se primeiro uma linha ondulada, depois o círculo e em seguida outra linha ondulada. Esses dois casos são mostrados na figura abaixo, respectivamente.
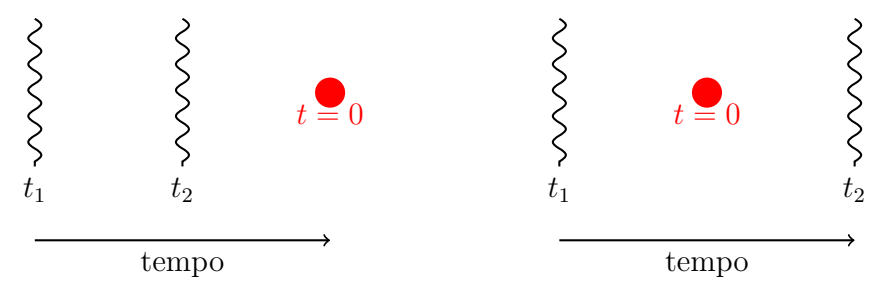

Figura 5.7: Dois diagramas de segunda ordem que correspondem a diferentes escolhas da ordem temporal. $\mathrm{O}$ da esquerda se refere a $t_{1} \leq t_{2} \leq 0$, e o da direita a $t_{1} \leq 0 \leq t_{2}$.

Por terem sido construídos considerando uma dada escolha de ordenamento temporal, esses são diagramas temporalmente ordenados, assim como os diagramas apresentados no capítulo 2. Eles possuem a seguinte vantagem: Como já explicado, as linhas representam contrações de operadores de criação com de aniquilação. Por exemplo, uma linha indo de uma interação com um instante de tempo $t_{1}$ até outra interação com um instante de tempo $t_{2}$ representa uma contração de um operador de aniquilação calculado em $t=t_{2}$ com um de criação calculado em $t=t_{1}$ : 


$$
\stackrel{q \longrightarrow t_{2}}{\longrightarrow}={ }_{t_{1}}\left(t_{2}\right) a_{q}^{\dagger}\left(t_{1}\right)
$$

Como a interação com o maior tempo é sempre colocada à direita, uma linha que aponta para a direita representa uma contração em que o tempo do operador de aniquilação é maior do que o tempo do de criação. Então, em virtude das equações (2.32) e (2.33), os orbitais associados a esses operadores devem ser orbitais virtuais, caso contrário o resultado da contração será zero. Por isso diz-se que linhas que apontam para a direita representam orbitais partículas. Por essas equações, uma contração só será não nula quando $p=q$, assim só é necessário usar uma única letra para cada linha. Analogamente, as linhas que apontam para a esquerda representam contrações que só serão não nulas quando os orbitais envolvidos forem ocupados, já que neste caso o tempo do operador de criação será maior do que o do de aniquilação. Portanto, linhas com sentido para a esquerda estão associadas a orbitais ocupados.

Como é dito na regra 2, para cada linha ondulada no diagrama há um elemento de matriz com a forma $\langle w, x|V| y, z\rangle$, onde $w$ e $x$ são as linhas que saem do diagrama e $y$ e $z$ as que entram. Esses termos surgem ao escrever os operadores em segunda quantização, o que também explica a somatória sobre todos esses índices. A princípio, seria necessário somar sobre todos os orbitais possíveis, entretanto, as contrações dos operadores limitam cada soma a apenas um dos dois tipos de orbitais, virtual ou ocupado.

Além disso, quando as interações $\hat{H}_{I}$ são escritas utilizando operadores de criação e aniquilação, surge um fator $1 / 2$ multiplicando o termo correspondente às interações entre elétrons (veja novamente a expressão (3.7)). Esse fator, entretanto, será cancelado pelos diagramas topologicamente equivalentes. Para entender o motivo disso, considere novamente como exemplo os diagramas da figura 5.4, mostrados novamente abaixo, com as respectivas contrações que eles representam.

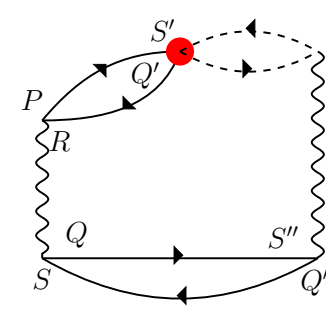

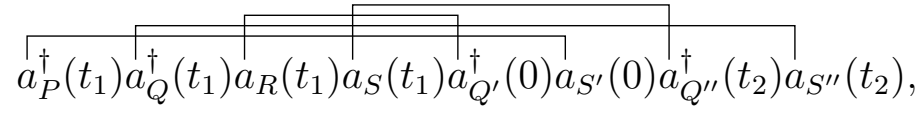

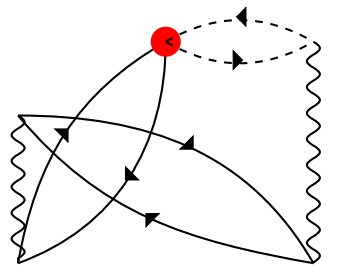

$$
a_{a_{P}^{\dagger}\left(t_{1}\right) a_{Q}^{\dagger}\left(t_{1}\right) a_{R}\left(t_{1}\right) a_{S}\left(t_{1}\right) a_{Q^{\prime}}^{\dagger}(0) a_{S^{\prime}}(0)} a_{Q^{\prime \prime}}^{\dagger}\left(t_{2}\right) a_{S^{\prime \prime}}\left(t_{2}\right) .
$$

Esses diagramas, apesar de representarem diferentes possibilidades de contrações vindas do 
teorema de Wick, têm a mesma contribuição, pois diferem apenas pelas permutações de índices de operadores de criação e aniquilação. Ao trocar a ordem dos operadores $\hat{a}_{P}^{\dagger}$ e $\hat{a}_{Q}^{\dagger}$ e de $\hat{a}_{S}$ e $\hat{a}_{R}$ dentro do produto $N$ (o que não altera o sinal, pois são necessárias duas permutações) e a notação dos seus índices, pode-se perceber que as duas contrações acima são de fato idênticas.

Sempre que existir um diagrama com uma ou mais interações entre elétrons, haverá outro diagrama quase idêntico, com a única diferença de que uma dessas interações estará rodada em 180 graus, como acontece acima. Esses diagramas possuem a mesma expressão matemática, então só é necessário manter apenas um deles e com isso pode-se cancelar o fator $1 / 2$ que acompanha cada interação eletrônica.

Agora a regra 3 será justificada. Considere um diagrama de ordem $n$, em que há $m$ interações de Coulomb à esquerda do círculo representando $\hat{\delta}$ e $n-m$ à sua direita, como indicado na figura abaixo.

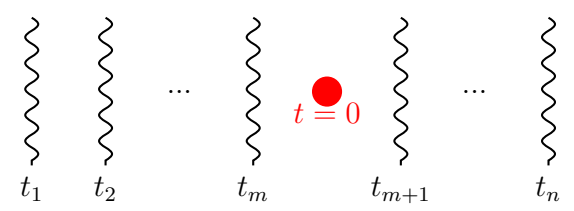

Figura 5.8: Um diagrama de ordem $n$ que tem $m$ interações à esquerda do círculo e $n-m$ à direita. À cada interação associa-se um instante de tempo $t_{i}$.

A expressão associada a esse diagrama pode ser escrita como várias somatórias de produtos de elementos de matriz multiplicados por integrais de contrações. Considerando apenas as integrais, as mesmas podem ser escritas como

$$
\begin{aligned}
\frac{(-i)^{n}}{n !} & \int_{-\infty}^{0} d t_{m} \int_{-\infty}^{t_{m}} d t_{m-1} \cdots \int_{-\infty}^{t_{2}} d t_{1} \\
& \int_{0}^{\infty} d t_{m+1} \int_{t_{m+1}}^{\infty} d t_{m+2} \cdots \int_{t_{n-1}}^{\infty} d t_{n} g\left(t_{1}, \ldots, t_{n}\right),
\end{aligned}
$$

onde a função $g$ representa o produto das várias contrações dos operadores de aniquilação e criação (multiplicado por $\exp \left[-\eta\left(\left|t_{1}\right|+\ldots+\left|t_{n}\right|\right)\right]$ ). Essa função pode ser obtida facilmente olhando para as linhas que ligam as interações e o círculo. Devido ao fato das contrações serem iguais a exponenciais (veja novamente (2.32) e (2.33)), cada linha representa uma exponencial:

$$
\begin{aligned}
& \overrightarrow{t_{1} \longrightarrow t_{2}}=e^{-i \varepsilon_{j}\left(t_{2}-t_{1}\right)}, \\
& \longdiv { \stackrel { a } { ! } \quad t _ { 2 } } = e ^ { i \varepsilon _ { a } ( t _ { 2 } - t _ { 1 } ) },
\end{aligned}
$$

e portanto cada linha ondulada contribui para a função $g$ com um fator $e^{-i \Delta_{j} t_{j}}$, onde $\Delta_{j}$ é igual a soma das energias das linhas que entram na $j$-ésima interação subtraída da soma das energias das linhas que saem desta interação. Assim, as $m$ primeiras integrais que aparecem na expressão 
desse diagrama podem ser escritas como

$$
(-i)^{m} \int_{-\infty}^{0} d t_{m} \cdots \int_{-\infty}^{t_{2}} d t_{1} \prod_{j=1}^{m} e^{-i\left(\Delta_{j}+i \eta\right) t_{j}}
$$

Cada integração fará aparecer um fator no denominador que envolve combinações lineares de energias de orbitais eletrônicos e positrônicos. As integrais, quando calculadas em $-\infty$, terão como resultado zero, por causa da exponencial contendo o $\eta$, que é um infinitesimal positivo. Além disso, à cada integração aparece um fator $-i$ no denominador. Como são realizadas $m$ integrais, o fator final será $(-i)^{m}$, o que cancela o mesmo fator que aparece multiplicando o numerador. O resultado dessas integrações é

$$
\frac{1}{\left(\Delta_{1}+i \eta\right)\left(\Delta_{1}+\Delta_{2}+i \eta\right) \cdots\left(\Delta_{1}+\ldots+\Delta_{m}+i \eta\right)} .
$$

Para justificar a terceira regra, é preciso mostrar que a soma $\Delta_{1}+\ldots+\Delta_{i}$ é igual à soma das energias das linhas de buracos menos as das linhas de partículas que passam entre as interações $t_{i}$ e $t_{i+1}$ (no caso de $i=m$, deve-se considerar as linhas que passam entre a interação $t_{m}$ e o círculo). Considere as linhas que entram e saem da primeira interação que aparece no diagrama. Pela escolha da ordem temporal adotada, a interação $t_{1}$ não possui nenhuma interação à sua esquerda, então as linhas que entram e saem dela devem estar à sua direita, como é indicado na figura 5.9.

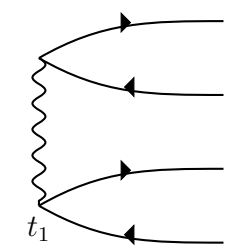

Figura 5.9: A primeira interação do diagrama, considerando o sentido da esquerda para a direita.

As linhas que entram nessa interação então serão necessariamente linhas de buracos, pois apontarão sempre para a esquerda, e as que saem, linhas de partículas, pois apontarão para a direita. Com isso, pode-se dizer que $\Delta_{1}$ é igual a soma das energias das linhas de buracos menos a soma das energias das linhas de partículas que estão entre a interação $t_{1}$ e a interação seguinte, que é a interação $t_{2}$. Para mostrar isso no caso geral, é preciso notar que as energias das linhas que estão à esquerda de uma interação $t_{i}$ e que não passam entre $t_{i}$ e $t_{i+1}$ não contribuem para a soma $\Delta_{1}+\ldots+\Delta_{i}$. Para entender essa propriedade, considere uma linha qualquer $x$, que pode representar tanto um orbital positrônico quanto um eletrônico, virtual ou ocupado, que está á esquerda de $t_{i}$. Então haverá um $\Delta$ em que a energia dessa linha $\varepsilon_{x}$ contribui de forma positiva e outro em que ela contribui de forma negativa, e quando ambos forem somados essas contribuições irão se cancelar. Por exemplo, se a linha $x$ sai de $t_{k}$ e entra em $t_{j}$, como mostrado na figura 5.10, então $\Delta_{j}=+\varepsilon_{x}+\left(\right.$ outros termos) e $\Delta_{k}=-\varepsilon_{x}+(\text { outros termos })^{\prime}$, e na soma $\Delta_{1}+\ldots+\Delta_{i}$ a energia da linha $x$ é cancelada (aqui, se considera $j, k \leq i$ ). 


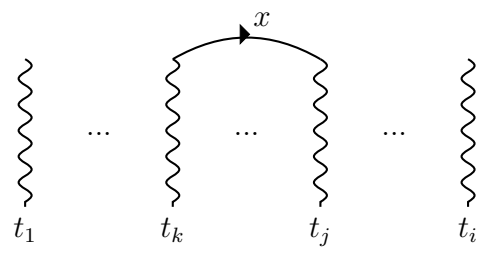

Figura 5.10: As $i$ primeiras linhas do diagrama, onde a linha $t_{j}$ está conectada à linha $t_{k}$.

Este cancelamento ocorrerá para todas as linhas que ligam interações que aparecem à esquerda da interação $t_{i}$ com outras interações também à esquerda de $t_{i}$ ou com a própria interação $t_{i}$. As únicas energias que não são canceladas na soma $\Delta_{1}+\ldots+\Delta_{i}$ são as das linhas que saem de uma interação $t_{j}$, com $j \leq i$, e entram em uma interação $t_{k}$, com $k>i$. Essas linhas necessariamente passarão entre $t_{i}$ e $t_{i+1}$, assim, no cálculo de $\Delta_{1}+\ldots+\Delta_{i}$ devem ser consideradas apenas as energias das linhas que passam entre essas duas interações.

A atenção agora será voltada para as linhas que possuem uma contribuição não nula para $\Delta_{1}+\ldots+\Delta_{i}$. As linhas de partículas (que apontam para a direita) estarão necessariamente saindo de alguma interação à esquerda de $t_{i}$ (ou da própria interação $t_{i}$ ) e portanto aparecerão com um sinal negativo em algum dos $\Delta$. Já as linhas de buracos estarão saindo de uma interação à direita de $t_{i}$, de modo que elas entram em uma das interações à esquerda de $t_{i}$ (ou na própria interação $t_{i}$ ) e portanto estarão presentes em um $\Delta$ com um sinal positivo. Por isso é necessário somar as energias das linhas de buracos e subtrair as de partículas. Além disso, como a energia dos orbitais virtuais é sempre maior que a dos ocupados, os fatores no denominador não podem ser nulos, e portanto é possível excluir os $i \eta$ presentes neles. Isto justifica a regra 3 para as $m$ primeiras integrais.

As $n-m$ integrais restantes correspondem às interações com $t_{j}>0$. Para analisá-las, é conveniente redefinir os $\Delta_{j}$ como a soma das energias das linhas que saem menos a soma das energias das linhas que entram na $j$-ésima interação. Com isso, a contribuição da interação $t_{j}$ para a função $g$ é $e^{i \Delta_{j} t_{j}}$, e a integral fica

$$
(-i)^{n-m} \int_{0}^{\infty} d t_{m+1} \cdots \int_{t_{n-1}}^{\infty} d t_{n} \prod_{j=1}^{n} e^{i\left(\Delta_{j}+i \eta\right) t_{j}}
$$

As integrais irão a zero quando calculadas em $+\infty$, e novamente haverá um fator $-i$ no denominador para cada integração, o que cancela o $(-i)^{n-m}$ no numerador. O resultado de todas as integrações é

$$
\frac{1}{\Delta_{n}\left(\Delta_{n}+\Delta_{n-1}\right) \cdots\left(\Delta_{n}+\ldots+\Delta_{m+1}\right)} .
$$

Deve-se mostrar que $\Delta_{n}+\ldots+\Delta_{j}$ será igual à soma das energias das linhas de buracos menos a de partículas que estão entre as interações $t_{j}$ e $t_{j-1}$ (ou entre $t_{m+1}$ e o círculo, no caso de $j=m+1$ ). Esta demonstração é análoga à anterior. Como as energias das linhas que conectam interações que estão à direita de uma interação $t_{i}$ não contribuem para a soma 
$\Delta_{n}+\ldots+\Delta_{i}$, pois elas sempre serão canceladas, as únicas que devem ser consideradas são as energias das linhas que saem das interações à direita de $t_{i}$ (ou dela própria) e entram nas interações à sua esquerda. Essas linhas passarão necessariamente entre $t_{i}$ e $t_{i-1}$. Dessas, as linhas de orbitais ocupados (que apontam para a esquerda) estarão saindo de uma interação, e portanto contribuirão positivamente para a soma $\Delta_{n}+\ldots+\Delta_{i}$, enquanto as linhas de partículas estarão entrando, tendo então uma contribuição negativa. Com isso, pode-se verificar a validade da terceira regra.

A seguir será mostrado que apenas os diagramas conectados do numerador da expansão de $\delta_{e p}$ precisam ser considerados, pois os desconectados serão cancelados pelo denominador. Um diagrama desconectado do numerador pode ter várias partes não ligadas, entretanto, uma delas sempre conterá o círculo representando o operador $\hat{\delta}$ e será igual a um dos diagramas conectados, e portanto é possível escrever a expressão de um diagrama desconectado como o produto de duas partes, uma delas contendo as contrações que geram o diagrama conectado com o círculo e a outra contendo as contrações que geram o restante do diagrama. Com esta observação, pode-se constatar que a soma de todos os diagramas conectados e desconectados de ordem $n$ do numerador de $\delta_{e p}$ pode ser escrita como

$$
\begin{gathered}
\frac{(-i)^{n}}{n !} \sum_{m=0}^{\infty} \sum_{l=0}^{\infty} \delta_{n, m+l} \frac{n !}{m ! l !} \int_{-\infty}^{\infty} d t_{1} \cdots \int_{-\infty}^{\infty} d t_{m}\left\langle\psi_{0}\left|T\left[\hat{H}_{I}\left(t_{1}\right) \cdots \hat{H}_{I}\left(t_{m}\right) \hat{\delta}\right]\right| \psi_{0}\right\rangle_{c} \\
\int_{-\infty}^{\infty} d t_{1}^{\prime} \cdots \int_{-\infty}^{\infty} d t_{l}^{\prime}\left\langle\psi_{0}\left|T\left[\hat{H}_{I}\left(t_{1}^{\prime}\right) \cdots \hat{H}_{I}\left(t_{l}^{\prime}\right)\right]\right| \psi_{0}\right\rangle,
\end{gathered}
$$

onde o índice $c$ no primeiro valor esperado indica que, ao aplicar o teorema de Wick a ele, deve-se considerar apenas as contrações que geram diagramas conectados.

Vamos agora justificar melhor a equação (5.27). A função delta de Kronecker $\delta_{n, m+l}$ está presente apenas para garantir que o diagrama tenha ordem $n$, já o fator $n ! / m ! l !$ é mais difícil de explicar. Se este fator não existisse, então a expressão acima não geraria todos os diagramas desconectados possíveis. Para entender o motivo disso, primeiro é necessário notar que os operadores $\hat{H}_{I}$ presentes na expressão de um diagrama desconectado podem ser divididos em dois grupos, o grupo das interações que aparecem na parte do diagrama que contém o círculo (que chamaremos de grupo 1) e o grupo das que aparecem no resto do diagrama (grupo 2). Agora construíremos apenas diagramas que não são temporalmente ordenados (ou seja, não dividimos o intervalo de integração). Nesses diagramas, a ordem em que as linhas onduladas e o círculo aprecem não é importante, e sua disposição não altera o valor do diagrama. Assim, ao aplicar o teorema de Wick à expressão acima, nem todos os diagramas desconectados possíveis serão gerados, pois, para cada diagrama desconectado obtido em que a parte conectada com o círculo equivale a um diagrama de ordem $m$, os diagramas que diferem dele apenas pela permutação das interações $\hat{H}_{I}$ do grupo 1 com as do outro grupo 2 não estarão sendo consideradas. Esses diagramas, entretanto, terão todos o mesmo valor, e como há um total de $n ! / m ! l$ ! deles, suas 
contribuições podem ser incluídas multiplicando a expressão por esse fator.

Para obter a adição de todos os diagramas, soma-se a expressão acima sobre todos os $n$ possíveis. O resultado é

$$
\begin{aligned}
\sum_{m=0}^{\infty} \frac{(-i)^{m}}{m !} \int_{-\infty}^{\infty} d t_{1} \cdots \int_{-\infty}^{\infty} d t_{m}\left\langle\psi_{0}\left|T\left[\hat{H}_{I}\left(t_{1}\right) \cdots \hat{H}_{I}\left(t_{m}\right)\right] \hat{\delta}\right| \psi_{0}\right\rangle_{c} \\
\sum_{l=0}^{\infty} \frac{(-1)^{l}}{l !} \int_{-\infty}^{\infty} d t_{1} \cdots \int_{-\infty}^{\infty} d t_{l}\left\langle\psi_{0}\left|T\left[\hat{H}_{I}\left(t_{1}\right) \cdots \hat{H}_{I}\left(t_{l}\right)\right]\right| \psi_{0}\right\rangle .
\end{aligned}
$$

A segunda parte dessa expressão é simplesmente igual ao denominador de $\delta_{e p}$, portanto ambos se cancelam e o que resta são os diagramas conectados do numerador. Esta dedução também se aplica para a função de Green, onde no lugar de $\hat{\delta}$ há os dois operadores de criação e aniquilação.

Agora será deduzido como determinar o sinal do diagrama. O sinal negativo vindo das interações entre elétrons e pósitrons é simplesmente devido ao fato dessa interação ser atrativa, havendo então um sinal - em sua expressão (veja (3.7)). Além disso, adiciona-se um sinal negativo para cada linha de buraco porque a contração entre operadores de criação e aniquilação de orbitais ocupados também possui sinal negativo (veja (2.33)). A regra do loop é mais difícil de deduzir, e aqui será seguida a demonstração apresentada na referência [72]. Para isso, considere um termo de ordem qualquer, com uma determinada contração dos operadores de criação e aniquilação. Como já explicado, o produto $T$ pode ser separado entre um só para os operadores de elétrons e outro para os de pósitrons. Por hora, será considerado apenas o produto $T$ dos operadores de elétrons. Após aplicar o teorema de Wick, esses operadores aparecerão contraídos de alguma forma dentro de um produto $N$. Note que cada interação entre elétrons contribui com dois operadores de criação e dois de aniquilação, enquanto as interações entre elétrons e pósitrons contribuem com um de criação e um de aniquilação. Uma contração qualquer desses operadores será representada por

$$
\overline{\hat{a}_{P_{1}}^{\dagger} \hat{a}_{Q_{1}}^{\dagger} \hat{a}_{S_{1}} \hat{a}_{R_{1}} \cdots \hat{a}_{P_{n}}^{\dagger} \hat{a}_{Q_{n}}^{\dagger} \hat{a}_{S_{n}} \hat{a}_{R_{n}} .}
$$

Por simplicidade, a dependência temporal dos operadores não está sendo escrita, e a barra representa alguma contração possível entre eles. Pela definição do produto $N$, pode-se permutar esses operadores trocando o sinal a cada permutação de dois deles. Assim, é possível reagrupálos de modo que o termo acima se torna

$$
\overline{\hat{a}_{P_{1}}^{\dagger} \hat{a}_{R_{1}} \hat{a}_{Q_{1}}^{\dagger} \hat{a}_{S_{1}} \cdots \hat{a}_{P_{n}}^{\dagger} \hat{a}_{R_{n}} \hat{a}_{Q_{n}}^{\dagger} \hat{a}_{S_{n}} .}
$$

Aqui, todos os operadores $\hat{a}_{R_{i}}$ foram colocados ao lado dos $\hat{a}_{P_{i}}^{\dagger}$. Para isso, é necessário permutar cada $\hat{a}_{R_{i}}$ duas vezes, primeiro com $\hat{a}_{S_{i}}$ e depois com $\hat{a}_{Q_{i}}^{\dagger}$, então o número de permutações é par e o sinal não é alterado. Nos diagramas, em que os operadores são representados por setas 
saindo das linhas onduladas, $\hat{a}_{R_{i}}$ e $\hat{a}_{P_{i}}^{\dagger}$ pertencem ao mesmo vértice, ou seja, $\hat{a}_{R_{i}}$ é a linha que entra numa das pontas de uma interação e $\hat{a}_{P_{i}}^{\dagger}$ é a linha que sai dessa mesma ponta, enquanto $\hat{a}_{S_{i}}$ e $\hat{a}_{Q_{i}}^{\dagger}$ são as linhas que entram e saem da outra ponta (veja a figura 5.1). Dois operadores $\hat{a}$ e $\hat{a}^{\dagger}$ que entram e saem da mesma ponta de uma interação (como $\hat{a}_{R_{i}}$ e $\hat{a}_{P_{i}}^{\dagger}$ ou $\hat{a}_{S_{i}}$ e $\hat{a}_{Q_{i}}^{\dagger}$ ) são chamados de coincidentes, e denotados por $\underbrace{\hat{a} \hat{a}^{\dagger}}$. Assim, na expressão acima os pares de operadores coincidentes estão agrupados um ao lado do outro. O operador de aniquilação e o de criação de elétrons vindos das interações elétron-pósitron e do círculo $\hat{\delta}$ são coincidentes e já estão agrupados juntos.

Para demonstrar a regra, deve-se observar que qualquer loop fechado é o resultado de contrações que só envolvem pares de operadores coincidentes. Então pode-se agrupar todos os pares de operadores coincidentes de um mesmo loop um ao lado do outro, o que não altera o sinal, pois para isso é necessário fazer um número par de permutações (trocar de lugar dois pares de operadores nunca altera o sinal, independente de onde estão esses pares). Assim, é possível escrever (5.30) como o produto das contribuições dos diversos loops do diagrama:

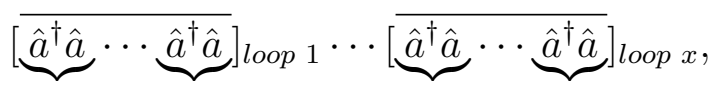

onde, por simplicidade, não indica-se mais os índices dos operadores. No que segue, considere contrações de um único loop. Escolhendo uma contração qualquer em que o operador de criação está à esquerda do de aniquilação e a colocando à direita dos outros operadores, se obtém

$$
\overline{\hat{a}^{\dagger} \hat{a}} \cdots \hat{a}_{3} \cdots \hat{a}_{4}^{\dagger} \cdots \underbrace{\hat{a}^{\dagger} \hat{a}} a_{1}^{\dagger} a_{2} .
$$

Essas permutações também não alteram o sinal. Como em um loop não ocorre contração entre dois operadores coincidentes (se ocorresse, o loop seria formado por apenas uma contração e este diagrama seria excluído pelo uso da partição de MP, como será mostrado a seguir), ao retirar essa contração haverá dois operadores sem seus pares coincidentes. Um deles será de criação (que acima foi chamado de $\hat{a}_{4}^{\dagger}$ ) e o outro de aniquilação $\left(\hat{a}_{3}\right)$. Neste caso, $\hat{a}_{3}$ seria o operador coincidente de $\hat{a}_{1}^{\dagger}$ e $\hat{a}_{4}^{\dagger} \mathrm{o}$ de $\hat{a}_{2}$. Coloca-se então o operador de criação à direita de todos os outros operadores, e o de aniquilação à esquerda:

$$
\overline{\hat{a}_{3} \underbrace{\hat{a}^{\dagger} \hat{a}} \cdots \underbrace{\hat{a}^{\dagger} \hat{a}} \hat{a}_{4}^{\dagger}} \bar{a}_{1}^{\dagger} a_{2} .
$$

Mais uma vez, o sinal não é alterado, pois realiza-se um número par de permutações. $\mathrm{O}$ operador de criação $\hat{a}_{4}^{\dagger}$ na equação acima estará necessariamente contraído com algum operador de aniquilação à sua esquerda. Novamente é possível remover essa contração, fazendo com que mais um operador de criação fique sem seu par, e colocá-lo à direita de todos os outros operadores sem alterar o sinal, obtendo assim

$$
\overline{\hat{a}_{3} \underbrace{\hat{a}^{\dagger} \hat{a}} \cdots \underbrace{\hat{a}^{\dagger} \hat{a}} \hat{a}_{6}^{\dagger}} \square_{5} a_{4}^{\dagger} \bigcap_{1}^{\dagger} a_{2} .
$$


Repetindo o procedimento até que todas as contrações tenham sido retiradas e postas lado a lado, chega-se a

$$
\square_{3} a_{x}^{\dagger} \square_{y} a_{z}^{\dagger} \cdots a_{5} a_{4}^{\dagger} \prod_{1}^{\dagger} a_{2} .
$$

Em todas as contrações o operador de criação está à direita do de aniquilação, exceto na última, em que eles aparecem invertidos. Utilizando a propriedade da contração de que inverter a ordem dos operadores altera o sinal, pode-se escrever

$$
-a_{3} a_{x}^{\dagger} a_{y} a_{z}^{\dagger} \cdots a_{5} a_{4}^{\dagger} a_{2} a_{1}^{\dagger}
$$

Com isso, a contribuição de cada loop pode ser escrita como o produto das diferentes contrações dadas pelas expressões (2.32) e (2.33) multiplicado por -1. Decorre que cada loop contribui com um sinal negativo para a expressão final do diagrama. A mesma prova se aplica aos operadores de pósitrons. Isto conclui a demonstração da regra do sinal do diagrama.

Por fim, será discutido o que acontece quando se adota a partição de MP. A aproximação Hartree-Fock pode ser generalizada para incluir o pósitron [37, 51]. Neste caso, usa-se uma função tentativa com a forma de (3.4) para minimizar a hamiltoniana (3.1), o que implica que os spins-orbitais de elétrons e pósitrons devem ser autofunções de determinados operadores:

$$
\begin{gathered}
\hat{f}^{(-)}(i) \varphi_{P}\left(\boldsymbol{x}_{i}\right)=\left[\hat{h}_{0}^{(-)}(i)+\sum_{A}\left(\hat{J}_{A}(i)-\hat{K}_{A}(i)\right)-\hat{J}_{a}(i)\right] \varphi_{P}\left(\boldsymbol{x}_{i}\right)=\varepsilon_{P} \varphi_{P}\left(\boldsymbol{x}_{i}\right), \\
\hat{f}^{(+)}(i) \varphi_{p}\left(\boldsymbol{x}_{i}\right)=\left[\hat{h}_{0}^{(+)}(i)-\sum_{A} \hat{J}_{A}(i)\right] \varphi_{p}\left(\boldsymbol{x}_{i}\right)=\varepsilon_{p} \varphi_{p}\left(\boldsymbol{x}_{i}\right) .
\end{gathered}
$$

O sinal negativo se refere ao elétron, e o positivo ao pósitron. Aqui, $\hat{h}_{0}$ é igual a energia cinética da partícula em questão somada a sua interação com os núcleos, enquanto $\hat{J}$ e $\hat{K}$ são os já citados operadores de Coulomb e Troca.

De maneira análoga ao que foi feito no capítulo 2, é possível somar termos à hamiltoniana do sistema de modo que se possa redefinir $\hat{H}_{0}$ como a soma dos operadores de Fock para elétrons e o pósitron. Com essa escolha, os orbitais $\varphi_{p}$ e $\varphi_{P}$ utilizados nas expressões dos diagramas passam a ser orbitais HF e a interação do sistema se torna

$$
\begin{aligned}
\hat{H}_{I}^{\prime}= & \hat{H}_{I}-\sum_{A, P, Q}\langle P, A|| Q, A\rangle \hat{a}_{P}^{\dagger} \hat{a}_{Q}+\sum_{a}\langle P, a|V| Q, a\rangle \hat{a}_{P}^{\dagger} \hat{a}_{Q} \\
& -\sum_{A}\langle p, A|V| q, A\rangle \hat{a}_{p}^{\dagger} \hat{a}_{q},
\end{aligned}
$$

onde $\langle P, A|| Q, A\rangle=\langle P, A|V| Q, A\rangle-\langle P, A|V| A, Q\rangle$ e $\hat{H}_{I}$ é dado por (3.7). Para representar 
esses novos termos, novos símbolos serão introduzidos para serem utilizados nos diagramas:

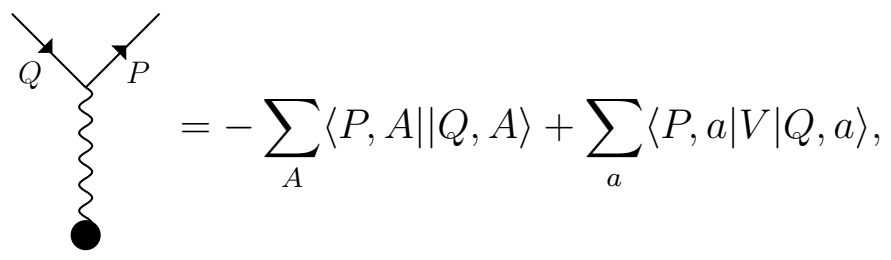

$\mathrm{e}$

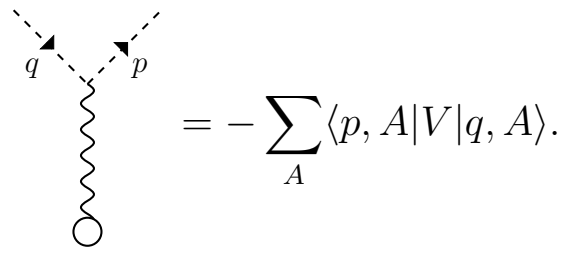

O método de construção dos diagramas continua o mesmo. As linhas onduladas são dispostas lado a lado junto com o círculo de várias maneiras diferentes, alternando a ordem em que aparecem, e suas linhas conectadas. Antes, cada linha ondulada poderia representar uma interação elétron-elétron ou elétron-pósitron, e ambos os casos deveriam ser considerados. Agora, cada linha ondulada também pode representar uma das duas interações acima, referentes aos potenciais HF (para elétrons e o pósitron), havendo portanto quatro possibilidades para se levar em conta no presente caso.

O que será mostrado agora é que os diagramas que contém as interações (5.40) e (5.41) irão se cancelar com as expressões associadas a outros tipos de diagramas. Esses outros diagramas são precisamente aqueles que contêm no mínimo uma das ligações mostradas na figura 5.5. Para explicar o motivo disso, serão utilizados como exemplo os diagramas da figura 5.11.
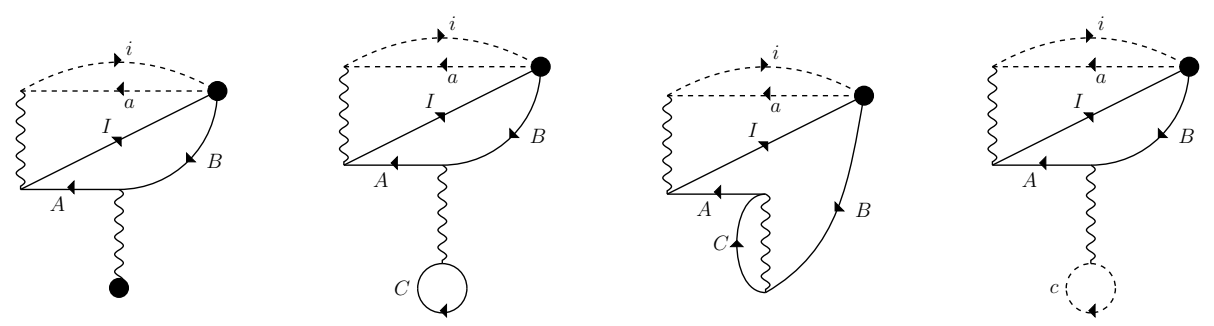

Figura 5.11: Exemplo de diagramas que irão se cancelar quando somados.

O primeiro diagrama possui uma interação (5.40), enquanto os outros diferem dele por terem no lugar dessa interação uma das três primeiras ligações que aparecem na figura 5.5. Esses diagramas serão somados. Por serem semelhantes, a maior parte das suas expressões será igual, o que permite fatorá-las, deixando em evidência a soma das expressões das parcelas que os diferem. Essa soma pode ser escrita como

$$
\sum_{a, i, A, B, I} \frac{\langle i, I|V| a, A\rangle\langle a, B|\delta| i, I\rangle}{\left(\varepsilon_{a}+\varepsilon_{A}-\varepsilon_{i}-\varepsilon_{I}\right)\left(\varepsilon_{a}+\varepsilon_{B}-\varepsilon_{i}-\varepsilon_{I}\right)} X_{A B},
$$

onde 


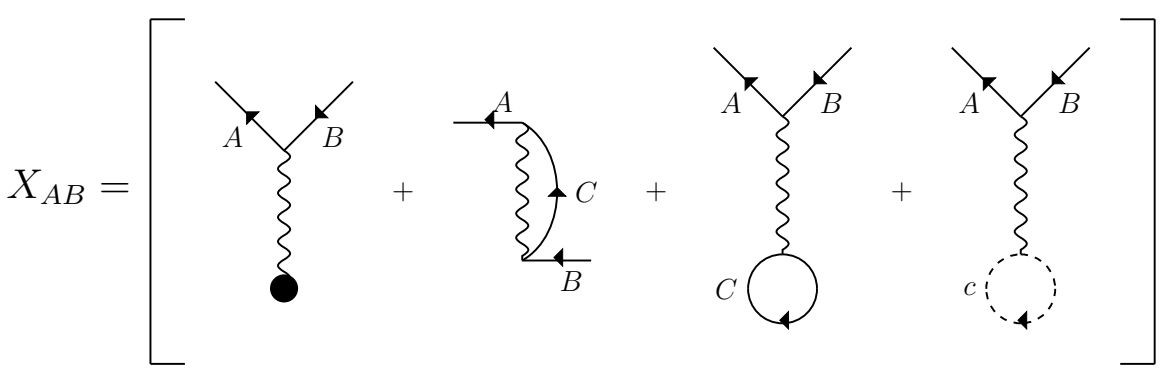

Em $X_{A B}$, cada interação representa elementos de matriz. Pela equação (5.40), a primeira contribui com $-\sum_{C}\langle A, C|V| B, C\rangle+\sum_{C}\langle A, C|V| C, B\rangle+\sum_{c}\langle A, c|V| B, c\rangle$. Enquanto isso, pelas regras para diagramas, pode-se deduzir que a segunda contribui com $-\sum_{C}\langle A, C|V| C, B\rangle$ (o sinal negativo é devido ao fato de haver um orbital ocupado, a linha $C$ ). Já a terceira e a quarta contribuirão com $\sum_{C}\langle A, C|V| B, C\rangle$ e $\sum_{c}-\langle A, c|V| B, c\rangle$, respectivamente. A contribuição da terceira é positiva, pois há um buraco e um loop, enquanto a da quarta é negativa, porque, além do loop e da linha buraco, essa é uma interação elétron-pósitron. Somando essas quantidades, constata-se que o resultado final é zero, então os diagramas se anulam, e é possível escrever
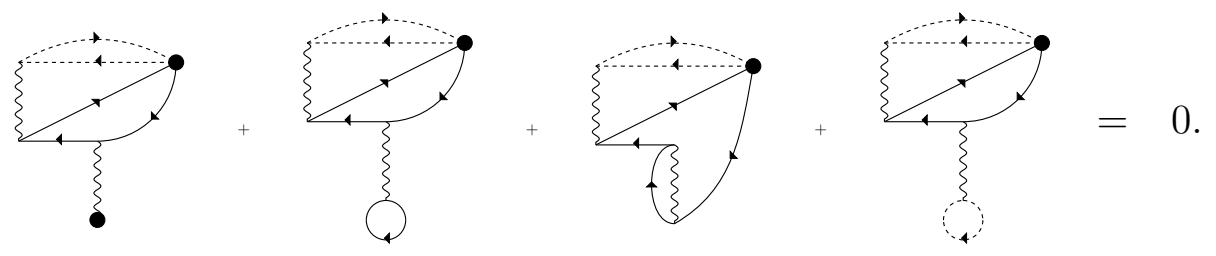

De maneira geral, a seguinte relação será válida
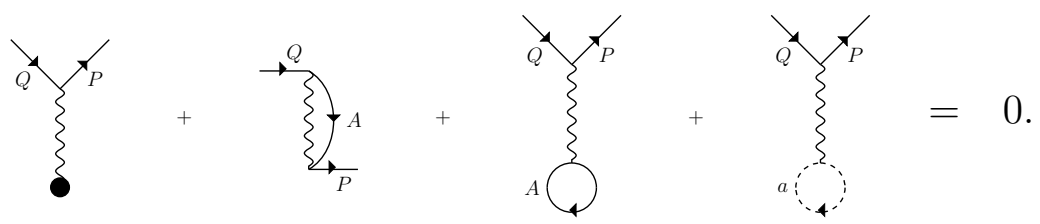

Para cada diagrama com no mínimo uma das interações acima, haverá outros três diagramas quase idênticos a ele, diferindo apenas por apresentarem, no lugar dessa interação, uma das outras três. Assim, quando somados, pode-se colocar a soma dessas contribuições em evidência e portanto o resultado será zero. O mesmo acontece para o potencial Hartree-Fock do pósitron. Seguindo a mesma lógica
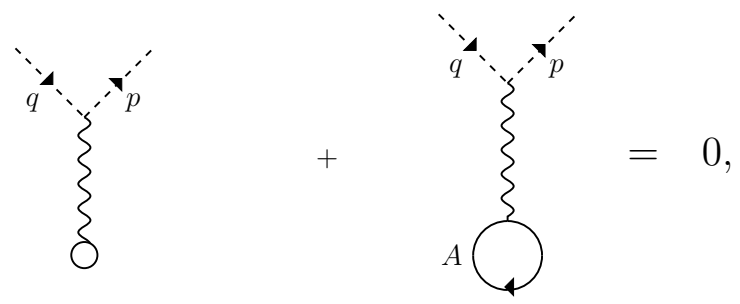

o que também elimina alguns diagramas. Assim, o uso da partição de MP simplifica consideravelmente o número de diagramas necessários. 


\subsection{Soma de diagramas}

Os diagramas obtidos na seção anterior possuem expressões semelhantes às da auto-energia, como pode-se perceber ao comparar os diagramas mostrados no apêndice com as expressões (4.20) e (4.21) apresentadas no capítulo anterior. A principal diferença está no fato de os diagramas de $\delta_{e p}$ possuírem uma somatória a mais e não dependerem da energia, além de que em um de seus elementos de matriz há uma função delta de Dirac no lugar de uma interação de Coulomb, o que simplifica a integração. Devido a isso, acredita-se que a implementação numérica desses diagramas no LOWDIN não deve ser difícil.

Como já mencionado, na prática a auto-energia só pode ser calculada até a terceira ordem, devido ao alto custo computacional, e portanto se espera que a mesma limitação se aplique ao cálculo das taxas de aniquilação, implicando que apenas os termos de ordens mais baixas possam ser computados. Assim, a princípio $\delta_{e p}$ será escrito apenas até a segunda ordem

$$
\delta_{e p} \approx \delta_{e p}^{(0)}+\delta_{e p}^{(1)}+\delta_{e p}^{(2)} .
$$

Para melhorar essa aproximação, é possível somar infinitos diagramas de forma semelhante à apresentada no capítulo anterior para o termo tipo Ps virtual. Por exemplo, a soma de todos os diagramas semelhantes ao diagrama de primeira ordem (5.13), que possuem uma ou mais interações elétron-pósitron no seu centro, pode ser escrita como
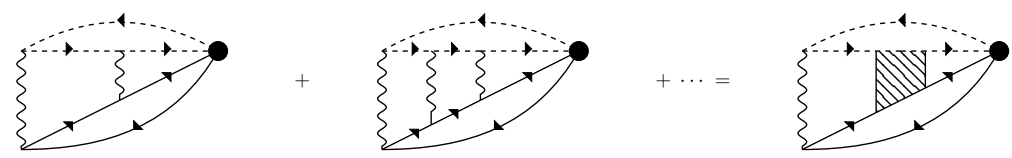

O diagrama no lado direito da série acima pode ser calculado através de

$$
-\sum_{\substack{a, b, i \\ A, I, J}} \frac{\langle i, I|V| a, A\rangle\left\langle j, J\left|\Gamma_{a, A}\right| i, I\right\rangle\langle a, A|\delta| j, J\rangle}{\left(\varepsilon_{a}+\varepsilon_{A}-\varepsilon_{i}-\varepsilon_{I}\right)\left(\varepsilon_{a}+\varepsilon_{A}-\varepsilon_{j}-\varepsilon_{J}\right)} .
$$

No presente caso, a interação representada pela região hachurada não será dependente da energia $E$. Seguindo o mesmo desenvolvimento apresentado no capítulo 3, o elemento de matriz dessa interação deve obedecer a equação

$$
-\left\langle j, J\left|\Gamma_{a, A}\right| i, I\right\rangle=\langle j, J|V| i, I\rangle+\sum_{k, K} \frac{\langle j, J|V| k, K\rangle\left\langle k, K\left|\Gamma_{a, A}\right| i, I\right\rangle}{\varepsilon_{a}+\varepsilon_{A}-\varepsilon_{k}-\varepsilon_{K}},
$$

o que permite calculá-lo usando a equação (3.22), com a diferença de que a matriz $\boldsymbol{E}$ agora será dada por

$$
E_{k, K ; k^{\prime}, K^{\prime}}=E_{\lambda, \lambda^{\prime}}=\frac{\delta_{\lambda, \lambda^{\prime}}}{\varepsilon_{a}+\varepsilon_{A}-\varepsilon_{k}-\varepsilon_{K}}
$$

Também é possível realizar outros tipos de somas de diagramas, e assim melhorar ainda mais a aproximação já existente. 


\subsection{Energia de correlação}

Pode-se utilizar diagramas semelhantes aos apresentados anteriormente para o cálculo das taxas de aniquilação para obter a energia do estado fundamental do sistema molécula-pósitron. O conhecimento dessa energia pode ser útil para, por exemplo, calcular energias de ligação do pósitron sem recorrer à auto-energia. Como antes, o uso dos diagramas facilita computar os termos de ordens mais altas, e também permite somar alguns deles em ordem infinita, o que deve melhorar significativamente a aproximação. O que é apresentado aqui é uma generalização do método descrito, por exemplo, no capítulo 12 da referência [46].

O estado fundamental exato do sistema satisfaz a equação de Schrodinger independente do tempo:

$$
\hat{H}\left|\Psi_{0}\right\rangle=E_{0}\left|\Psi_{0}\right\rangle \text {. }
$$

Usando o estado do sistema não interagente $\psi_{0}$, a energia do estado fundamental pode ser escrita como

$$
E_{0}=\frac{\left\langle\psi_{0}|\hat{H}| \Psi_{0}\right\rangle}{\left\langle\psi_{0} \mid \Psi_{0}\right\rangle}
$$

Recordando que $\hat{H}=\hat{H}_{0}+\hat{H}_{I}$, e que $\psi_{0}$ é um auto-estado de $\hat{H}_{0}$ com autovalor $E_{0}^{(0)}$, é possível escrever a energia de correlação, que é a diferença entre $E_{0}$ e $E_{0}^{(0)}$, como

$$
E_{\text {cor }}=\frac{\left\langle\psi_{0}\left|\hat{H}_{I}\right| \Psi_{0}\right\rangle}{\left\langle\psi_{0} \mid \Psi_{0}\right\rangle} .
$$

Usando novamente o teorema de Gell-Mann e Low, se obtém

$$
E_{c o r}=\frac{\left\langle\psi_{0}\left|\hat{H}_{I} \hat{U}_{\eta}(0,-\infty)\right| \psi_{0}\right\rangle}{\left\langle\psi_{0}\left|\hat{U}_{\eta}(0,-\infty)\right| \psi_{0}\right\rangle} .
$$

Note que $\hat{U}_{\eta}$ é o operador de evolução temporal na representação de interação para um sistema descrito por uma hamiltoniana dependente do tempo dada por $\hat{H}(t)=\hat{H}_{0}+e^{-\eta|t|} \hat{H}_{I}=\hat{H}_{0}+$ $\hat{H}_{I}(t)$, e portanto satisfaz a equação

$$
i \frac{d}{d t} \hat{U}_{\eta}\left(t, t_{0}\right)=\hat{H}_{I}(t) \hat{U}_{\eta}\left(t, t_{0}\right),
$$

o que permite reescrever a equação (5.55) na forma

$$
E_{c o r}=i\left[\frac{d}{d t} \ln \left\langle\psi_{0}\left|\hat{U}_{\eta}(t,-\infty)\right| \psi_{0}\right\rangle\right]_{t=0} .
$$

A relação acima, apesar de parecer complexa, possibilita expressar a energia de correlação utilizando diagramas iguais aos utilizados para o denominador da função de Green. Entretanto, no presente caso haverá alguns diagramas adicionais, em que aparecem interações de elétrons 
com o pósitron. Assim, os diagramas para $E_{\text {cor }}$ são iguais aos diagramas para o denominador da função de Green somados aos mesmos diagramas com uma ou mais das interações de Coulomb substituídas por uma interação elétron-pósitron. Alguns dos novos diagramas que contribuem para a energia de correlação são mostrados na figura 5.12.
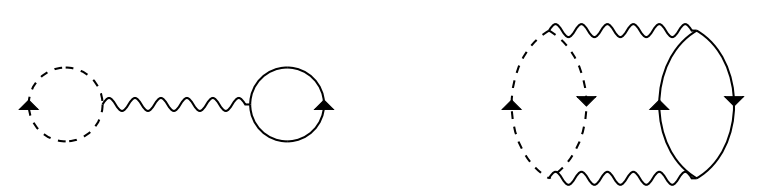

Figura 5.12: Alguns diagramas possíveis para a energia de correlação.

Também podem ocorrer, a partir da segunda ordem, diagramas desconectados, como os que aparecem na figura 5.13. Porém, como será mostrado a seguir, é possível escrever a energia de correlação utilizando apenas os diagramas conectados.

Para tanto, deve-se notar que as partes desconectadas de um diagrama desconectado são iguais à diagramas conectados de ordens menores. Isso permite afirmar que a expressão de um diagrama desconectado é proporcional ao produto das expressões dos diagramas conectados que o formam. Considere a soma de todos os diagramas de ordem $n$ que possuem duas partes desconectadas. Essa soma pode ser escrita como

$$
\begin{array}{r}
\frac{1}{2} \frac{(-i)^{n}}{n !} \sum_{m=1}^{\infty} \sum_{l=1}^{\infty} \delta_{n, m+l} \frac{n !}{m ! l !} \int_{-\infty}^{t} d t_{1} \cdots \int_{-\infty}^{t} d t_{m}\left\langle\psi_{0}\left|T\left[H_{I}\left(t_{1}\right) \cdots H_{I}\left(t_{m}\right)\right]\right| \psi_{0}\right\rangle_{c} \\
\int_{-\infty}^{t} d t_{1}^{\prime} \cdots \int_{-\infty}^{t} d t_{l}^{\prime}\left\langle\psi_{0}\left|T\left[H_{I}\left(t_{1}^{\prime}\right) \cdots H_{I}\left(t_{l}\right)^{\prime}\right]\right| \psi_{0}\right\rangle_{c} .
\end{array}
$$

A expressão (5.58) segue a mesma lógica usada para demonstrar que os diagramas desconectados do numerador de $\delta_{e p}$ se cancelam com os do denominador. Entretanto, aqui o resultado está sendo dividido por 2, pois cada diagrama desconectado está sendo considerado duas vezes. Para obter a soma de todos os diagramas desconectados com duas partes, deve-se somar sobre todos os $n \geq 2$ possíveis:
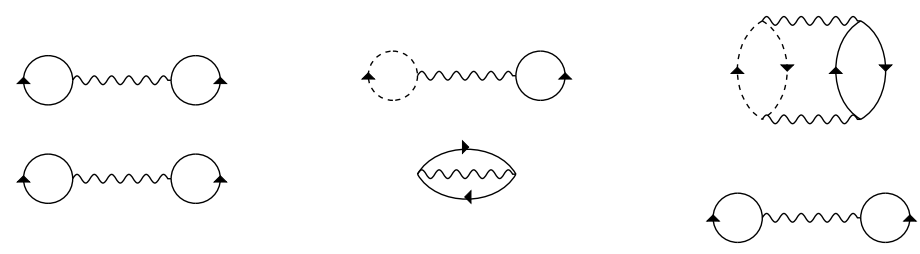

Figura 5.13: Alguns diagramas desconectados da energia de correlação. 


$$
\begin{aligned}
\frac{1}{2} \sum_{m=1}^{\infty} \frac{(-i)^{m}}{m !} \int_{-\infty}^{t} d t_{1} \cdots \int_{-\infty}^{t} d t_{m}\left\langle\psi_{0}\left|T\left[\hat{H}_{I}\left(t_{1}\right) \cdots \hat{H}_{I}\left(t_{m}\right)\right]\right| \psi_{0}\right\rangle_{c} \\
\sum_{l=1}^{\infty} \frac{(-i)^{l}}{l !} \int_{-\infty}^{t} d t_{1} \cdots \int_{-\infty}^{t} d t_{l}\left\langle\psi_{0}\left|T\left[\hat{H}_{I}\left(t_{1}\right) \cdots \hat{H}_{I}\left(t_{l}\right)\right]\right| \psi_{0}\right\rangle_{c} .
\end{aligned}
$$

Generalizando, pode-se dizer que a soma de todos os diagramas desconectados com $k$ partes conectadas é igual a

$$
\frac{1}{k !}\left(\sum_{m=1}^{\infty} \frac{(-i)^{m}}{m !} \int_{-\infty}^{t} d t_{1} \cdots \int_{-\infty}^{t} d t_{m}\left\langle\psi_{0}\left|T\left[\hat{H}_{I}\left(t_{1}\right) \cdots \hat{H}_{I}\left(t_{m}\right)\right]\right| \psi_{0}\right\rangle_{c}\right)^{k}=\frac{L(t)^{k}}{k !}
$$

Aqui, $L(t)$ é a soma de todos os diagramas conectados. Agora, note que a soma de todos os diagramas é igual à um mais a soma dos diagramas conectados, mais a dos diagramas desconectados com duas partes conectadas, mais os desconectados com três partes conectadas, e assim por diante. Então, pode-se escrever

$$
\left\langle\psi_{0}|\hat{U}(t,-\infty)| \psi_{0}\right\rangle=1+L(t)+\frac{L(t)^{2}}{2}+\ldots=\sum_{k=0}^{\infty} \frac{L(t)^{k}}{k !}=e^{L(t)} .
$$

Substituindo esse resultado na expressão (5.57), se obtém

$$
E_{c o r}=i\left[\frac{\mathrm{d} L(t)}{\mathrm{d} t}\right]_{t=0}
$$

o que conclui a demonstração. As regras para computar as expressões associadas aos diagramas para a energia de correlação são iguais às utilizadas para os diagramas de $\delta_{e p}$. A única diferença é que, se o diagrama em questão tiver apenas interações entre elétrons e for simétrico em relação à uma linha vertical que o divide ao meio, deve-se adicionar um fator $1 / 2$ a sua expressão (o sentido das linhas orientadas que ligam as interações deve ser considerado ao tentar determinar se o diagrama é ou não simétrico). Por exemplo, os dois primeiros diagramas que aparecem na equação (5.66) possuem essa simetria. Essa última regra se deve ao fato de que, nesses casos, um dos fatores $1 / 2$ vindos das interações de Coulomb entre elétrons não será cancelado invertendo uma das linhas onduladas do diagrama (como foi discutido na seção 5.3), pois inverter todas as interações do diagrama gera exatamente o mesmo diagrama.

A demonstração e justificativa das regras para determinar o sinal e o numerador desses diagramas são iguais às já apresentadas. Aqui será demonstrada apenas a regra para obter o denominador da expressão do diagrama, pois a sua justificativa difere da apresentada para os diagramas das taxas de aniquilação. A expressão associada a um diagrama temporalmente ordenado de ordem $n$ é igual a 


$$
i \frac{d}{d t}\left[(-i)^{n} \int_{-\infty}^{t} d t_{n} \cdots \int_{-\infty}^{t_{2}} d t_{1} \prod_{j=1}^{m} e^{-i\left(\Delta_{j}+i \eta\right) t_{j}}\right]
$$

calculada em $t=0$. Após realizar todas as integrações exceto a última, o resultado é

$$
\frac{d}{d t} \frac{1}{\left(\Delta_{1}\right)\left(\Delta_{1}+\Delta_{2}\right) \cdots\left(\Delta_{1}+\ldots+\Delta_{n-1}\right)} \int_{-\infty}^{t} d t_{n} e^{\eta t_{n}} e^{-i\left(\Delta_{1}+\ldots+\Delta_{n}\right) t_{n}}
$$

Na expressão acima a soma $\Delta_{1}+\ldots+\Delta_{n}$ será igual a zero. Isso ocorre porque uma linha qualquer do diagrama sempre contribuirá com uma energia positiva para um $\Delta$ e com uma energia negativa para outro, pois ela entra e sai de duas interações do diagrama, e portanto essas contribuições se cancelarão quando todos os $\Delta$ forem somados. Assim, a integral acima será igual a $e^{\eta t} / \eta$. Derivando e calculando o resultado em $t=0$, se chega a

$$
\frac{1}{\Delta_{1}\left(\Delta_{1}+\Delta_{2}\right) \cdots\left(\Delta_{1}+\ldots+\Delta_{n-1}\right)},
$$

e como foi demonstrado anteriormente, $\Delta_{1}+\ldots+\Delta_{j}$ é igual a soma das energias das linhas de buraco menos às das linhas de partícula que passam entre $t_{j}$ e $t_{j+1}$, o que conclui a demonstração da regra para determinar o denominador.

Como antes, se adotará a soma dos operadores de Fock como hamiltoniana não perturbada, o que cancela todos os diagramas que possuem interações ligadas a si mesmas, eliminando assim os termos de ordem um. Então a contribuição para a energia de correlação começa na segunda ordem, sendo dada por

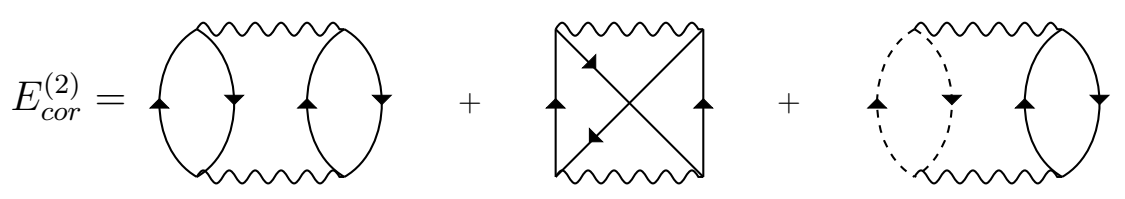

Aplicando as regras para diagramas, se obtém

$$
\begin{aligned}
E_{c o r}^{(2)}= & \frac{1}{2} \sum_{A, B, I, J} \frac{\langle A, B|V| I, J\rangle\langle I, J|V| A, B\rangle}{\varepsilon_{A}+\varepsilon_{B}-\varepsilon_{I}-\varepsilon_{J}}+ \\
& -\frac{1}{2} \sum_{A, B, I, J} \frac{\langle A, B|V| I, J\rangle\langle I, J|V| B, A\rangle}{\varepsilon_{A}+\varepsilon_{B}-\varepsilon_{I}-\varepsilon_{J}}+ \\
& +\sum_{a, i, A, I} \frac{\langle a, A|V| i, I\rangle\langle i, I|V| a, A\rangle}{\varepsilon_{a}+\varepsilon_{A}-\varepsilon_{i}-\varepsilon_{I}}
\end{aligned}
$$

No presente caso também é possível somar os diagramas com interações de um pósitron com um elétron em um orbital virtual aparecendo no centro do diagrama. O resultado é 


$$
\left\{\begin{array}{c}
{ }^{-\cdots} \\
\longrightarrow
\end{array}=\sum_{\substack{a, i, j \\
A, I, J}} \frac{\langle i, I|V| a, A\rangle\left\langle i, I\left|\Gamma_{a, A}\right| j, J\right\rangle\langle a, A|V| j, J\rangle}{\left(\varepsilon_{a}+\varepsilon_{A}-\varepsilon_{i}-\varepsilon_{I}\right)\left(\varepsilon_{a}+\varepsilon_{A}-\varepsilon_{j}-\varepsilon_{J}\right)}\right.
$$

A inclusão desse termo deve ser importante para obter uma melhor aproximação para a energia de correlação. Com o uso de diagramas, também é possível incluir termos de terceira ordem e até de ordens mais altas, assim como performar outros tipos de somas infinitas. 


\section{Conclusões e Perspectivas}

A definição da função de Green para o pósitron utilizada pela teoria APMO é diferente da de outros autores. Isto leva à diferenças nas expressões das auto-energias obtidas através da equação de Dyson, entretanto, ambas podem ser utilizadas para computar a energia de ligação do pósitron. Neste trabalho, foi mostrado que o método OVGF, quando generalizado para a auto-energia de um pósitron em um sistema contendo vários elétrons, desconsidera vários termos importantes. Entretanto, com uma modificação simples do resultado final do método, é possível incluir tais termos na aproximação feita. Correções foram propostas para a versão A, B e a versão REN/PP3. Espera-se que, com essas modificações, o cálculo de energias de ligação usando propagadores seja melhorado e que tais resultados possam ajudar a entender melhor a física na interação de pósitrons em baixas energias com moléculas.

$\mathrm{Na}$ segunda parte desta dissertação, foi proposta uma expansão perturbativa das taxas de aniquilação para estados ligados de pósitrons em moléculas, o que permite calcular o tempo de vida de tais sistemas em relação a aniquilação. Foi mostrado como a aproximação pode ser melhorada somando infinitos termos representados por diagramas. Este resultado também pode ser utilizado para calcular taxas de aniquilação de pósitrons em gases moleculares, entretanto, devido às aproximações feitas, isso só seria aplicável para moléculas com um único modo vibracional.

O mesmo método foi aplicado para computar a energia de correlação do sistema moléculapósitron através do uso de diagramas, o que possibilita uma outra maneira de calcular energias de ligação, assim como a energia do estado fundamental do sistema. Mais uma vez, a aproximação feita pode ser melhorada através da soma de diagramas. Também espera-se que no futuro as fórmulas apresentadas aqui possam ser implementadas no código LOWDIN, possibilitando assim estudar mais propriedades de sistemas moleculares positrônicos. 


\section{Apêndice A}

\section{Diagramas de segunda ordem}

Abaixo são mostrados os diagramas de segunda ordem para $\delta_{e p}$ e suas respectivas expressões.
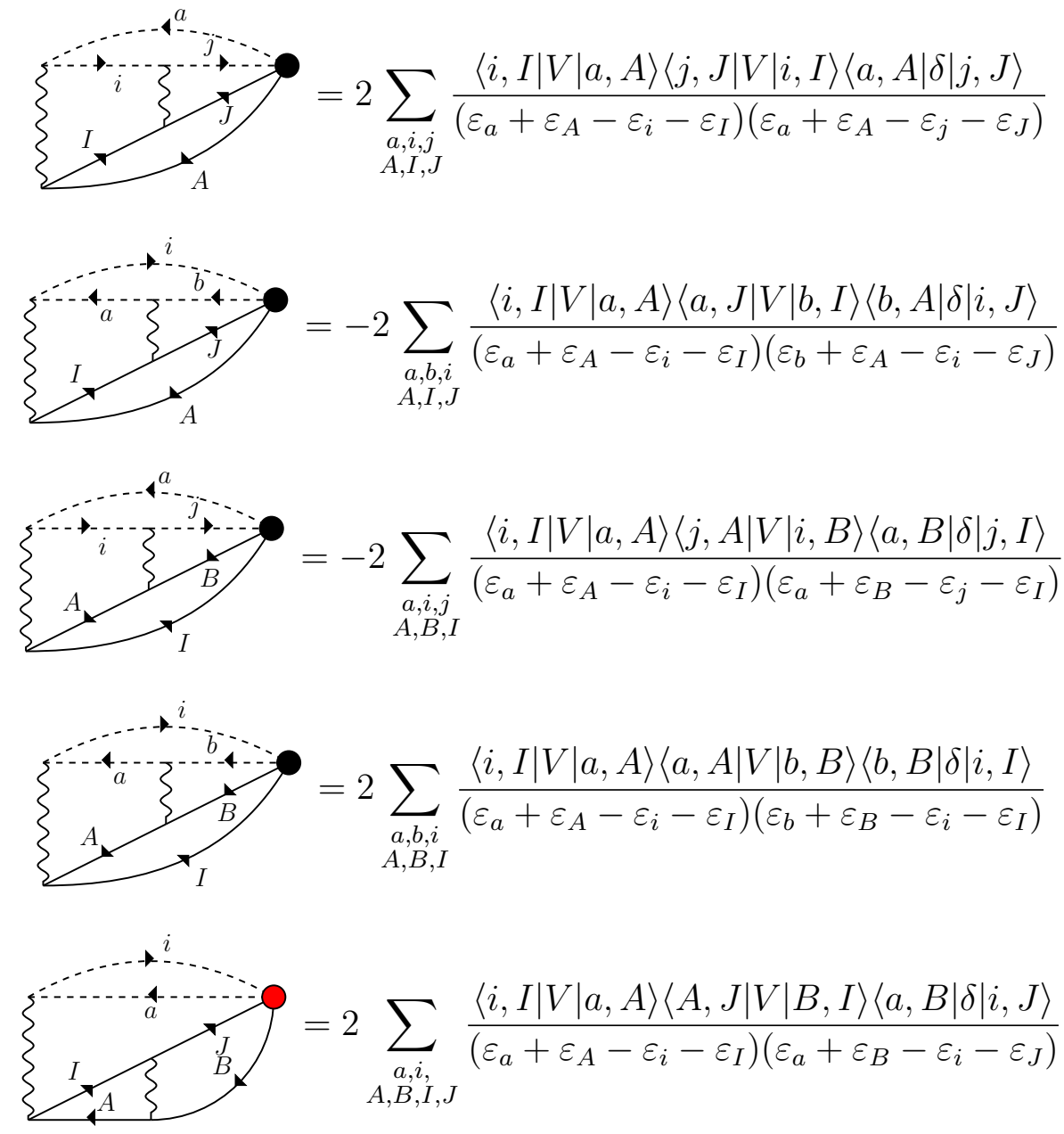

$\underbrace{I}_{A} \sum_{B}=-2 \sum_{\substack{a, i, A, B, I, J}} \frac{\langle i, I|V| a, A\rangle\langle A, J|V| I, B\rangle\langle a, B|\delta| i, J\rangle}{\left(\varepsilon_{a}+\varepsilon_{A}-\varepsilon_{i}-\varepsilon_{I}\right)\left(\varepsilon_{a}+\varepsilon_{B}-\varepsilon_{i}-\varepsilon_{J}\right)}$ 

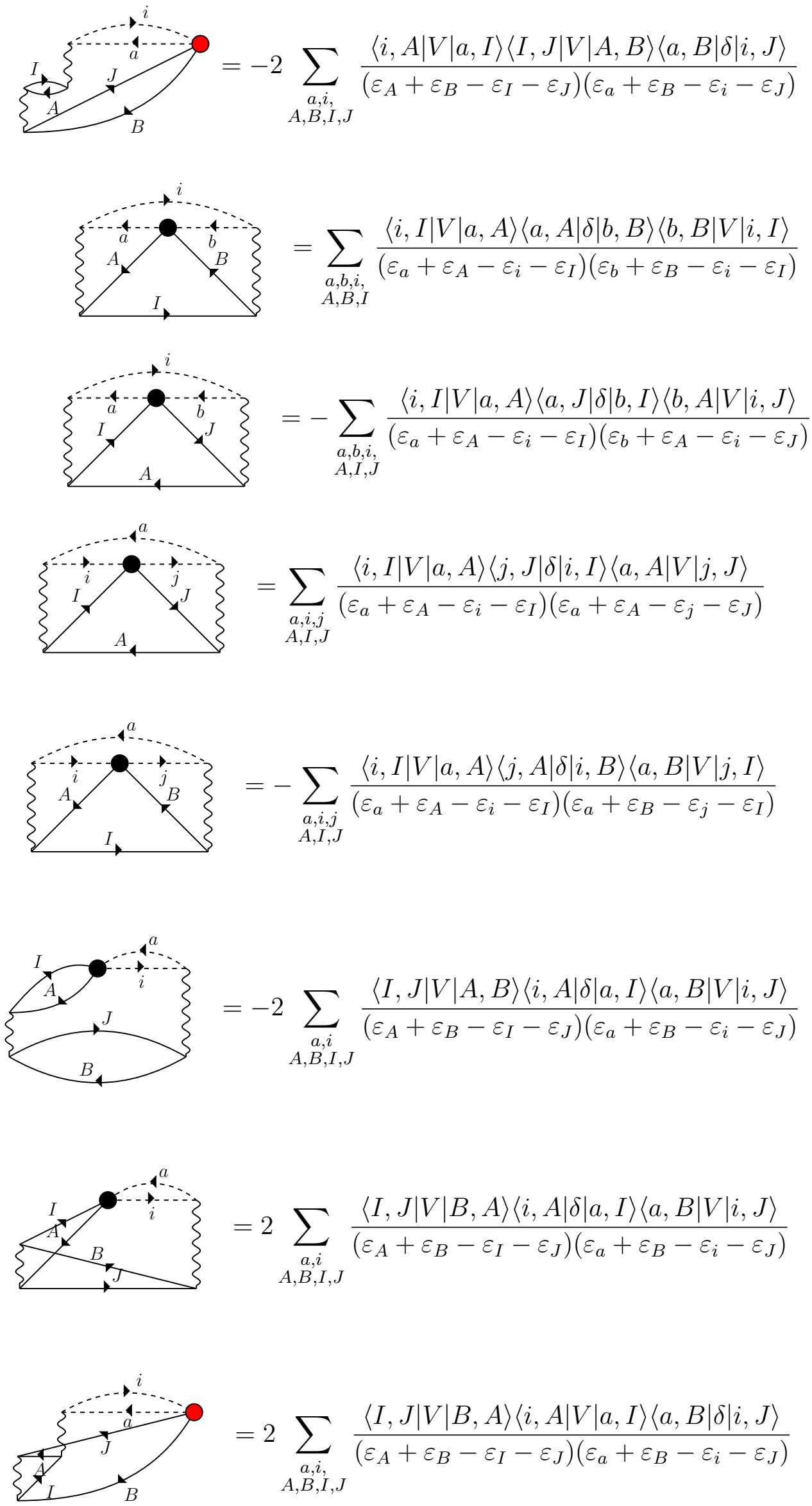

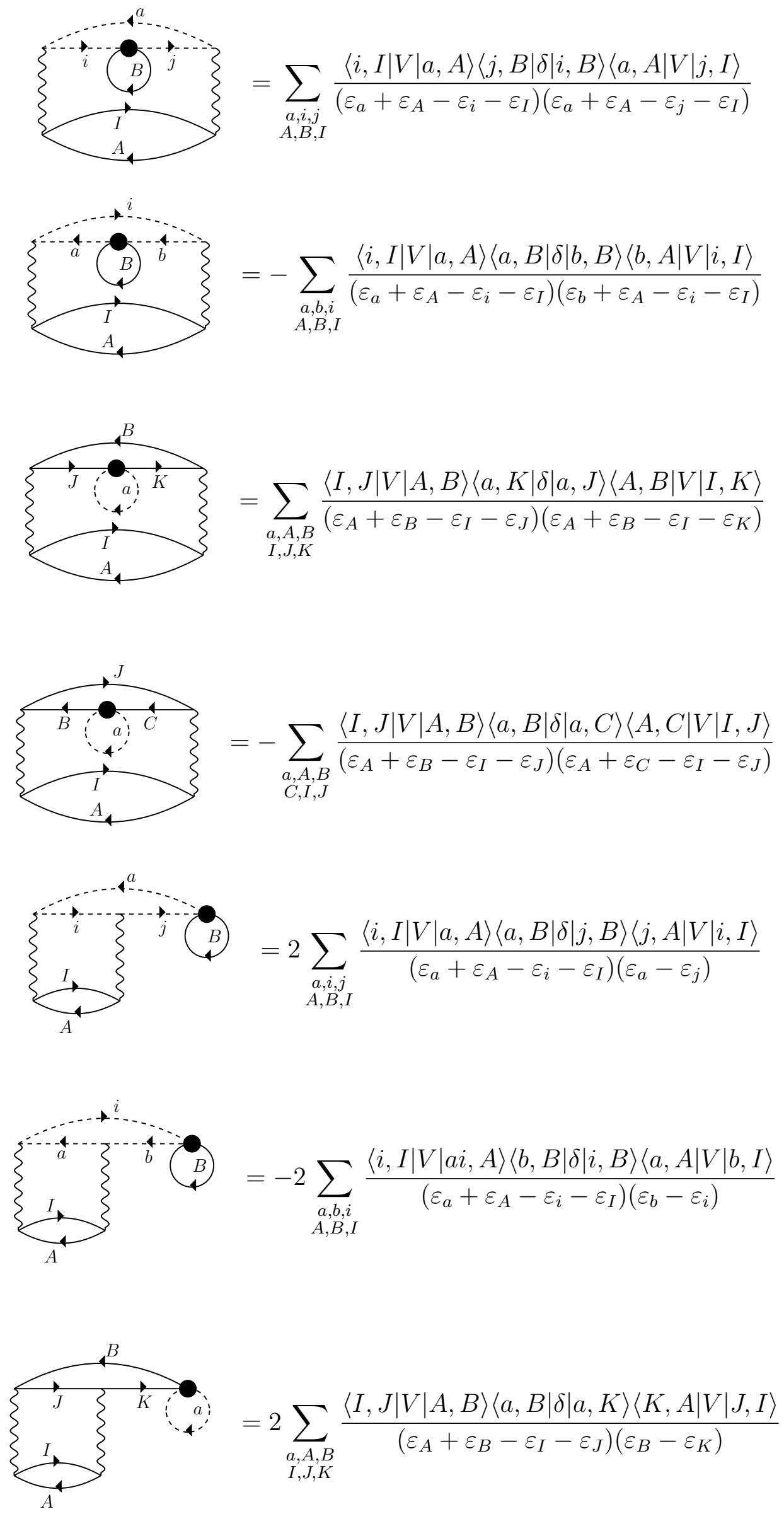


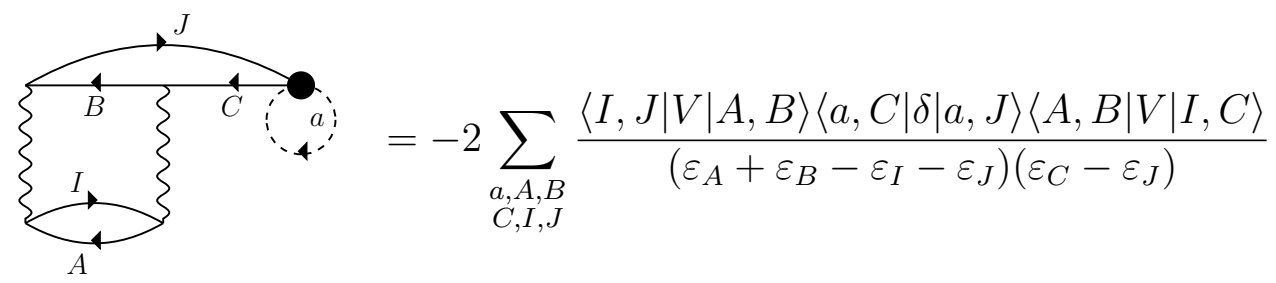




\section{Bibliografia}

[1] JR Danielson, JJ Gosselin, and CM Surko. Dipole enhancement of positron binding to molecules. Physical review letters, 104(23):233201, 2010.

[2] JR Danielson, ACL Jones, JJ Gosselin, MR Natisin, and CM Surko. Interplay between permanent dipole moments and polarizability in positron-molecule binding. Physical Review A, 85(2):022709, 2012.

[3] Masanori Tachikawa. Positron-attachment to acetonitrile, acetaldehyde, and acetone molecules: Vibrational enhancement of positron affinities with configuration interaction level of multi-component molecular orbital approach. In Journal of Physics: Conference Series, volume 488, page 012053. IOP Publishing, 2014.

[4] Masanori Tachikawa, Yukiumi Kita, and Robert J Buenker. Bound states of positron with simple carbonyl and aldehyde species with configuration interaction multi-component molecular orbital and local vibrational approaches. New Journal of Physics, 14(3):035004, 2012.

[5] Katsuhiko Koyanagi, Yu Takeda, Takayuki Oyamada, Yukiumi Kita, and Masanori Tachikawa. Positron-attachment to nonpolar or small dipole cxy ( $x, y=0, s$, and se) molecules: vibrational enhancement of positron affinities with configuration interaction level of multi-component molecular orbital approach. Physical Chemistry Chemical Physics, 15(38):16208-16213, 2013.

[6] Masanori Tachikawa, Yukiumi Kita, and Robert J Buenker. Bound states of the positron with nitrile species with a configuration interaction multi-component molecular orbital approach. Physical Chemistry Chemical Physics, 13(7):2701-2705, 2011.

[7] Krzysztof Strasburger. Positronic formaldehyde-the configuration interaction study. Structural Chemistry, 15(5):415-420, 2004.

[8] Yukiumi Kita, Ryo Maezono, Masanori Tachikawa, Mike Towler, and Richard J Needs. $\mathrm{Ab}$ initio quantum monte carlo study of the positronic hydrogen cyanide molecule. The Journal of chemical physics, 131(13):134310, 2009. 
[9] GF Gribakin and CMR Lee. Positron annihilation in molecules by capture into vibrational feshbach resonances of infrared-active modes. Physical review letters, 97(19):193201, 2006.

[10] Paul Adrien Maurice Dirac. A theory of electrons and protons. Proceedings of the Royal Society of London. Series A, Containing papers of a mathematical and physical character, 126(801):360-365, 1930.

[11] Carl D Anderson. The positive electron. Physical Review, 43(6):491, 1933.

[12] Nidhal Guessoum. Positron astrophysics and areas of relation to low-energy positron physics. The European Physical Journal D, 68(5):137, 2014.

[13] M Alatalo, B Barbiellini, M Hakala, H Kauppinen, T Korhonen, Martti J Puska, K Saarinen, P Hautojärvi, and Risto $\mathrm{M}$ Nieminen. Theoretical and experimental study of positron annihilation with core electrons in solids. Physical Review B, 54(4):2397, 1996.

[14] Takayuki Tachibana, Takashi Yamashita, Masaru Nagira, Hisakuni Yabuki, and Yasuyuki Nagashima. Efficient and surface site-selective ion desorption by positron annihilation. Scientific reports, 8(1):1-7, 2018.

[15] T Yamashita, S Hagiwara, T Tachibana, Kazuyuki Watanabe, and Yasuyuki Nagashima. Experimental and computational studies of positron-stimulated ion desorption from tio2 (1 110$)$ surface. Materials Research Express, 4(11):116303, 2017.

[16] Dale L Bailey, Michael N Maisey, David W Townsend, and Peter E Valk. Positron emission tomography, volume 2. Springer, 2005.

[17] Ron D White, Wade Tattersall, G Boyle, Robert E Robson, Saša Dujko, Z Lj Petrovic, A Bankovic, Michael J Brunger, James P Sullivan, Stephen J Buckman, et al. Lowenergy electron and positron transport in gases and soft-condensed systems of biological relevance. Applied Radiation and Isotopes, 83:77-85, 2014.

[18] Michael James Brunger, Stephen J Buckman, and Antonio Zecca. Electron and positron scattering from biomolecules. In Journal of Physics: Conference Series, volume 194, page 012034, 2009.

[19] Renee M Moadel, Richard H Weldon, Ellen B Katz, Ping Lu, Joseph Mani, Mark Stahl, M Donald Blaufox, Richard G Pestell, Maureen J Charron, and Ekaterina Dadachova. Positherapy: targeted nuclear therapy of breast cancer with 18f-2-deoxy-2-fluoro-d-glucose. Cancer research, 65(3):698-702, 2005.

[20] Martin Deutsch. Evidence for the formation of positronium in gases. Physical Review, 82(3):455, 1951. 
[21] M Shipman, SJ Brawley, László Sarkadi, and G Laricchia. Resonant scattering of positronium as a quasifree electron. Physical Review A, 95(3):032704, 2017.

[22] DB Cassidy, TH Hisakado, HWK Tom, and AP Mills Jr. Laser excitation of positronium in the paschen-back regime. Physical review letters, 106(17):173401, 2011.

[23] Allen P Mills Jr. Observation of the positronium negative ion. Physical Review Letters, 46(11):717, 1981.

[24] DM Schrader, Finn M Jacobsen, Niels-Peter Frandsen, and Ulrik Mikkelsen. Formation of positronium hydride. Physical review letters, 69(1):57, 1992.

[25] David B Cassidy and AP Mills. The production of molecular positronium. Nature, 449(7159):195-197, 2007.

[26] G ai Baur, G Boero, A Brauksiepe, A Buzzo, W Eyrich, R Geyer, D Grzonka, J Hauffe, K Kilian, M LoVetere, et al. Production of antihydrogen. Physics Letters B, 368(3):251$258,1996$.

[27] GF Gribakin, Jason Asher Young, and CM Surko. Positron-molecule interactions: Resonant attachment, annihilation, and bound states. Reviews of Modern Physics, 82(3):2557, 2010.

[28] AR Swann and GF Gribakin. Calculations of positron binding and annihilation in polyatomic molecules. The Journal of chemical physics, 149(24):244305, 2018.

[29] AR Swann and GF Gribakin. Model-potential calculations of positron binding, scattering, and annihilation for atoms and small molecules using a gaussian basis. Physical Review A, 101(2):022702, 2020.

[30] JR Danielson, JA Young, and CM Surko. Dependence of positron-molecule binding energies on molecular properties. Journal of Physics B: Atomic, Molecular and Optical Physics, 42(23):235203, 2009.

[31] Jonathan Romero, Jorge A Charry, Roberto Flores-Moreno, Márcio T do N Varella, and Andrés Reyes. Calculation of positron binding energies using the generalized any particle propagator theory. The Journal of chemical physics, 141(11):114103, 2014.

[32] Andrés Reyes, Félix Moncada, and Jorge Charry. The any particle molecular orbital approach: A short review of the theory and applications. International Journal of Quantum Chemistry, 119(2):e25705, 2019.

[33] Roberto Flores-Moreno, Edwin Posada, Félix Moncada, Jonathan Romero, Jorge Charry, Manuel Díaz-Tinoco, Sergio A González, Néstor F Aguirre, and Andrés Reyes. Lowdin: 
The any particle molecular orbital code. International Journal of Quantum Chemistry, 114(1):50-56, 2014.

[34] Wolfgang von Niessen, Jochen Schirmer, and Lorenz S Cederbaum. Computational methods for the one-particle green's function. Computer Physics Reports, 1(2):57-125, 1984.

[35] LS Cederbaum and W Domcke. Theoretical aspects of ionization potentials and photoelectron spectroscopy: A green's function approach. Adv. Chem. Phys, 36:205-344, 1977.

[36] LS Cederbaum. One-body green's function for atoms and molecules: theory and application. Journal of Physics B: Atomic and Molecular Physics, 8(2):290, 1975.

[37] J Charry, J Romero, MT do N Varella, and A Reyes. Calculation of positron binding energies of amino acids with the any-particle molecular-orbital approach. Physical Review A, 89(5):052709, 2014.

[38] JA Ludlow and GF Gribakin. Many-body theory calculations of positron binding to negative ions. arXiv preprint arXiv:1002.3125, 2010.

[39] GF Gribakin and J Ludlow. Many-body theory of positron-atom interactions. Physical Review A, 70(3):032720, 2004.

[40] VA Dzuba, VV Flambaum, GF Gribakin, and WA King. Many-body calculations of positron scattering and annihilation from noble-gas atoms. Journal of Physics B: Atomic, Molecular and Optical Physics, 29(14):3151, 1996.

[41] VA Dzuba, VV Flambaum, WA King, BN Miller, and OP Sushkov. Interaction between slow positrons and atoms. Physica Scripta, 1993(T46):248, 1993.

[42] Jochen Schirmer, Schirmer, and Zakharchenko. Many-Body Methods for Atoms, Molecules and Clusters. Springer, 2018.

[43] Eberhard KU Gross and Erich Runge. Many-particle theory. 1986.

[44] Richard Feynman. Statistical mechanics: a set of lectures (advanced book classics). 1998.

[45] A. L. Fetter and J. D. Walecka. Quantum theory of many-particle systems. Courier Corporation, 2012.

[46] Richard D Mattuck. A guide to Feynman diagrams in the many-body problem. Courier Corporation, 1992.

[47] Gy Csanak, HS Taylor, and Robert Yaris. Green's function technique in atomic and molecular physics. In Advances in atomic and molecular physics, volume 7, pages 287-361. Elsevier, 1971. 
[48] José David M Viana, Adalberto Fazzio, and Sylvio Canuto. Teoria quântica de moléculas e sólidos: Simulaçao computacional. Editora Livraria da Física, São Paulo, 2004.

[49] David J Griffiths. Mecânica Quântica. Pearson Education do Brasil, 2011.

[50] Attila Szabo and Neil S Ostlund. Modern quantum chemistry: introduction to advanced electronic structure theory. Courier Corporation, 2012.

[51] M Müller and LS Cederbaum. Many-body theory of composite electronic-positronic systems. Physical Review A, 42(1):170, 1990.

[52] LS Cederbaum and J Schirmer. Green's functions for open-shell atoms and molecules. Zeitschrift für Physik, 271(3):221-227, 1974.

[53] David J Thouless. The quantum mechanics of many-body systems. Courier Corporation, 2014.

[54] DJ Thouless. Green functions in low-energy nuclear physics. Reports on Progress in Physics, 27(1):53, 1964.

[55] L-S_Cederbaum. Non-single-particle excitations in finite fermi systems. The Journal of Chemical Physics, 62(6):2160-2170, 1975.

[56] DM Schrader. Bound states of positrons with atoms and molecules: theory. Nuclear Instruments and Methods in Physics Research Section B: Beam Interactions with Materials and Atoms, 143(1-2):209-217, 1998.

[57] C Harabati, VA Dzuba, and VV Flambaum. Identification of atoms that can bind positrons. Physical Review A, 89(2):022517, 2014.

[58] Jim Mitroy, Michael WJ Bromley, and GG Ryzhikh. Positron and positronium binding to atoms. Journal of Physics B: Atomic, Molecular and Optical Physics, 35(13):R81, 2002.

[59] Oakley H Crawford. Bound states of a charged particle in a dipole field. Proceedings of the Physical Society, 91(2):279, 1967.

[60] Andre Luis Dias Santana. Moléculas positrônicas: densidade eletrônica e taxas de aniquilação. PhD thesis, Universidade de São Paulo, 2017.

[61] Jorge Charry, Márcio T do N Varella, and Andrés Reyes. Binding matter with antimatter: The covalent positron bond. Angewandte Chemie International Edition, 57(29):88598864, 2018.

[62] Mohammad Goli and Shant Shahbazian. On the nature of the positronic bond. ChemPhysChem, 20(6):831-837, 2019. 
[63] Félix Moncada, Laura Pedraza-González, Jorge Charry, Márcio T do N Varella, and Andrés Reyes. Covalent bonds in positron dihalides. Chemical Science, 11(1):44-52, 2020.

[64] Jan Linderberg and Yngve Öhrn. Propagators in quantum chemistry. John Wiley \& Sons, 2004.

[65] Jonathan Romero, Edwin Posada, Roberto Flores-Moreno, and Andrés Reyes. A generalized any particle propagator theory: Assessment of nuclear quantum effects on electron propagator calculations. The Journal of Chemical Physics, 137(7):074105, 2012.

[66] Jhonathan Romero Fontalvo. Desarrollo de métodos de propagador para el estudio de procesos de ionización molecular empleando la metodología del orbital nuclear molecular y su implementación en el paquete computacional lowdin. Departamento de Química.

[67] Vladimir Borisovich Berestetskii, Evgenii Mikhailovich Lifshitz, and Lev Petrovich Pitaevskii. Quantum Electrodynamics: Volume 4, volume 4. Butterworth-Heinemann, 1982.

[68] LJM Dunlop and GF Gribakin. Many-body theory of gamma spectra from positron-atom annihilation. Journal of Physics B: Atomic, Molecular and Optical Physics, 39(7):1647, 2006.

[69] Alexei M Frolov. Annihilation of electron-positron pairs in the positronium ion ps- and bipositronium ps 2. Physical Review A, 80(1):014502, 2009.

[70] Alexei M Frolov and Vedene H Smith. Positronium hydrides and the ps 2 molecule: Bound-state properties, positron annihilation rates, and hyperfine structure. Physical Review A, 55(4):2662, 1997.

[71] Gleb Gribakin. Theory of positron annihilation on molecules. In New Directions in Antimatter Chemistry and Physics, pages 413-435. Springer, 2001.

[72] Norman Henry March, William H Young, and Sangarapillai Sampanthar. The many-body problem in quantum mechanics. Courier Corporation, 1995. 